\title{
Tipos posturais: variações anatômicas e seus efeitos sobre a gravidez
}

\section{Lea de Oliveira Françoso}

Dissertação apresentada ao

Programa de Pós-Graduação em Saúde Pública da Faculdade de Saúde Pública da Universidade de São Paulo para obtenção do título de Mestre em Saúde Pública.

Área de Concentração: Materno-Infantil Orientadora:

Profa. Dra. Ana Cristina d'Andretta Tanaka

São Paulo 2004

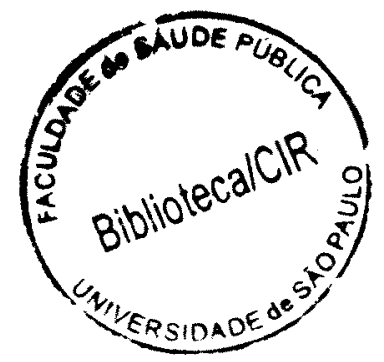


À minha amada avó "NENA" in memorian, em razão dos acontecimentos passados e futuros que me farão lembrá-la para sempre.

Aos meus queridos pais, VANDERLEI e MARIA ZÉLIA, por me fazerem crescer a cada dia.

Com muito amor

Lea

Ao meu irmão ROGÉRIO, pelos momentos que vivemos ao compartilhar histórias semelhantes. 
"Porque todas as coisas vêm Dele e para Ele são todas as coisas;

Glórias pois a Ele".

\section{Dedicatória}

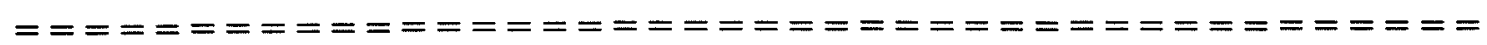

Ofereço esse trabalho à:

Profa. Dra. ANA CRISTINA d'ANDRETTA TANAKA, minha mestra, orientadora e amiga, pelo cuidado, carinho e incentivo. Por estar ao meu lado em todos os momentos.

Com profunda admiração

Lea 


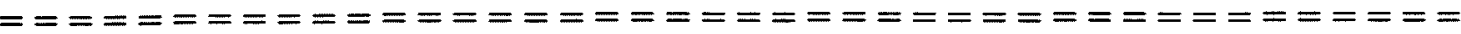

Em especial, à minha querida amiga, Profa. Dra. AUSONIA FAVORIDO DONATO, que me estimulou a fazer o mestrado. $O$ meu muito obrigado por me desafiar a estar hoje aqui.

À querida Profa. Dra. MARIA ALICE TSUNECHIRO por investir na leitura do meu trabalho, pelas correções e sugestões que aperfeiçoaram a minha dissertação. Também agradeço de todo o coração os livros e os lenços emprestados.

À carinhosa Profa. Dra. CARMEN SIMONE GRILO DINIZ, pelas contribuições, apoio e encorajamento.

Ao editor CLÁUDIO GIORDANO por dispor do seu tempo precioso e com carinho ler o trabalho. $\mathrm{O}$ meu obrigado pelas correções.

À escritora ANA FLORA COELHO por suas idéias enriquecedoras para o meu projeto de pesquisa inicial, e pela inspiração de algum dia conseguir escrever como ela.

Agradeço ao SR. JOSÉ CORDEIRO DOS SANTOS pela doação do seu Pelvímetro de Martin, e acreditar na ciência em prol dos desfavorecidos, em sua maravilhosa profissão de restaurar equipamentos médicos antigos.

Aos funcionários e amigos do Departamento de Saúde Materno-infantil da FSP da USP (Faculdade de Saúde Pública da Universidade de São Paulo): Iara de Macedo e Leandro Cleto.

Às colegas da FSP da USP: Maria do Carmo Avamilano Alvarez por me ajudar a encontrar um artigo importante para o meu estudo, e Jenny Izumi Kose por anotar os comentários das professoras da banca da minha defesa de projeto.

Aos colegas da UBS Parque da Lapa que contribuíram para a execução desse trabalho:

Em especial à amiga Lumari Marin Silveira Madruga, e à querida agente comunitária de saúde "Lu" - Luciene Vieira de Jesus pela ajuda não só no trabalho, mas em situações pessoais.

Também aos queridos e importantes agentes comunitários de saúde: Maria Luiza da Costa, Antônio Carlos de Andrade Silva, Cleide Helena Nardi Raposo, "Vavá" Edvaldo Felipe Marques, Tereza Cardoso, Rita de Cássia Jacinto, Odair Bonifácio Mello, Margarida Helena Ferreira, Isilda Cristiane Corrêa Braga, Maria Aparecida Reis, Maria Aparecida Serrer, Maria Gorette de Lima Cortina, Michele Cristina Rodrigues, e Silvia Regina Borges Coelho. 
À auxiliar técnica administrativa Priscila dos Santos Silva, à enfermeira da equipe laranja Josette Cristina Gomes Ângelo, e o meu muito obrigado às auxiliares de enfermagem Raimunda Roque de Castro e Maria Cecilia Alexandre.

Ao doce Dr. Noé Camacho Mendes, pelas dicas quanto à pelve, e a amiga Dra. Edna Azevedo Marques pelo consolo em situações dificeis.

Às colegas de outras unidades da Prefeitura Municipal de São Paulo que ultrapassaram a categoria de colegas para amigas, e que permanecerão no meu coração: Dra. Albina Garzillo, Dra. Berenice Bustamante Kavakama, Elaine Sutto Arcalá e Leda Amaral Vieira.

Aos meus amigos de sempre: Adriano Brottos Souza, Alessandro dos Santos Reis e Débora Tavares Souza. Um grande abraço por me ensinarem a amar e nunca desistirem de mim.

Aos profissionais que cuidaram da minha saúde para que eu tivesse êxito e concluísse o trabalho: Rosana del Nero, Dra. Fabiane Noronha Bergonse, Sideli Biazzi, Maria Tereza Rossini Braz, Renée Edery, Angela Maria Alfano e Lúcia Barreiro Tosto.

O meu carinho especial ao Pr. Enéas Tognini e Elia da Costa Tognini por me socorrem em momentos de grande tristeza. Também o meu muito obrigado pelas suas orações.

Aos meus tios adotivos por fazerem muito mais que papel de familia. Tia Jandira Martins Enachev e tio Vitório Enachev, 'pelo amor de vocês e auxílio em circunstâncias que atrapalhariam o meu trabalho.

À minha grande herança, melhor amiga da minha avó e agora minha grande amiga também: Mafalda Gomes Machado.

Às minhas gestantes porque sem elas nada disso seria possível. 


\section{Resumo}

Françoso LO. Tipos posturais: variações anatômicas e seus efeitos sobre a gravidez. São Paulo; 2004. [Dissertação de Mestrado - Faculdade de Saúde Pública da Universidade de São Paulo].

A anatomia e as dimensões da pelve feminina têm impactos sobre a saúde maternoinfantil. Pelo menos $70 \%$ das gestantes apresentam lombalgia e quase nenhum tratamento é oferecido à gestante. Esse trabalho pretende resgatar o uso do Losango de Michaelis, ampliando as suas funções, viabilizando a prevenção, o diagnóstico diferencial de lombalgia e dor sacriliaca, a fim de nortear um programa terapêutico de intervenção adequado. Objetivo. Avaliar a capacidade pélvica de moldar-se mês a mês, à medida que o feto se desenvolve e construir um método que selecione gestantes que apresentem os maiores riscos de lesões. Métodos. Utilizou-se o Pelvimetro de Martin e as medidas das dimensões do Losango de Michaelis. Foram realizadas em 39 gestantes 2 avaliações: a primeira até o quarto mês de gestação, e a segunda entre as $32^{\mathrm{a}}$ e $36^{\mathrm{a}}$ semanas gestacionais. Preencheu-se uma ficha contendo dados de identificação pessoal e exame geral. Quanto aos quadros álgicos localizados na região pélvica, as gestantes receberam um desenho para assinalar a dor. Resultados. Foram encontradas 6 formas de losangos: A, B, C, D, E e F, sendo possivel classificá-los em ordem crescente de apresentar lesões das estruturas pélvicas: $\mathrm{C}<\mathrm{D}<\mathrm{B}<\mathrm{E}<\mathrm{A}<\mathrm{F}$. Conclusōes. $\mathrm{O}$ Losango pode ser utilizado para fins de acompanhar o afastamento das articulações sacrilíacas e identificar estados patológicos de relaxação pélvica. Pode-se utilizar o método desenvolvido para avaliar a dor decorrente das adaptações inadequadas do sistema musculoesquelético durante a gravidez. Ações preventivas e $\cap$ tratamento fisioterápico devem ser incluidos no pré-natal.

Descritores: Gravidez, Saúde Materna, Lombalgia, Pelve, Articulação Sacrilíaca e Fisioterapia. 


\section{Summary}

Françoso LO. Tipos posturais: variações anatômicas e seus efeitos sobre a gravidez. [Types postures: anatomical variations and their effects on the pregnancy]. São Paulo (BR); 2004. [MD dissertation - Faculdade de Saúde Pública da Universidade de São Paulo Brazil].

The anatomy and the dimensions of the feminine pelvis have impacts about the maternal-infantile health. At least $70 \%$ of the pregnant women present back pain and almost no treatment is offered to the pregnant woman. That work intends to rescue the use of the Lozenge of Michaelis, enlarging their functions, making possible the prevention, the differential diagnosis of back pain and pain sacriliac, in order to orientate a therapeutic program. Objective. To evaluate the pelvic capacity to mold month to month, as the fetus grows and to build a method that selects pregnant that present the largest risks of lesions. Methods. It was used Pelvimetry and the measures of the dimensions of the Lozenge of Michaelis. They were accomplished in 39 pregnant 2 evaluations: the first until the fourth month of gestation, and second between the $32^{\mathrm{a}}$ and $36^{\mathrm{a}}$ weeks. A record was filled out containing data of personal identification and general exam. As for the pictures located pain in the pelvic area, the pregnant women received a drawing to mark the pain. Results. They were found 6 forms of lozenges: A, B, C, D, E and F, being possible to classify them in growing order of presenting lesions of the pelvic structures: $C<D<B<A<E<F$. Conclusions. The Lozenge can be used for ends of to accompany the removal of the sacriliacs joints and to identify pathological states of pelvic relaxation. The method can be used developed to evaluate the pain due to the inadequate adaptations of the musculoskeletal system during the pregnancy. Injunctions and the physiotherapeutic treatment should be included in the antenatal care.

Descriptors: Pregnancy, Maternal Health, Back Pain, Pelvis, Sacriliac Joints, and Physiotherapy. 


\section{ÍNDICE}

1 CONSIDERAÇÕES INICIAIS

2 INTRODUÇÃO

3 HIPÓTESE

4 OBJETIVOS

5 PROCEDIMENTOS METODOLÓGICOS

5.0 População do Estudo

5.1 Local

5.1.2 características do local

5.2 Critérios de Exclusão do Estudo

5.3 Instrumento de Coleta de Dados

5.4 Avaliação Antropométrica

5.5 Pelvimetria

5.6 Losango de Michaelis $\quad 35$

5.7 Avaliação da Dor Pélvica 39

5.8 Avaliação da Posição do Sacro $\quad 40$

5.9 Análise dos Dados $\quad 40$

5.10 Aspectos Éticos $\quad 40$

6 RESULTADOS E DISCUSSÃO $\quad 42$

6.1 Caracterização Demográfica do Território $\quad 42$

6.2 Perfil Socioeconômico $\quad 45$

6.3 Discussão dos Resultados Obtidos 46

7 CONSIDERAÇÕES FINAIS

8 CONCLUSÕES $\quad 98$

9 REFERÊNCIAS 101

$\begin{array}{ll}10 \text { ANEXOS } & 109\end{array}$

Anexo 1 - Ficha de avaliação inicial $\quad$ A1

Anexo 2 - Ficha de avaliação da dor pélvica $\quad$ A4

Anexo 3 - Ficha de avaliação final $\quad$ A5

Anexo 4 - Modelo do termo de consentimento livre e esclarecido A6

Anexo 5 - Documento de aprovação do projeto pelo comitê de ética em pesquisa da Faculdade de Saúde Pública da Universidade de São Paulo $\quad$ A7

Anexo 6 - Relatório do exame do projeto 


\section{Considerações Iniciais}

A forma anatômica da pelve feminina sempre foi preocupação para aqueles que têm em mente o parto normal, pois a sua forma pode determinar os resultados do parto. Avaliar a morfotipologia pélvica e as suas dimensões são fundamentais devido aos impactos sobre a saúde materno-infantil. Até o século passado, media-se com o uso do pelvímetro, os diâmetros externos que correspondiam às medidas anatômicas internas, obtendo-se um valor aproximado da câmara pélvica. Com o avanço tecnológico, estes métodos de avaliação foram sendo abandonados. Atualmente, mede-se o conjugado verdadeiro e o feto a termo pela ultra-sonografia, o que nos leva a suspeitar que em todo o desenvolvimento gestacional as adaptações que ocorrem na pelve não são verificadas. Quando os ajustes da pelve materna não são atingidos adequadamente, constituem uma ameaça para a mãe e o feto.

Assim, a realização deste trabalho justifica-se à medida que pretende averiguar em quais situações a maior ou menor ampliação da capacidade pélvica constitui risco de lesões para a mãe e para o bebê. 


\section{Introdução}

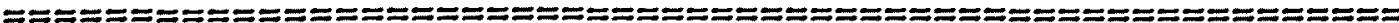

Não raramente, os médicos do passado reconheciam os três fatores que interferem no parto: a força (contração uterina e músculos abdominais), o feto e a pelve óssea (o trajeto a ser percorrido pelo feto). Sendo assim, os obstetras realizavam a avaliação de todos esses fatores envolvidos no processo do parto.

Em relação à pelve óssea, o crescimento tecnológico interrompeu o desenvolvimento de um importante conhecimento. Deixa-se de observar a pelve da mulher, sendo atualmente a avaliação da pelve óssea da gestante o que menos se considera em toda a gestação; mas o desenvolvimento e o crescimento do feto é quase sempre acompanhado pela ultra-sonografia.

MARISCAL (2001), ginecologista, obstetra, assessor e consultor de várias instituições internacionais refere que muitos colegas quando questionados sobre a paciente respondem:

“... a altura do fundo uterino está bem, corresponde à idade gestacional e o feto se mexe ". Questiona se os seus colegas são pediatras ou obstetras, pois “ se preocupam muito mais com a perinatologia"(P. 4).

A seguir retomam-se questões mais remotas e importantes sobre a construção da teoria pélvica, abandonada no passado, principalmente pelos médicos brasileiros.

Aranzo (citado por THIERY, 1995) foi o primeiro médico a observar os efeitos do desenho pélvico sobre o prognóstico do parto; também fez a relação das principais causas de dificuldade da parturição com as desigualdades entre o tamanho do feto e o tamanho da pelve materna. A partir dele muitos outros estudiosos caminharam nessa 
direção. Vale a pena citar o tratado publicado por VAUGHAN em 1931, sobre a variedade das formas pélvicas.

Esse mesmo autor observou diferentes formas pélvicas classificando-as em: forma de rim, oval, redonda e em forma de "Y". Verificou em seus estudos que a forma da margem pélvica era um fator determinante do parto e que certas condições e hábitos de vida levavam a maiores dificuldades e perigos para ambos: mãe e feto.

Notou que mulheres de tribos indianas nômades confinadas a permanecerem de cócoras, boa parte de suas vidas, tinham seus filhos de maneira mais segura e com grande facilidade quando comparadas com mulheres chinesas ou com as residentes em grandes cidades como Nova York. Sugeriu que não era devido às questões raciais, mas relacionadas à maneira de viver dessas mulheres.

As mulheres indianas, que passavam a maior parte de suas vidas de cócoras tinham a pelve com margem redonda, enquanto que as das grandes cidades, sedentárias, tinham perda de área, e a margem ao invés de ser circular era oval. Concluiu que a causa da mudança era o uso maior ou menor da articulação sacriliaca, ampliando ou reduzindo a área, alterando a forma durante o desenvolvimento pélvico, antes dos 14 anos de idade. Após Vaughan, merecem destaque CALDWELL e MOLOY (1933).

Em 1933, CALDWELL e MOLOY, elaboraram uma classificação da pelve feminina segundo as formas de estreito superior e suas implicações no parto. Seguese a ilustração esquemática desta classificação, segundo DELEE e GREENNHILL, 1950 (figura 1). E para facilitar a compreensão da relação da morfotipologia pélvica e sua provável determinação na apresentação fetal e prognóstico obstétrico, elaborouse o quadro 1 . 
Figura 1 Esquema de classificação da pelve feminina.
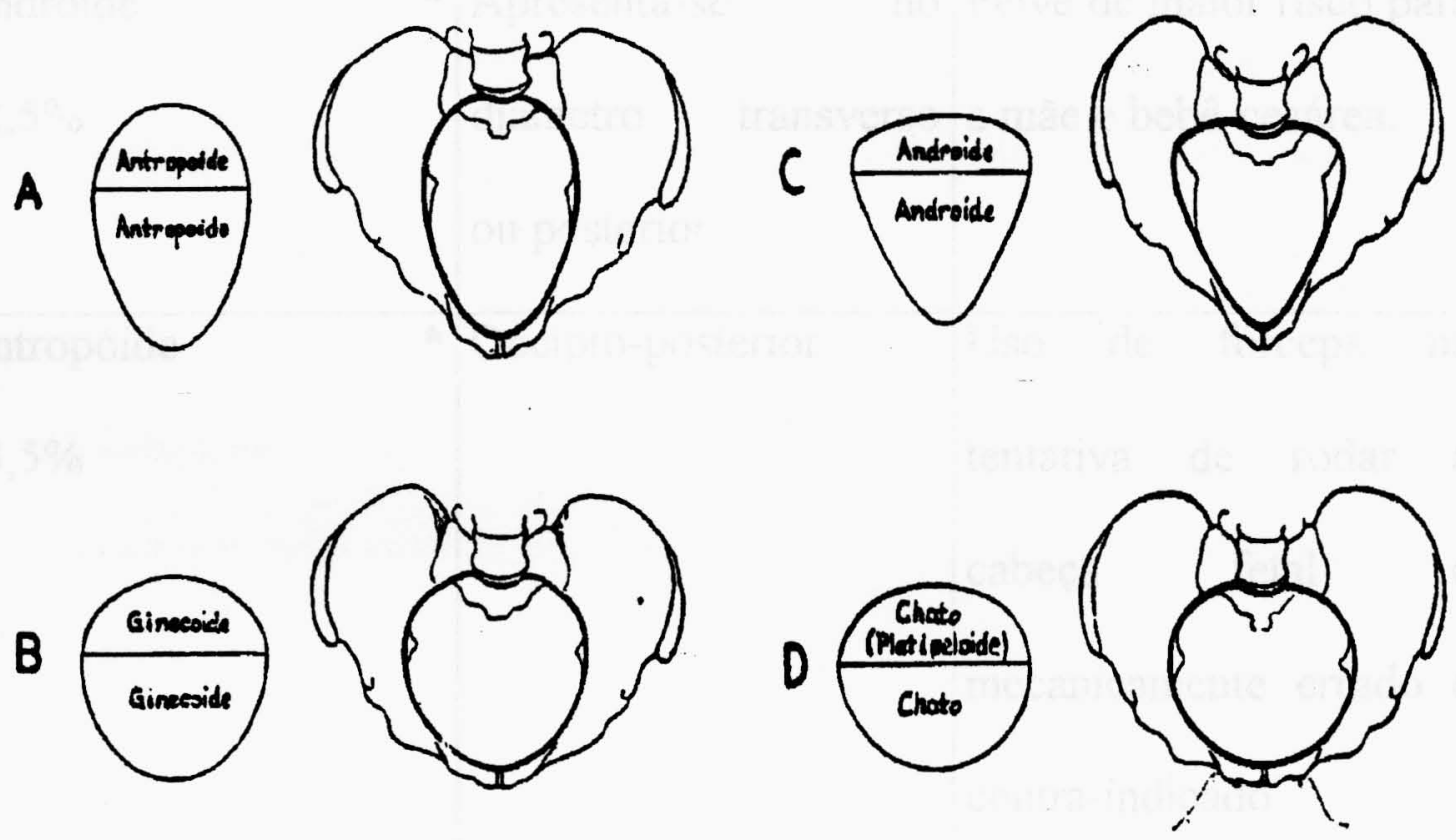

Fonte: Tratado de Obstetrícia Tomo II. DELLE e GREENNHILL, 1950. 
Quadro 1 Tipologia pélvica e prognóstico obstétrico.

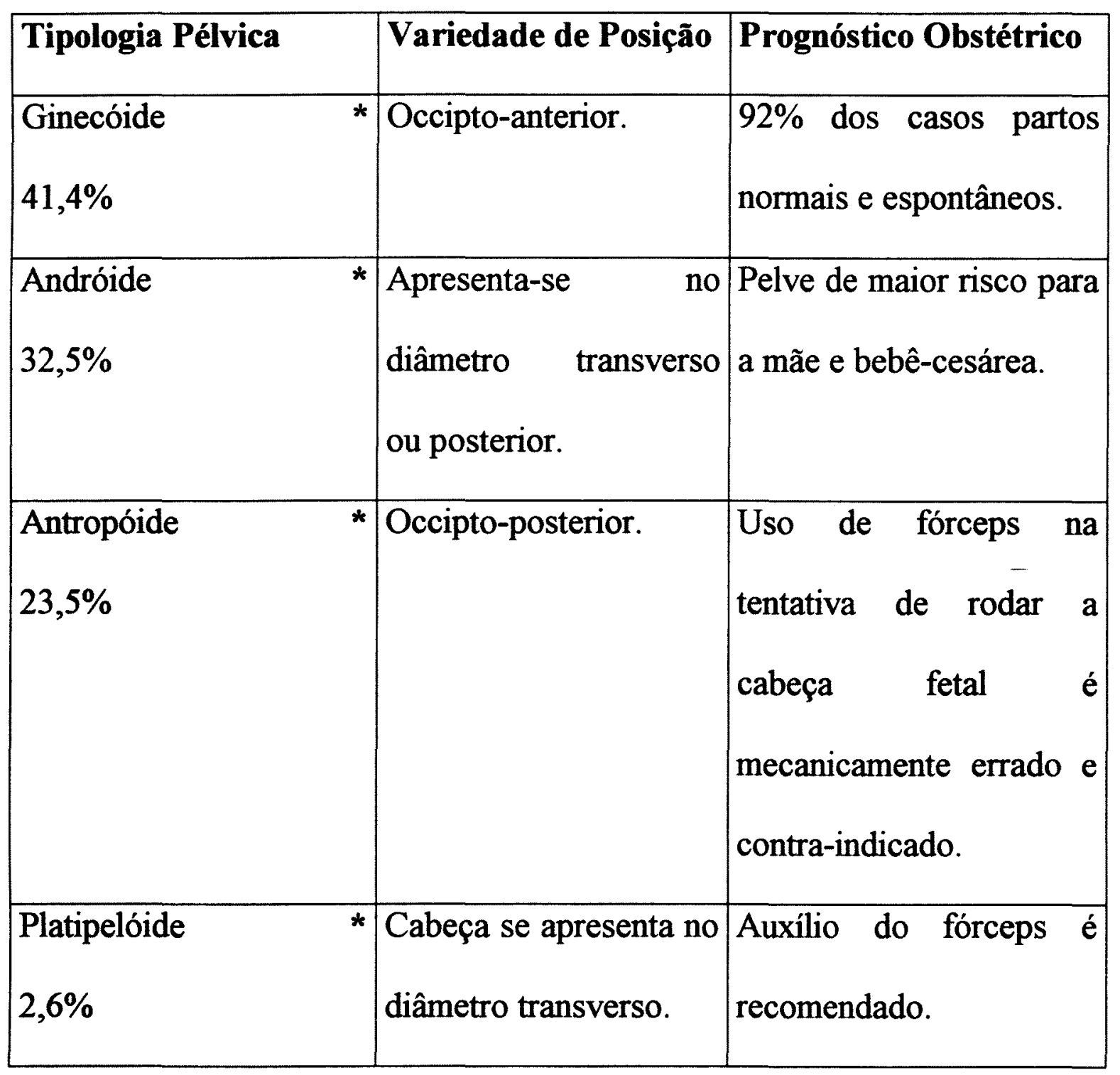

*Incidência da tipologia pélvica entre as mulheres segundo DELEE e GREENHILL, 1950. 
Mais recentemente, (ABITBOL em 1997) mostrou que as diferenças nas dimensões pélvicas eram também devido às dietas de baixa ou alta oferta protéica. Ele constatou que as mães nascidas nos países economicamente desfavorecidos tinham tamanho, peso, dimensões pélvicas e fetos menores que as mulheres norte americanas. Seus bebês nasciam também sem dificuldade. No entanto, as mães migrantes, que cresciam nos Estados Unidos, recebendo cuidados pré-natais e alimentação adequada, tinham bebês maiores resultando em desproporção cefalopélvica.

Entre as causas dos partos obstruídos, a desproporção cefalopélvica é a responsável em $67 \%$ das vezes. Segundo KWAST, 1992, muitas mulheres morrem, por ano, no Reino Unido devido ao parto obstruído; muitas delas perdem seus bebês e têm incapacidade fisica, ou outros danos, como resultado. SILBAR, 1986, sugere que, paralelamente aos aumentos nacionais nos índices de cesárea, a desproporção cefalopélvica é a razão primária e o fator primordial que contribui para o aumento das cesáreas.

A incidência da desproporção cefalopélvica varia numa amplitude de $4,7 \%$ a $33 \%$, sendo cada vez mais alta nas mulheres que não fizeram pré-natais (OZUMBA e UCHEGBU, 1991). Segundo estes mesmos autores, em $85 \%$ dos casos faz-se necessário o emprego da cesárea. Evidências disponíveis indicam que o parto cirúrgico aumenta o risco de morte materno-infantil em três vezes mais que o parto normal (SCHUITEMAKER e col, 1997). Somam-se a isso, os riscos das principais complicações maternas por desproporção cefalopélvica: sepsis puerperal $(57 \%)$, hemorragia pós-parto (15\%), ruptura uterina (14\%) e laceração do trato genital (14\%). A razão de mortalidade materna é de 32 por 1000 nascidos vivos e o de 
mortalidade perinatal, por esta causa, é de 294 por 1000 nascidos vivos. Dos bebês que sobrevivem, 67,9\% evoluem para uma encefalopatia devido a hipóxia cerebral isquêmica e $33 \%$ morrem após seis dias de vida.

Diante de tudo isto, a arquitetura da pelve feminina torna-se fundamental, enquanto um espelho das condições de vida da mulher, como também quanto às suas implicações no prognóstico do parto.

As implicações das variações anatômicas da pelve feminina sobre o parto sempre foram motivo de preocupação devido às suas repercussões, mas a necessidade real de se conhecer o tamanho da pelve e do crânio fetal, reviveu somente no século XVIII, por ocasião da extração a fórceps.

Observa-se que nessa época a ciência orientou-se no sentido de predizer doenças por meio da avaliação da forma corporal externa e interna do ponto de vista anatômico. Em função disto, surgiu à necessidade de desenvolver instrumentos de avaliação, que permitissem a aplicação clínica válida das deduções anatômicas.

Verifica-se que os princípios da "estrutura quartenária" da biotipologia e a sua aplicação na identificação da predisposição dos riscos de adoecer, indicados por medidas corporais, influenciaram nitidamente os trabalhos dos anatomistas e obstetras das épocas contemporâneas, como os trabalhos de Baudelocque, em que por meio de medidas antropométricas e da inspeção morfológica externa, identificava anomalias pélvicas na tentativa de prever complicações no parto.

Segundo THIERY, 1995, a obstetrícia teve em Baudelocque a origem da pelvimetria externa, onde as dimensões da bacia eram determinadas por meio do pelvímetro (figura 2). 
Figura 2 Pelvímetro de Martin.

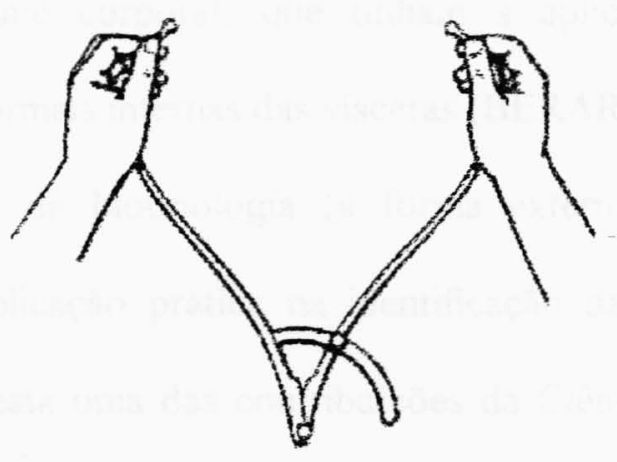

Fonte: PSCHYREMBEL. Obstetricia Practica, 1967. 
Datam dessa época, os trabalhos de Leon Rostan (citado por BERARDINELLI, 1932) que descreveu os quatro tipos morfológicos: respiratório, digestivo, cerebral e muscular, classificando-os de acordo com a predominância das respectivas partes corporais em relação às demais. Acreditava-se que o desenvolvimento anormal das vísceras, apontado por estas desproporções, podia predispor, por exemplo, o tipo respiratório às doenças pulmonares, enquanto que o tipo digestivo seria mais acometido por doenças relacionadas aos órgãos abdominais e assim por diante.

Os quatro tipos foram esquematizados por Sigaud (figura 3) pela combinação de formas geométricas, na tentativa de demonstrar que existiam relações matemáticas de comprimento e volume corporal, que tinham a aplicação clínica a fim de diagnosticar situações anormais internas das vísceras (BERARDINELLI, 1932).

O princípio básico da biotipologia (a forma externa expressa a anatomia interna), passou a ter aplicação prática na identificação da arquitetura e desenho pélvico feminino, sendo esta uma das contribuições da Ciência das Constituições, a Biotipologia, para a obstetrícia (figura 4). 
Figura 3 Tipos de Sigaud.

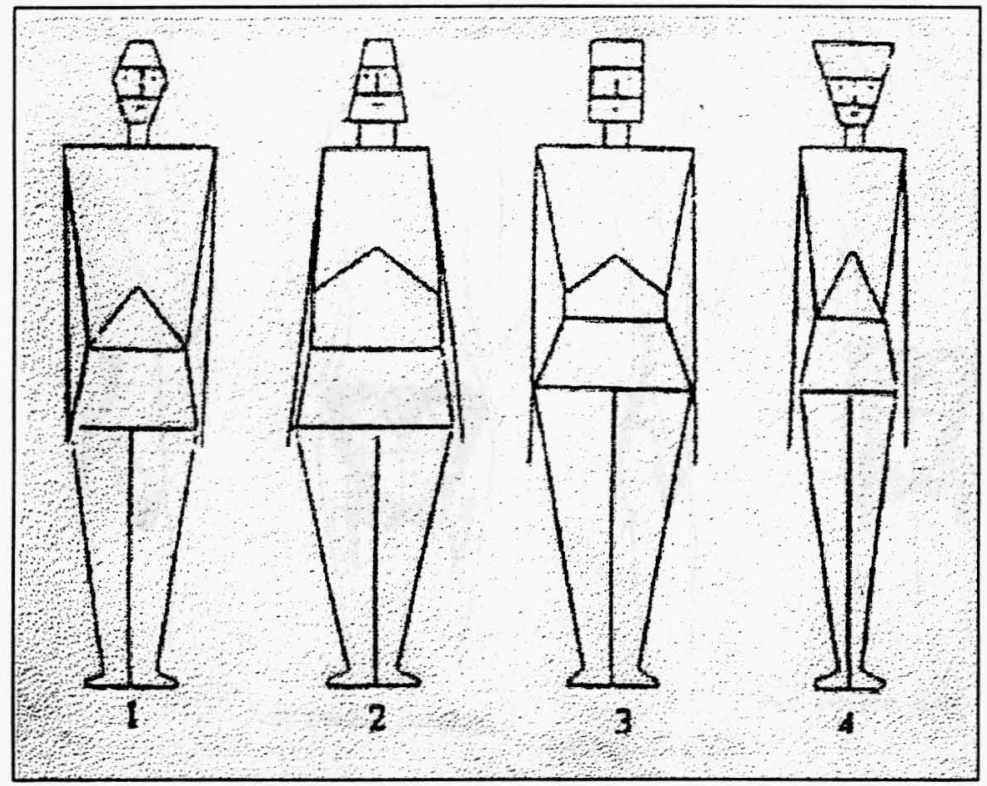

1. Tipo Respiratório

2. Tipo Digestivo

3. Tipo Muscular

4. Tipo Cerebral

Fonte: Noções de Biotypologia. BERARDINELLI, 1932. 
Figura 4 Morfologia corporal externa e interna.
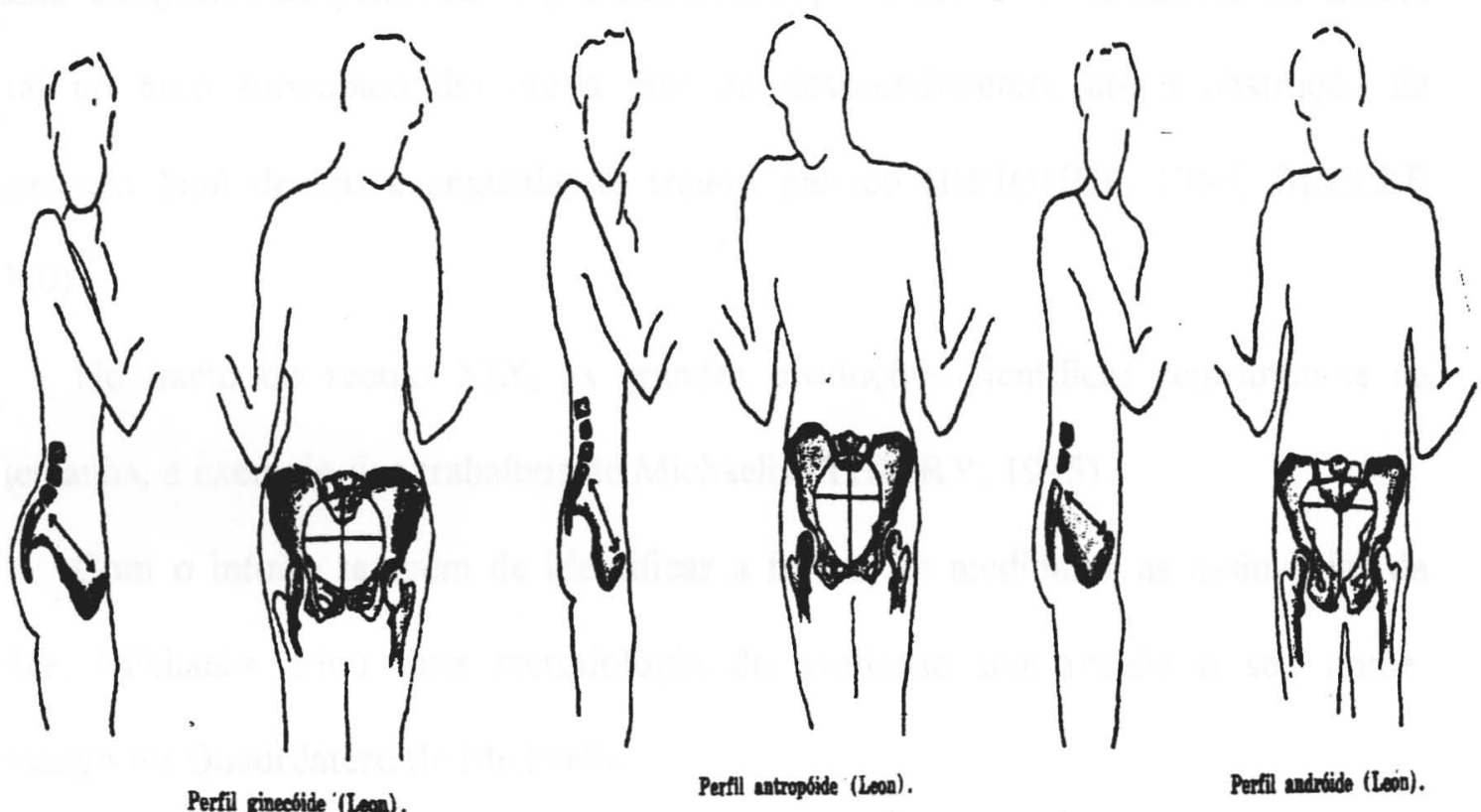

Fonte: Manual de Obstetrícia. GRELLE, 1960. 
Assim, pré-determinar a existência de desproporção fetopélvica, avaliar a morfotipologia pélvica e as suas dimensões é fundamental.

Utilizava-se o pelvímetro, verificando os diâmetros externos que correspondiam às medidas anatômicas internas, obtendo-se assim, um valor aproximado da câmara pélvica.

Variações nas medidas destes diâmetros denunciavam alterações anatômicas que implicam estreitamentos, diminuições da capacidade pélvica que se refletem como desajustes de pequenas a grandes proporções, desde o desencaixe da cabeça fetal no arco subpúbico durante a fase de desprendimento, até a obstrução da passagem fetal devido à angústia do trajeto pélvico (BRIQUET, 1956; GRELLE 1960).

No início do século XIX, as grandes produções científicas centraram-se na Alemanha, a exemplo dos trabalhos de Michaelis (THIERY, 1995).

Com o intuito também de identificar a forma, as medidas e as assimetrias da pelve, Michaelis criou uma metodologia de avaliação que recebe o seu nome: Losango ou Quadrilátero de Michaelis.

Os seus limites anatômicos e metodologia de avaliação estão representados e descritos no capítulo procedimentos metodológicos do presente estudo.

As referências ósseas utilizadas no Losango sinalizam a forma e a posição do sacro. Em relação ao sacro, os médicos dos séculos anteriores consideravam não só a sua forma, mas a sua inclinação que interfere na orientação da parede lateral da pelve, e também a sua curvatura que determina a capacidade pélvica posterior. 
Solonem em 1957 (citado por LEE em 2001) realizou desenhos estereométricos da pelve demonstrando que a orientação articular do sacro determina a forma e dimensão do trajeto pélvico (figura 5 A e B).

Figura 5 Desenhos estereométricos da pelve por Solonem.
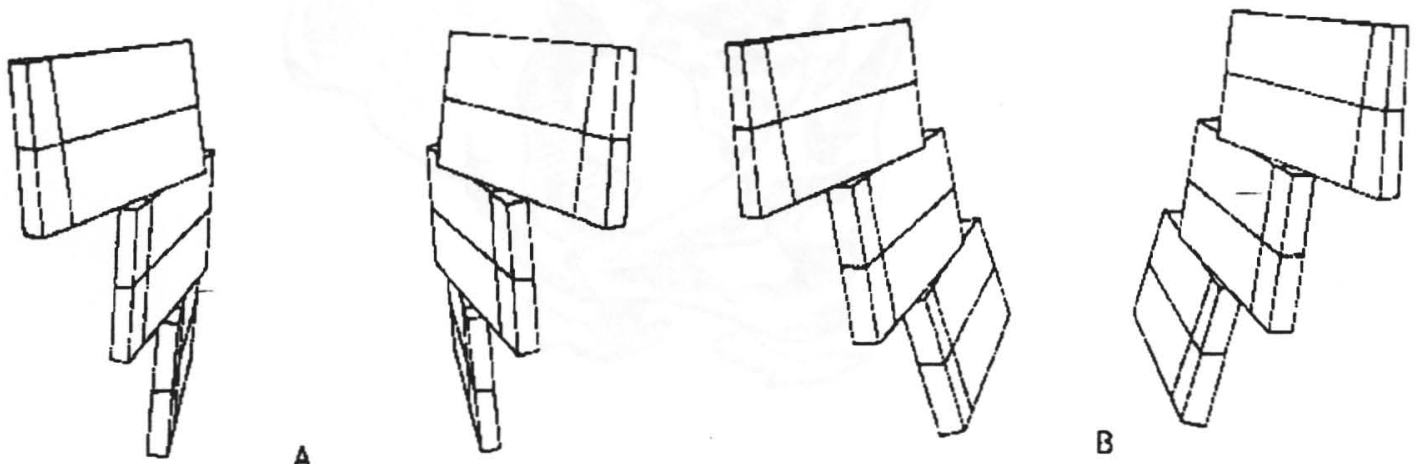

A

Fonte: A Cintura Pélvica. LEE, 2001.

Nota-se o afunilamento do trajeto pélvico em B, e a redução nas dimensões dos estreitos médio e inferior quando comparados com os estreitos do desenho $\mathrm{A}$. 
A forma anatômica do sacro informa além de tudo isso citado anteriormente, sobre a mobilidade articular.

Embora sejam pequenos movimentos, eles são essenciais no alargamento do canal do parto (figura $6 \mathrm{~A}$ e B respectivamente).

Segundo Duncan, citado por DUNN, 1997, esses movimentos são um dos principais motores do parto.

Figura 6 Movimentos da articulação sacrilíaca (A) e alargamento pélvico(B).

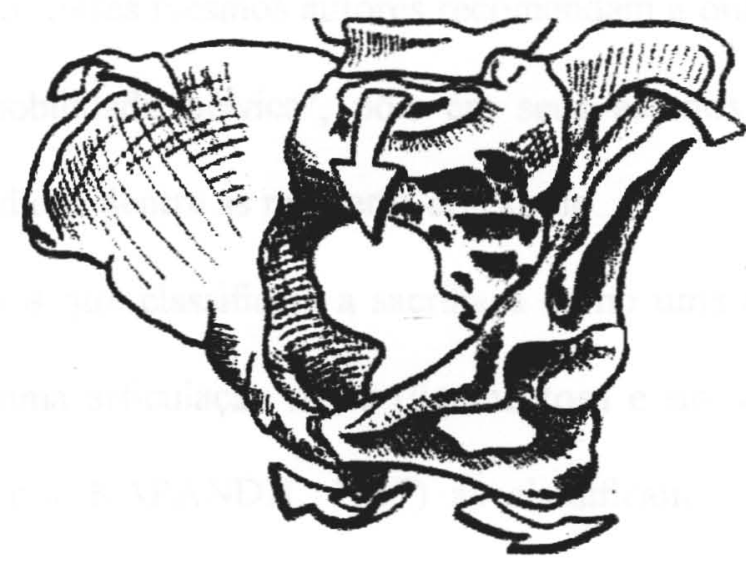

A

Fonte: Fisiologia Articular. KAPANDJI, 1987.

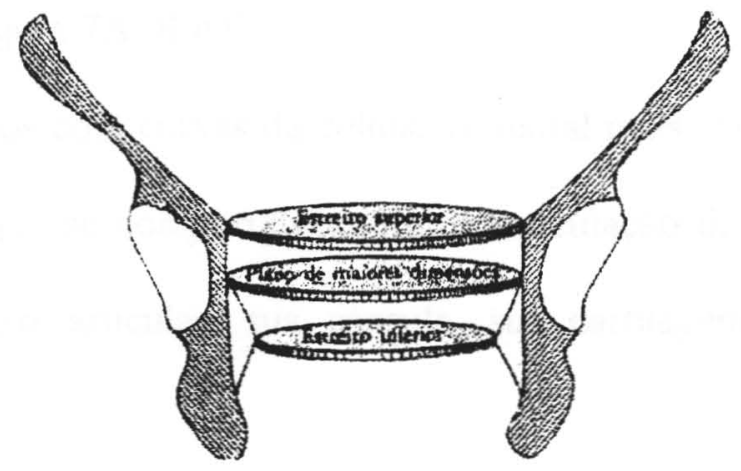

Fonte: Manual de Obstetrícia.GRELLE, 1960. 
Em 1854, Duncan descreveu pela primeira vez os movimentos da sacriliaca durante o parto. $\mathrm{O}$ conhecimento do real comportamento das articulações sacriliacas ainda hoje é discutível, havendo muitas controvérsias e indefinições.

A respeito dos movimentos de rotação do sacro entre os ilíacos existem várias teorias que se propõem a elucidá-los. A rigor, durante o parto, apesar da diversidade de medidas encontradas, os movimentos das aniculações sacrilíacas afetam os diâmetros sagitais, e em especial o do conjugado verdadeiro; de acordo com BORELL e FERNSTROM (1957), consideráveis mudanças nas dimensões pélvicas ocorrem durante o parto. Esses mesmos autores recomendam a outros a continuidade da investigação da "mobilidade pélvica", pois em seus estudos encontraram uma grande variação nas medidas dentre as mulheres do estudo.

Existem estudiosos que classificam a sacrilíaca como uma articulação do tipo sinovial, outros como uma articulação mista (ligamentosa e sinovial) e cinesiólogos como Delmas (citado por KAPANDJ, 1987) as classificam conforme o tipo de coluna vertebral.

Delmas considera que os indivíduos de acordo com o seu tipo postural têm uma dinâmica própria e não patológica, mas relacionada a sua morfotipologia anatômica ilustrada na figura 7A, B e C.

Assim, os indivíduos com curvas da coluna vertebral mais acentuadas (figura 7 A), têm uma dinâmica que se comporta como uma articulação do tipo diartrose ou sinovial, com seu espaço articular, sua cápsula, sua cartilagem e com maiores amplitudes de movimento. 
Já os indivíduos que têm uma articulação do tipo anfiartrose, muito limitada em seus movimentos, são indivíduos com curvas da coluna vertebral mais retas (figura 7 B).

$\mathrm{E}$ os individuos do tipo $\mathrm{C}$ apresentam o sacro em posição neutra.

Outros estudiosos examinaram os aspectos clínicos e biomecânicos das articulações sacriliacas em cadáveres humanos. VLEEMING e col (1990 parte b) notaram a presença de saliências e depressões que se complementavam (se na superficie do sacro há uma saliência, na superficie articular do ilíaco há uma depressão em que esta se encaixa perfeitamente e vice-versa). Muitos autores descrevem estas "rugas" como patológicas.

Figura 7 Formas de coluna segundo orientação articular do sacro.

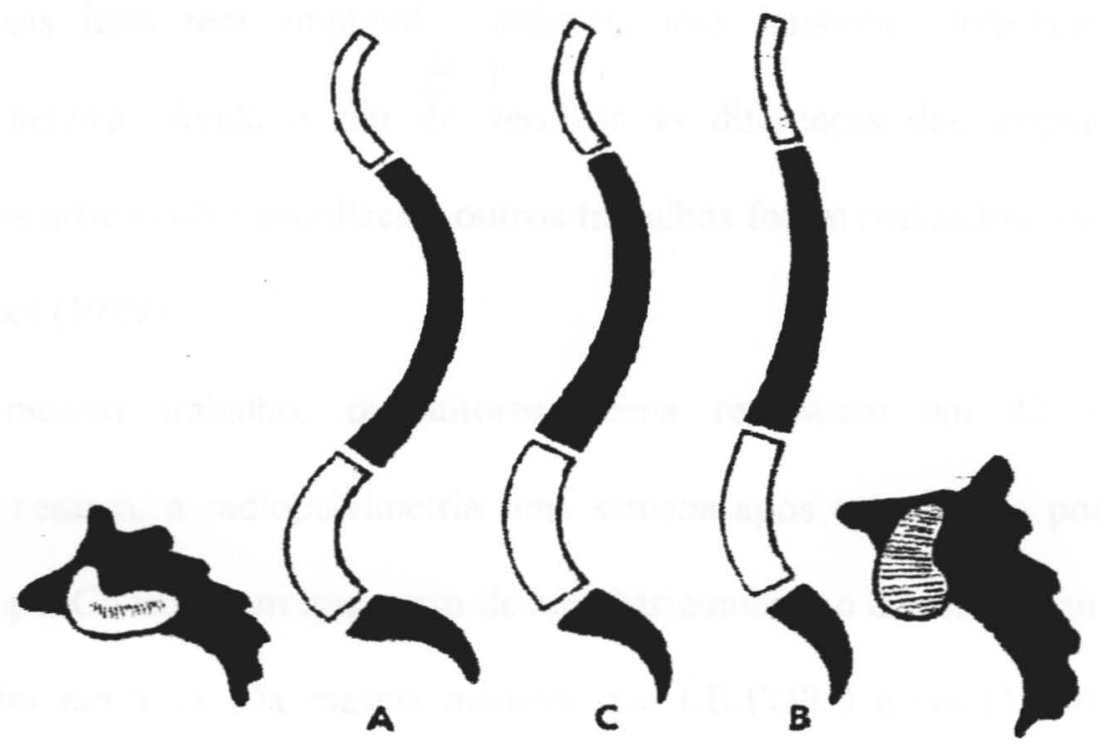

Fonte: Fisiologia Articular. KAPANDJ, 1987. 
No entanto, em 1990, VLEEMING e seus colaboradores consideraram esta aspereza, visível macroscopicamente, como uma adaptação funcional, a qual constitui um sistema de encaixe para gerar maior estabilidade.

Para as mulheres em que o movimento articular é importante por causa do parto, as superficies articulares são mais lisas. Nos homens, pela localização mais ventral do centro de gravidade, ocorre um aumento das saliências e depressões devido ao maior atrito entre as superficies articulares, em função da sobrecarga sobre a articulação sacrilíaca. O estudo de VLEEMING e col, 1990(parte b), enfatizou que as variações anatômicas entre os sexos refletem-se na fisiologia articular (maior ou menor movimento) diferenciada também pelos aspectos biomecânicos (localização do centro de gravidade).

Pode-se presumir que conforme o tipo postural, o atrito articular é maior e resulta em maior aspereza das superficies articulares, com amplitudes de movimento menores; no entanto, têm maior estabilidade. Por outro lado, mulheres com superficies mais lisas têm amplitudes maiores, mas também apresentam maior instabilidade pélvica. Ainda a fim de verificar as diferenças das amplitudes de movimento das articulações sacriliacas, outros trabalhos foram realizados como os de LILFORD e col (1989).

Nesse mesmo trabalho, os autores acima realizaram em 43 mulheres submetidas à cesárea, a radiopelvimetria uma semana após o parto, na posição de cócoras e em pé. Constataram que o ato de agachar aumenta o diâmetro transverso e antero-posterior em $1 \%$. Da mesma maneira que LILFORD e col (1989), outros estudiosos verificaram que há uma diferença nas dimensões pélvicas de acordo com a posição (decúbito dorsal com os membros inferiores em extensão, ou em flexão, ou 
na posição de gato), propondo novas posições para facilitar a passagem do feto pelo canal do parto (KAPANDJ, 1987; STEER e FLINT, 1999).

As amplitudes pélvicas variam não só com a forma, mas também com o movimento articular, e também sofrem influência da posição corporal.

A variedade de teorias revela que existe uma dificuldade de avaliar os movimentos desta articulação, ou mesmo que os trabalhos realizados não padronizaram as posições em que as pacientes foram avaliadas, dificultando as comparações. Também pode se conjeturar a possibilidade da existência de diferentes amplitudes de movimento variando de acordo com as características anatômicas individuais conforme Delmas enunciou.

VLEEMING e col, 1990 (parte b), fizeram objeções quanto aos procedimentos de diagnóstico da articulação sacrilíaca. Estes mesmos autores enfatizaram em seus estudos os diagnósticos incorretos de artropatias da sacrilíaca por imagem radiológica, onde saliências consideradas por eles como adaptações funcionais são mal interpretadas como sendo osteófitos e degeneração da cartilagem articular.

A avaliação da forma do sacro, a qual pode ser realizada pelo Losango de Michaelis, contribui para revelar diversas facetas, podendo ser utilizada para a promoção da saúde feminina.

Reconhece-se que com o avanço tecnológico, métodos de avaliação manual, como o losango de Michaelis, foram sendo progressivamente abandonados e que a mudança da visão clínica inicial resultou em prejuizos do conhecimento, gerando também graves questões éticas que serão discutidas posteriormente.

Com a descoberta do raio-X, em 1895, o uso da pelvimetria instrumental também deixou de ser utilizado e deu seu lugar à radiopelvimetria. Não é mais 
utilizada desde fins do século XX no Brasil, permanecendo seu emprego em alguns paises da África. O uso do pelvímetro e Losango de Michaelis são instrumentos de avaliação considerados obsoletos em outras regiões do mundo "moderno" (THIERY, 1995).

Em decorrência dos riscos fetais e maternos da exposição à radiação, a radiopelvimetria, tornou-se também moda passageira.

Atualmente, vê-se o resgate da pelvimetria associada aos recursos tecnológicos em voga nos países desenvolvidos. Principalmente nos países europeus e, em especial, no Reino Unido. No entanto, as técnicas de pelvimetria por tomografia computadorizada e imagem por ressonância magnética, também oferecem desvantagens como a da radiopelvimetria, podendo corresponder às mesmas cargas de radiação (THOMAS e col, 1998), além de acarretarem custo mais elevado.

Opta-se por medidas de avaliação mais seguras com redução de danos para a mãe e o feto. Comumente, mede-se o conjugado verdadeiro próximo ao evento do parto e as medidas do feto a termo pela ultra-sonografia.

DEURELL e WORM, em 2001, investigaram o significado clínico do conjugado verdadeiro por meio do ultra-som, visando estimar com mais precisão o parto vaginal ou a possibilidade de cesárea. Ao compararem o parto de 246 mulheres do Hospital Herleve, na Dinamarca, verificaram as diferenças nas medidas nas mulheres que apresentaram partos normais e cesarianos. Os valores do conjugado verdadeiro menores que $11 \mathrm{~cm}$ aumentavam a probabilidade de cesárea em $50 \%$, os valores menores ou iguais a $10 \mathrm{~cm}$, em três vezes mais com significativa asfixia por desproporção cefalopélvica, com complicações também para a mãe. 
Médicos no Brasil consideraram como fatores de risco para cesárea no anteparto: gestante com menos de 20 anos ou mais de 28 anos de idade, que tenham tido cesárea prévia, apresentação pélvica, gemelalidade, hemorragia na segunda metade da gestação, pré-eclampsia ou hipertensão arterial sistêmica (CUNHA e col 2002).

A pelve normalmente não é citada como um fator de risco para cesárea. O que leva a crer que a mesma não é avaliada. $O$ fato também pode ser comprovado pela avaliação somente a termo do conjugado verdadeiro, suspeitando-se que, em todo o desenvolvimento gestacional, as adaptações que ocorrem na pelve não são verificadas. Quando os ajustes da pelve materna não são atingidos adequadamente constituem uma ameaça para a mãe e o feto. No nosso país, questões que envolvem a pelve óssea não são consideradas entre as causas de morbidade e mortalidade materna.

Segundo MELLO JORGE e col, 2001, as causas obstétricas diretas correspondentes às complicações específicas da gravidez, parto e puerpério foram as responsáveis por 74,9\% dos óbitos maternos em 1999. Para os mesmos autores, embora subestimado o valor, o Brasil tem uma situação considerada grave quando comparado com países desenvolvidos, também porque as mortes por causas obstétricas diretas são reflexo de má assistência, dependentes de fatores socioeconômicos e o não acesso a serviços de saúde de qualidade.

Não se encontrou dados estatísticos de mortes por parto obstruido, no Brasil, bem como trabalhos que investiguem a estrutura da pelve da gestante, ou façam uso de métodos como a pelvimetria instrumental. 
Em 1890, Matersen (citado por KEIFER 1993) já havia em sua época percebido essa situação de não se avaliar a pelve óssea. Preocupava-se com as inovações e evolução dos procedimentos cirúrgicos, e que os mesmos afastariam os profissionais da época em promover o treinamento enfatizando, a acurada avaliação da mulher incluindo a pelvimetria nos cursos médicos.

Além dos procedimentos cirúrgicos, como a banalização da cesárea, em que a avaliação da pelve óssea não importa, a pelvimetria também entrou em decadência com o conhecimento dos fenômenos plásticos e de acomodação durante o parto, em que, o concepto modifica a sua forma e estruturas moles e rígidas, transitoriamente, a fim de adequar-se ao tamanho e morfologia da pelve materna. Em especial, destacase o acavalgamento dos ossos do crânio, ou moldagem (a parte escamosa do occipital é deslocada para baixo dos parietais, bem como os frontais), permitindo assim, maior proporcionalidade fetopélvica.

Esses fatos contribuíram nitidamente para o descrédito da pelvimetria em relação aos propósitos para qual foi criada, o de prognosticar o parto e a desproporção cefalopélvica.

No entanto, nesse trabalho pretende-se resgatar prováveis pontos positivos quanto a sua utilidade para outros fins, e não somente quanto aos apregoados por seus inventores, inserindo novamente esse conhecimento entre os profissionais que atuam frente a gestante.

Mais recentemente, BÖTTCHER e RADLEY (2001) mostraram em seu trabalho que houve um declínio nítido no ensino da pelvimetria em um hospital obstétrico de Londres. A utilização da pelvimetria caiu em 55,3\% de 1993 para 1998. Ressaltaram que a tendência nas mudanças das atitudes médicas e a relutância 
em utilizá-la, decorrem da forte influência de recentes publicações dos guias de obstetrícia, os quais afetaram dramaticamente o uso desse recurso nas últimas décadas, restringindo o seu uso para um pequeno grupo selecionado de pacientes com cesárea prévia.

KEIFER (1993) refletindo sobre o caminho da obstetrícia, cita frases de outros colegas indignados com o índice de cesáreas que na época tinha aumentado lentamente para $10 \%$.

Ultimamente, no Brasil, o número elevado de cesáreas tem sido fruto de muitas discussões, pois aumentam em sete vezes o risco para a mãe e bebê quando comparado com o parto normal segundo SCHUITMAKER e col (1997). Mas apesar dessas constatações a obstetrícia prossegue nesse caminho.

AL-MUFTI e col (2000) em seu artigo "Obstetricians'personal choice and mode of delivery", afirmam que a maioria dos obstetras escolhe a cesárea como o tipo de parto mesmo na ausência de indicação. Dos $73 \%$ dos médicos da pesquisa que indicaram a cesárea como modo de parto de sua preferência, justificaram a escolha devido ao medo de causar danos ao períneo ou efeitos prejudiciais à função sexual e mais da metade referem à insegurança de causar lesões ao bebê. Enquanto os médicos de outros países assumem ser da sua própria escolha, no Brasil tem-se outro agravante. Além dos altos índices, os médicos culpabilizam as mulheres do setor privado, dizendo ser uma escolha delas. E embasam as suas informações, demonstrando a grande diferença entre os índices de cesárea do setor público (31\%) e os índices do setor privado de 70\% (POTTER e col em 2001).

Os mesmos, provaram em seu trabalho que os aumentos nos índices de cesárea no Brasil não refletem necessariamente a demanda de um parto cirúrgico. Ao 
contrário do que se acredita, as mulheres da classe média e alta no Brasil não querem o parto cesárea.

No entendimento dos autores trata-se da conveniência médica e do ganho econômico. Este último fato se comprova mais ainda porque no serviço público enfermeiras realizam os partos normais, enquanto que no setor privado só médicos podem parturiar.

Estas distorções das verdadeiras intenções de se realizar uma cesariana geraram em pouco mais de trinta anos no país, de acordo com a antropóloga BELLINGHINI (2002), uma cultura que ela denominou "cultura da cesariana" que se expandiu pelo Brasil, a tal ponto que as mulheres pobres acham que a cesariana é uma opção de bom atendimento, gerando um conflito, pois não têm essa opção no setor público nas mesmas proporções que no particular.

Em debate promovido pela Revista Ser Médico, 2002, vários médicos brasileiros falaram sobre as dificuldades em atender partos normais, como a questão da anestesia para fazer o bloqueio peridural em uma paciente do SUS (Sistema Único de Saúde).

Para o parto vaginal, também consideram a baixa remuneração e o risco de ser prolongado. Com sinceridade, alguns médicos falaram da falta de tempo para acompanhar um trabalho de parto, enquanto há outras pacientes esperando no consultório. Assumem que os altos índices de cesárea são em função de seus interesses, mesmo que a intervenção ofereça risco e nenhuma vantagem para a saúde da mulher.

KEIFER (1993) questionando sobre para onde caminha a obstetricia do século vinte e um, afirmou que em 725 dos casos era possível o parto normal desde que as 
pacientes fossem cuidadosamente selecionadas por um profissional habilidoso requerendo mudanças no ensino. Considera ainda, que o aumento das intervenções cesarianas desnecessárias é devido à ameaçadora má prática dos profissionais.

Assim, a realização deste nosso trabalho justifica-se na medida em que pretende resgatar o uso da pelvimetria associada ao uso do Losango de Michaelis e aos princípios tipológicos da Ciência das Constituições, não só averiguando o prognóstico do parto, mas refletindo sobre a utilização desses métodos para outros fins, como acompanhar as mudanças pélvicas, e em quais situações a maior ou menor ampliação da capacidade pélvica constitui risco de lesões para a mãe e para o bebê, pois se sabe que a pelve da mulher durante o período gravídico sofre grandes transformações tanto do seu conteúdo interno, quanto dos ossos, articulações, ligamentos e músculos que a compõem, sendo um período de risco de desorganização do organismo materno, que não esteja preparado para essas mudanças, consideradas fisiológicas.

Em relação ao conteúdo interno:

"... o útero aumenta 150 vezes durante a gravidez e a capacidade aumenta mais de 1000 vezes. Seu peso aumenta até 20 vezes no termo, não levando em conta o peso do feto" (ARTAL e col, 1999, P. 9).

Secundariamente à liberação dos estrógenos e relaxina, ocorre desde o início da gravidez, uma crescente lassidão ligamentar, aumento de líqüido sinovial e amolecimento da cartilagem articular. Disto resulta uma maior mobilidade e instabilidade (IRELAND e OTT, 2000). Esta instabilidade é acrescida do deslocamento do centro de gravidade, onde a pelve roda em torno do eixo femoral 
com o aumento da lordose lombar (DAVIS, 1996; FRANKLIN e CONNER, 1998; ARTAL e col, 1999).

A estabilidade é obtida pela contração dos músculos lombares. Além da sobrecarga sobre os músculos e coluna lombossacra, a articulação sacrilíaca também é colocada sob tensão, sendo queixas comuns na gravidez, além de lombalgia, dor ao nível das articulações sacrilíacas (YOUNG, 1940; SCHWARZER e col, 1995; RUSSELL e col, 1996; OSTGAARD e col, 1997; HANSEN e col, 1999; LARSEN e col, 1999).

As ações do estrógeno, relaxina e prolactina sobre 0 sistema musculoesquelético não são ainda totalmente conhecidas. A função exata dos receptores para estes hormônios encontrados nos ligamentos articulares, nos sinoviócitos da membrana sinovial e parede dos vasos sanguíneos, não está claramente elucidada. Contudo sabe-se que as altas concentrações de estrógeno diminuem a síntese de colágeno e aumenta a incidência de lesões ligamentares (IRELAND e OTT, 2000).

Segundo estes mesmos autores, no terceiro trimestre da gravidez e puerpério há um aumento na formação e reabsorção óssea, sendo a incidência de osteoporose idiopática associada com a gravidez provavelmente muito maior do que é sugerido na literatura atual.

Fato conhecido é o afrouxamento ligamentar e o afastamento articular particularmente bem perceptível após o quinto mês devido à ação da relaxina (IRELAND e OTT, 2000). 
A diástase pubiana fisiológica é de $3 \mathrm{~mm}$ a $7 \mathrm{~mm}$, podendo assumir graus acima dos normais (acima de $10 \mathrm{~mm}$ ) fundamentando o aparecimento de dor púbica e lombar (YOUNG, 1940; ARTAL e col, 1999).

A sínfise púbica relaxa na primeira metade da gestação, retornando ao normal do terceiro ao quinto mês no pós-parto. Em $25 \%$ dos casos, de maneira anômala, a articulação não se restabelece (BRIQUET, 1956; VLEEMING e col, 1992).

No caso da articulação sacrilíaca, o não retorno ao normal não se dá somente pelo resultado da embebição, mas também pelo trauma no momento do parto (RUSSELL e col, 1996).

As complicações da relaxação pélvica variam de acordo com os relatos dos estudos de $0,8 \%$ a $16 \%$. Normalmente, têm início entre o quinto e o oitavo mês de gestação (LARSEN e col, 1999). Entre as lesões que mais afetam a pelve da gestante pode-se citar: fratura púbica por estresse, disjunção da sínfise púbica, osteíte condensante do ílio e a meralgia parestética, por estiramento do nervo cutâneo femoral lateral (ARTAL e col, 1999).

A relaxação pélvica pode trazer outras complicações ortopédicas na gravidez; entre as já citadas, há o risco de luxação articular também gerando dor e incapacidade.

A dor e incapacidade têm um impacto social e econômico importante, principalmente nas mulheres que desenvolvem dor pélvica crônica. Além dos gastos com tratamento, o afastamento/doença por esta causa.

A dor lombar é a queixa musculoesquelética mais comum na gravidez. Estimase que atinge de $50 \%$ a $70 \%$ das gestantes (OSTGAARD e col 1997, FERREIRA e 
NAKANO, 2000). E observa-se que pouco ou nenhum tratamento à gestante é oferecido por esse motivo.

É razoável pensar em medidas preventivas, pois se somam a tudo isto os possíveis efeitos deletérios sobre o desempenho da sacrilíaca na ampliação das dimensões pélvicas durante a passagem do feto.

Estes ajustes são comumente atribuídos aos efeitos hormonais sobre o sistema osteomioarticular. Cabe questionar qual a resposta do sistema ao efeito, ou mesmo se as respostas exageradas e desagradáveis gerando dores e disfunções são resultado de condições prévias determinadas pela forma anatômica, ou um simples despreparo físico. Alguns autores como ALBERT e col (2000) propõem que se distingua a dor sacriliaca da lombar, criando modelos que as diferenciem.

Como se desconhecem instrumentos de avaliação da relaxação pélvica e o que ocorre durante a adaptação da pelve da gestante em resposta à ação hormonal, resgatou-se o uso dos princípios da Biotipologia, do Losango de Michaelis e da pelvimetria manual a fim de clarificar este fenômeno. 
3 Hipótese

Partindo da suposição de que as variações anatômicas dos tipos posturais determinam comportamentos biomecânicos e clínicos da fisiologia articular com efeitos sobre o parto, a hipótese que se pretende sustentar é a de que as adaptações plásticas que ocorrem na pelve materna, paralelamente ao desenvolvimento fetal, não são só decorrentes dos efeitos hormonais, mas também dependem do comportamento cinemático da articulação sacrilíaca determinada pelo tipo postural e sua variação anatômica. 
4 Objetivos

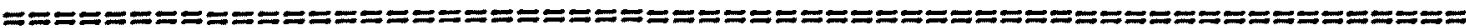

- Geral:

O objetivo deste trabalho é verificar como a plasticidade pélvica, ou seja, a sua capacidade de moldar-se mês a mês, ocorre à medida que o feto se desenvolve, por meio de uma medida objetiva, associando a morfologia externa e interna.

\section{- Específicos:}

1. Identificar e analisar se há entre os tipos posturais diferenças nos mecanismos de adaptação, resultando em maior ou menor fator de risco para a freqüência de comprometimento pélvico durante a gestação, bem como repercussões negativas sobre a gravidez.

2. Construir um método que auxilie na seleção das gestantes que possam apresentar riscos no manejo do parto e identifique as estruturas pélvicas que apresentem os maiores riscos de lesões para a mãe e o bebê.

3. Propor um modelo que discrimine as algias de origem musculoesquelética na gravidez, a fim de nortear um programa terapêutico de intervenção adequado ao quadro dessa mulher. 


\section{Procedimentos Metodológicos}

- Desenho da pesquisa

A análise foi feita a partir de um estudo de casos de trinta e nove gestantes.

5.0 População do estudo: 39 gestantes matriculadas na Unidade Básica de Saúde Parque da Lapa nos meses de setembro e outubro de 2002.

5.1 Local: Distrito Administrativo da Vila Leopoldina no Município de São Paulo, onde também se localiza a Unidade, sendo esta a única referência de saúde da região.

5.1.2 Características do local: O levantamento das características do local foi feito a partir do consolidado de famílias cadastradas no PSF da região estudada, no qual apresenta indicadores sociodemográficos.

Este consolidado foi obtido do SIAB (Sistema de Informação da Atenção Básica). O sistema representa um instrumento para avaliar a efetividade das ações pelos serviços de saúde, sendo a territorialização um fator importante e que pretende identificar desigualdades e localizar espacialmente os problemas de saúde.

Dentro desse princípio, as gestantes do estudo também foram avaliadas segundo questões que envolvem cada área da Vila Leopoldina, muito embora esse não seja o objeto de estudo do trabalho; no entanto, os dados estão inseridos nesse contexto, não sendo razoável eliminar tais conceitos do trabalho.

5.2 Critérios de exclusão do estudo: Das quarenta e sete gestantes matriculadas na unidade nos meses de setembro e outubro de 2002, 8 foram excluídas por apresentar uma ou mais das situações definidas como critério de exclusão tais como: idade gestacional maior que dezoito semanas e a negação de participar da pesquisa. 
Assim, participaram as gestantes que consentiram de acordo com a Resolução n ${ }^{\circ} 196$ de 10 de outubro de 1996 e que estavam entre as $13^{a}$ e $17^{a}$ semanas gestacionais nos meses de setembro e outubro de 2002.

Além da caracterização das gestantes relacionadas às dificuldades do território, levantou-se também dados pessoais, as histórias pregressas de gestações anteriores e hábitos.

5.3 Instrumento de coleta de dados: Os elementos utilizados para distinguir as 39(trinta e nove) gestantes do estudo foram os dados obtidos da ficha de avaliação inicial (anexo 1) segundo as variáveis: idade, estado conjugal, profissão, número de gestações prévias, número de abortos e óbitos infantis de gestações anteriores, nível de atividade fisica, cor e hábitos (tabagismo e etilismo).

Também foram perguntados sobre antecedentes pessoais, quedas ou acidentes e se realizavam algum tipo de tratamento na ocasião.

Além do levantamento desses dados, efetuaram-se avaliações antropométricas e medidas específicas da pelve.

\subsection{Avaliação Antropométrica}

Foram avaliados: o peso em quilogramas $(\mathrm{kg})$, e a altura em centímetros $(\mathrm{cm})$ com o uso de uma balança mecânica adulto marca Filizola.

As medidas foram realizadas entre as $13^{\mathrm{a}}$ e $17^{\mathrm{a}}$ semanas e entre as $32^{\mathrm{a}}$ e $36^{\mathrm{a}}$ semanas gestacionais, na posição ortostática.

O número do sapato também foi anotado a fim de se verificar a provável relação do tamanho dos pés com o tamanho da pelve, segundo a proposta de alguns estudos como o de FRAME e col (1985). E se o mesmo poderá ser um dado que em conjunto com os demais, favoreça uma melhor análise da pelve gestante. 
A medida específica das dimensões pélvicas foi realizada por meio da pelvimetria instrumental e do Losango de Michaelis.

\subsection{Pelvimetria}

As medidas foram determinadas na posição bípede com o uso do pelvímetro de Martin (figura 2). As dimensões foram definidas de acordo com os padrões clínicos de BRIQUET (1953) e de PSCHYREMBEL (1976).

Avaliou-se três diâmetros: o interespinhoso que reflete a medida do estreito médio, o intertrocantérico que avalia o estreito inferior, e o conjugado externo cuja medida auxilia no prognóstico da passagem do feto.

$\checkmark$ Interespinhoso:

Relaciona-se diretamente com as espinhas ciáticas que influenciam a base do estreito médio, ou seja, se a base for ampla, trata-se de uma bacia ginecóide, e se estreitada diz respeito a uma bacia andróide. A distância normal entre as espinhas ilíacas ântero-superiores para Briquet era de $24 \mathrm{~cm}$ e para Pschyrembel era de 25 a $26 \mathrm{~cm}$ (figura 8), assim definiu-se o intervalo de normalidade entre 24 e $26 \mathrm{~cm}$.

Figura 8 Diâmetro Interespinhoso.

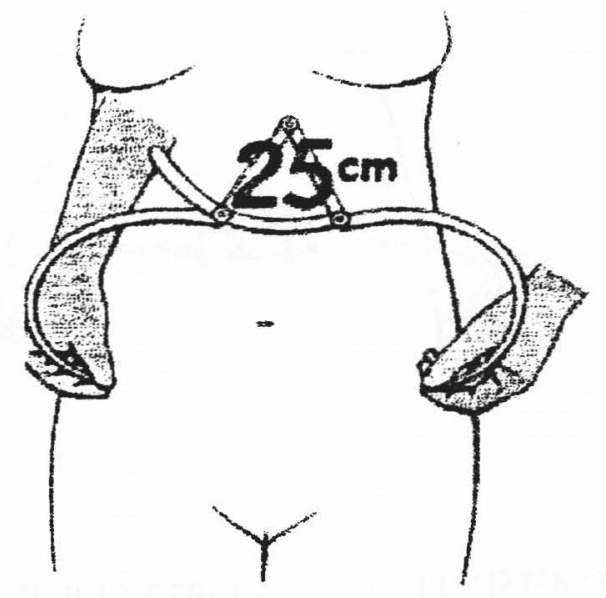

Fonte: Obstetricia practica, PSCHYREMBEL, 1976. 


\section{$\checkmark$ Intertrocanteriano:}

Identifica alterações na profundidade pélvica, e suas medidas quando diminuídas implicam o alongamento do ramo do púbis e significa uma diminuição do ângulo subpúbico (figura 9).

O diâmetro intertrocanteriano compreende a distância entre os trocânteres femorais que para Briquet o normal era de $32 \mathrm{~cm}$ e para Pschyrembel era de $31 \mathrm{~cm}$, assim escolheu-se o intervalo de normalidade entre 31 a $32 \mathrm{~cm}$.

O aumento ou diminuição das dimensões do diâmetro intertrocanteriano equivale a uma anatomia que poderá complicar a saída do feto por modificar o ângulo subpúbico (figura 10) para maior ou menor amplitude.

A importância do ângulo subpúbico reside no perfeito encaixe da cabeça do feto na fase de desprendimento (figura11 A).

Principalmente a diminuição do ângulo subpúbico gera desajustes (figura 11 B) no encaixe da cabeça fetal.

Figura 9 Intertrocanteriano.

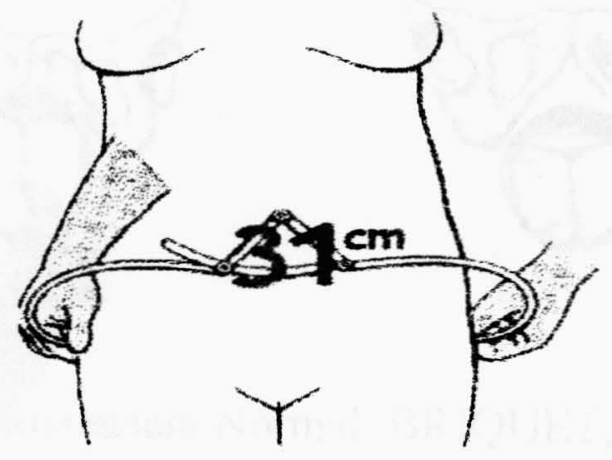

Fonte: Obstetricia practica, PSCHYREMBEL, 1976. 
Figura 10 Alterações no ângulo subpúbico.

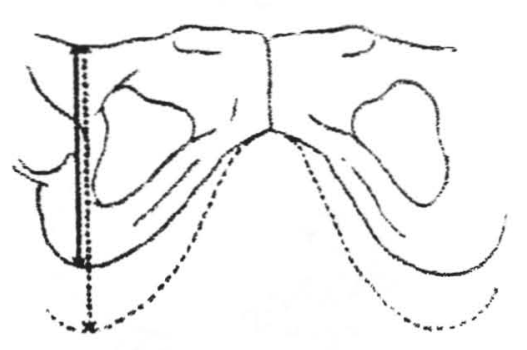

Fonte: Manual de Obstetrícia, GRELLE, 1970.

Figura 11 Encaixe (A) e desencaixe(B) da cabeça fetal no arco subpúbico durante o desprendimento.

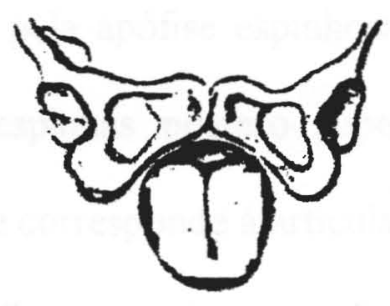

A

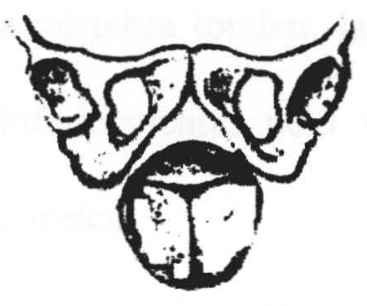

B

Fonte: Obstetrícia Normal. BRIQUET, 1956. 
$\checkmark$ Conjugado Externo ou de Baudelocque:

Mede-se com a mulher na posição lateral a distância entre a quinta vértebra lombar e a borda superior da sínfise púbica. $\mathrm{O}$ valor considerado normal para ambos é de $20 \mathrm{~cm}$ (figura 12).

Figura 12 Conjugado Externo.

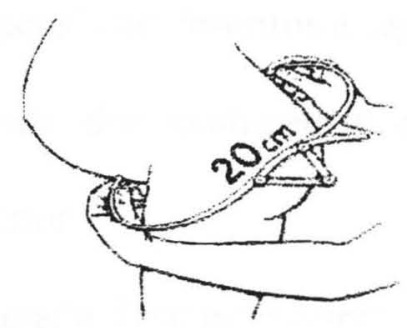

Fonte: Obstetricia Practica, Pschyrembel, 1976.

A outra forma utilizada para verificar a capacidade pélvica foi a medida do Losango de Michaelis.

\subsection{Losango de Michaelis}

O Losango de Michaelis corresponde à região lombossacra delimitada superiormente pela apófise espinhosa da quinta vértebra lombar, lateralmente, pelas fossetas das espinhas póstero superiores e inferiormente, pelo vértice do sulco interglúteo que corresponde à articulação sacrocóccica.

As suas dimensões foram avaliadas na posição bípede com o uso de marcadores esféricos adesivos (figura 13), colados sobre a pele nos pontos de referência anatômicos preconizados pela literatura (BRIQUET, 1957).

Para a mensuração utilizou-se uma fita métrica (figura 14), e as medidas foram registradas em duas ocasiões: entre as $13^{a}$ e $17^{a}$ semanas gestacionais e a outra entre 
as $33^{a}$ e $37^{a}$ semanas. $O$ registro também foi feito com o uso de uma máquina fotográfica com fins de auxiliar na avaliação do Losango de Michaelis.

Por sugestão do Comitê de Ética as mesmas não deveriam ser utilizadas para ilustração e foram devolvidas para as gestantes conforme consta nos termos do Termo de Consentimento Livre e Esclarecido.

As medidas padronizadas como referência (figura 15 a) do Losango de Michaelis e seus significados clínicos ${ }^{1}$ são descritos a seguir.

A diagonal transversa mede dez centímetros e divide o losango em dois triângulos: um superior e um inferior.

O triângulo superior é chamado Triângulo Supra Sacro de Tarnier e tem altura de quatro centímetros. Quando a altura diminui para $3 \mathrm{~cm}$ (centímetros) ou menos, há um achatamento da pelve (figura 15 b), isto é, uma redução do conjugado verdadeiro ou de Baudelocque.

A diagonal vertical mede onze centímetros e divide o losango em dois triângulos laterais. A deformação de um dos triângulos laterais informa sobre assimetria pélvica (figura $15 \mathrm{c}$ ).

Todas as trinta e nove gestantes foram avaliadas segundo todos os itens acima. Exceto, em relação à comparação do afastamento da sacrilíaca e da área final e inicial do losango.

\footnotetext{
${ }^{1}$ Estas referências clínicas foram extraídas de BRIQUET, 1956.
} 
Figura 13 Adesivos nos pontos de referência anatômica.

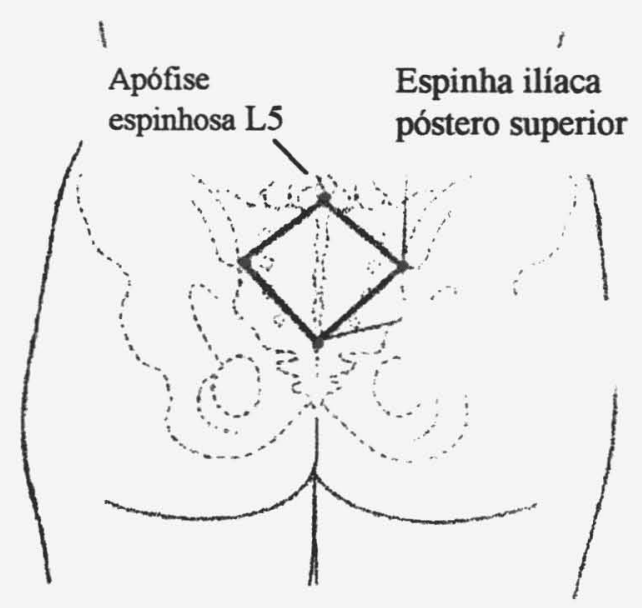

Fonte: Anatomia médico-cirúrgica da pelve feminina. COSTACURTA, 1975.

Figura 14 Losango de Michaelis.

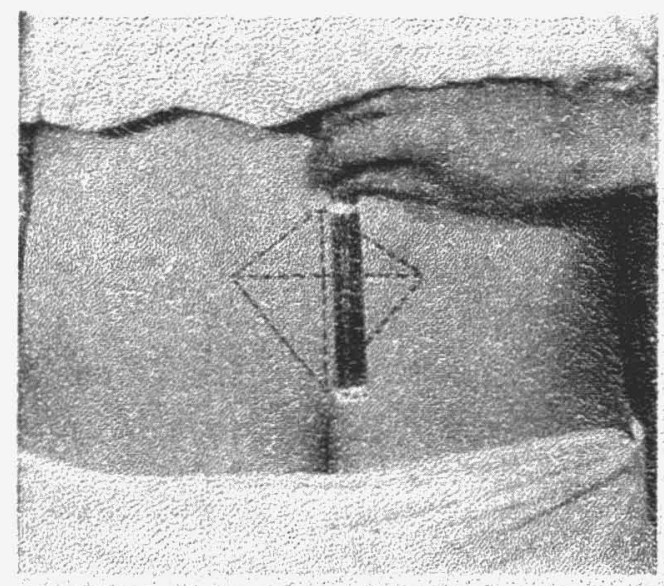

Fonte: Obstetrícia Normal, BRIQUET, 1956. 
Figura 15 Losango de Michaelis em pelve normal, achatada e assimétrica.

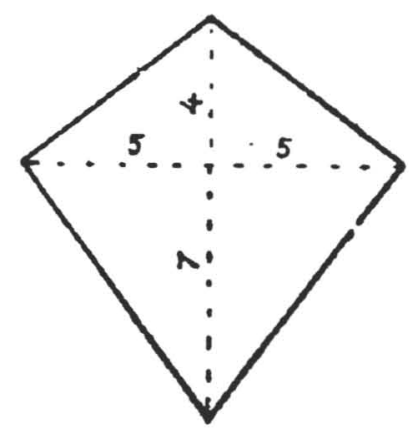

A

Pelve normal

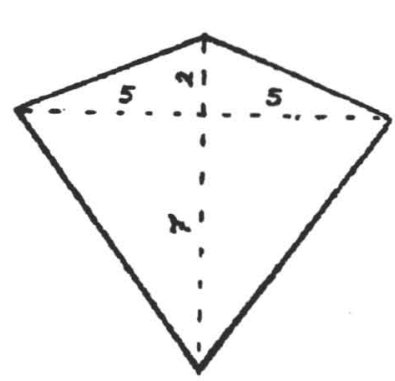

B

Pelve achatada

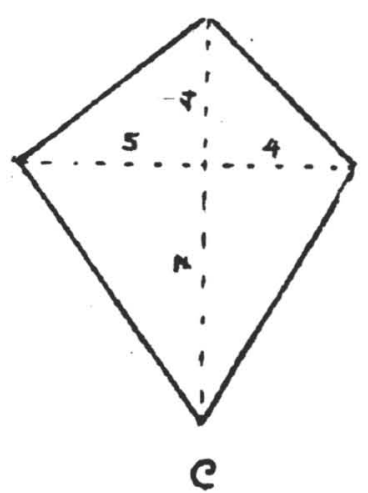

Pelve assimétrica

Fonte: Obstetrícia Normal, BRIQUET, 1956. 
Contabilizou-se somente em vinte e nove gestantes o afastamento final menos o inicial das articulações sacrilíacas,bem como a comparação das áreas inicial e a final do Quadrilátero de Michaelis; pois 10(dez) gestantes saíram do estudo: uma das gestantes mudou-se da região, cinco evoluíram com aborto, e quatro adolescentes não aderiram ao pré-natal.

Um dos abortos foi devido à hipertensão arterial sistêmica,quanto aos demais,os motivos não foram elucidados por falta de informações.

Assim, a medida foi realizada nas duas ocasiões anteriormente citadas $\left(13^{\mathrm{a}} \mathrm{e}\right.$ $17^{\mathrm{a}}$ semanas gestacionais e a outra entre as $33^{\mathrm{a}}$ e $37^{\mathrm{a}}$ semanas) em apenas vinte e nove gestantes.

No item resolução da gravidez, os dados foram obtidos de prontuário e/(ou informação do agente comunitário), não foram excluídas do total as que não aderiram (quatro) e a que se mudou (uma), sendo os dados analisados sobre um total de trinta e nove gestantes.

A avaliação da dor de origem osteomioarticular, na região pélvica, foi avaliada nas trinta e nove gestantes, com base nos desenhos da primeira avaliação. E não nas demais, pois houve intervenção da pesquisadora sobre os quadros álgicos, alterando o padrão que foi apresentado somente na ocasião da primeira avaliação.

\subsection{Avaliação da Dor Pélvica}

Foi entregue a cada gestante um desenho (anexo 2) e perguntado sobre a presença de dor na região pélvica, sendo solicitado que a mesma registrasse livremente no desenho a localização da dor, e falasse o que sentia.

Foram avaliadas e excluídas as dores de outras origens como, por exemplo, lombalgia por infecção urinária (dado obtido do prontuário da gestante). 
Como a dor lombar é muito relacionada com o aumento de lordose, a anteversão e a retroversão do sacro também foram analisadas.

\subsection{Avaliação da posição do sacro}

Para classificar as gestantes com sacro em anteversão ou em retroversão utilizamos os seguintes procedimentos:

1. Aplicou-se uma régua da cifose torácica à face posterior do sacro, e com outra régua perpendicular a primeira, mediu-se a distância entre a quinta vértebra lombar e a primeira régua.

2. Classificou-se o sacro em retroversão quando as medidas encontravam-se no intervalo entre $2,5 \mid-3,5 \mathrm{~cm}$, na posição neutra quando as medidas estavam entre $3,5-4,5 \mathrm{~cm}$, e em anteversão quando as medidas estavam entre $4,5 \mid-5,5 \mathrm{~cm}$

\subsection{Análise dos Dados}

Os dados coletados foram analisados de maneira descritiva e os resultados apresentados em: tabelas, gráficos, figuras esquematizadas e quadros no Capítulo 6 Resultados e Discussões.

\subsection{Aspectos Éticos}

Quanto aos aspectos éticos relacionados ao projeto, as gestantes que participaram da pesquisa receberam esclarecimento detalhado em linguagem acessivel, incluindo as justificativas e os objetivos dos procedimentos, os desconfortos e riscos possiveis, bem como os beneficios esperados. Também foi garantido o sigilo absoluto, assegurando a privacidade.

Considerando-se as eventuais interferências sobre a gravidez, mulheres que corriam o risco do agravo de seu quadro patológico, seriam excluídas do estudo. 
Foram assegurados às gestantes os beneficios resultantes da pesquisa, o acesso aos procedimentos, as condições de acompanhamento, tratamento e orientação conforme o caso.

Também foram assegurados os recursos humanos e os materiais necessários ao bem-estar da gestante, protegendo-lhe a imagem e a não estigmatização, garantindo a não utilização das informações em prejuizo das participantes ou de sua comunidade, inclusive em termos de auto-estima e de prestígio econômico-financeiro. Foi garantida a devolução das fotos no término do trabalho.

Tem-se no anexo 4 o modelo do termo de consentimento livre e esclarecido, no anexo 5, a aprovação deste projeto, pelo Comitê de Ética em Pesquisa da Faculdade de Saúde Pública da Universidade de São Paulo, de acordo com a Resolução CNS/196/96 e no anexo 6, o relatório do exame de qualificação do projeto. 


\section{Resultados e Discussão}

A Unidade Básica de Saúde Parque da Lapa era anteriormente um Ambulatório de Especialidades, hoje (2004) uma Unidade Básica de Saúde, onde foi implantado o Programa de Saúde da Família (PSF), em 2001, com cinco equipes compostas por: um médico generalista, uma enfermeira, dois auxiliares de enfermagem e seis agentes comunitários de saúde. Além de uma equipe denominada de apoio composta por: uma fisioterapeuta, uma assistente social, uma terapeuta ocupacional, uma psicóloga e uma fonoaudióloga.

Não é comum existir em outras unidades de PSF a equipe de apoio, pois não fazem parte da equipe nuclear do programa (médico, equipe de enfermagem e agentes comunitários de saúde). Essa em particular subsiste devido ao precedente da unidade ter sido um Ambulatório de Especialidades.

O Distrito da Vila Leopoldina está dividido em cinco áreas, nas quais cada equipe é responsável pela população que a ocupa. As equipes são denominadas por cores que correspondem às respectivas áreas.

Essas cinco equipes (azul, vermelha, verde, amarela e laranja), não são suficientes para garantir o cuidado de todo o território. Deste modo existem famílias que não estão incluidas no Programa e são chamados de "fora de área".

6.1 Caracterização demográfica do Território: O Distrito Administrativo da Vila Leopoldina localiza-se na zona oeste da capital de São Paulo e faz fronteira com a Vila Jaguara, Lapa, Jaguaré e Alto de Pinheiros (Mapa Esquemático da Vila Leoplodina-figura 16 a seguir). Dados de 2002 estimaram que a população da Vila Leopoldina era de 26.769 habitantes em 2001, residentes em 7933 domicílios em 
uma área de $7,2 \mathrm{~km}^{2}$. Totalizando uma densidade demográfica de 3.679 habitantes por $\mathrm{km}^{2}$, de acordo com informações do jornal Folha de São Paulo (2003).

Até 2003, aproximadamente 12.000 habitantes foram assistidos pelo PSF (dados do SIAB de 2003 da Unidade Básica de Saúde Parque da Lapa). O que corresponderia a $44 \%$ da população do território com cobertura do Programa de Saúde da Família. 
Figura 16 Mapa da Vila Leopoldina modificado e assinalado com "X" a regionalização esquemática por equipes.

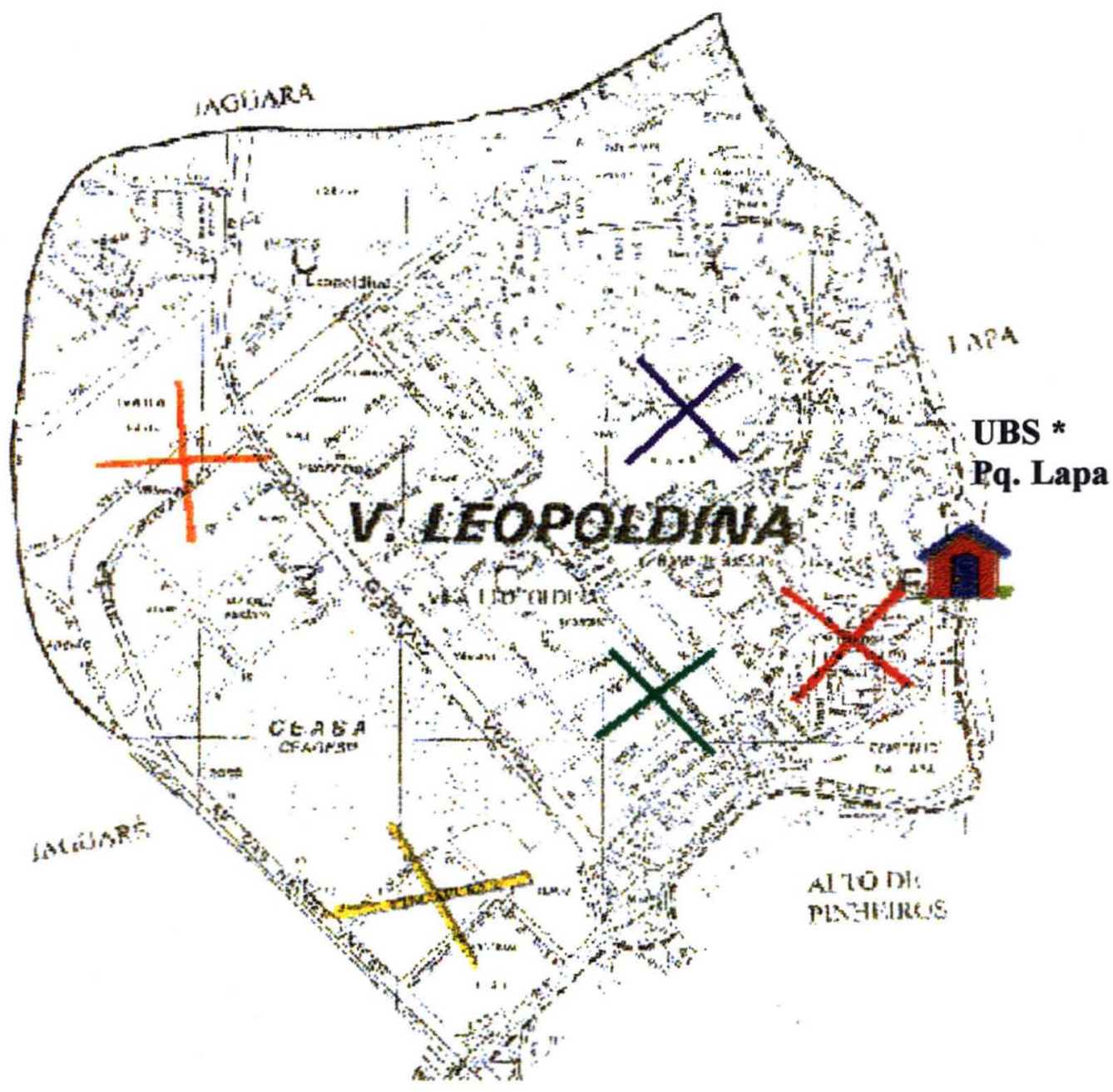

Fonte: Vila Leopoldina.Mapograf Editora, 2002.

UBS * Pq. Lapa = Unidade Básica de Saúde Parque da Lapa.

$\mathrm{X}$ equipe vermelha

$\mathrm{X}$ equipe verde equipe amarela

$\mathrm{X}$ equipe laranja

$\mathrm{X}$ equipe azul 
6.2 Perfil socioeconômico: Como nos outros noventa e um distritos do município, a Vila Leopoldina possui um contraste social e econômico entre uma população que faz parte de um estrato superior (classe média alta) e populações de estratos inferiores residentes em favelas da região e nos prédios do Projeto Cingapura (ex-situação de favela).

Também ocorrem diferenças quanto ao perfil epidemiológico das populações residentes nas diferentes áreas.

As gestantes do estudo fazem parte de três áreas distintas que correspondem às áreas das equipes: amarela, laranja e vermelha que estão assinaladas no mapa da figura 16 com um " $\mathrm{X}$ " nas respectivas cores.

Das três áreas, a amarela é a que concentra o maior número de gestantes residentes nos prédios do Cingapura (ex-situação de favela).

No Cingapura (equipe amarela) $4,16 \%$ das pessoas são cobertas com plano de saúde, contrastando com a população coberta pela equipe vermelha e verde que possuem maior número de idosos e $45,41 \%$ das pessoas têm plano de saúde, e estão na circunvizinhança da unidade. As da favela da Mofarrej (equipe laranja) residem em área mais afastada da unidade e possuem $25,09 \%$ de pessoas com plano de saúde. A equipe azul assite uma microárea circunvizinha a Lapa em que $67,71 \%$ da população utilizam o SUS (Sistema Único de Saúde) e apresentam também o predomínio de adultos e indivíduos na terceira idade. Dados obtidos do SIAB (Sistema de Informação da Atenção Básica) segundo as informações coletadas pelos agentes comunitários de saúde em julho de 2003 . 
As populações mais carentes da Vila Leopoldina são as que têm maior dificuldade de acesso ao serviço de saúde, residindo mais afastadas da mesma (visualiza-se melhor no mapa - Figura 16).

Também não existem próximo ao seu local de residência espaços para práticas de esporte. É uma área desprovida de cinemas, parques, bibliotecas, ou quaisquer outras facilidades de lazer ou cultura.

Na Vila Leopoldina está estabelecida a CEAGESP (Companhia de Entrepostos e Armazéns Gerais de São Paulo), e é conhecida pela sua notável capacidade de comercializar diariamente dez mil toneladas de produtos hortifrutigranjeiros, sendo o comércio a principal atividade e um meio de subsistência da região.

Como já citado, as 39 (trinta e nove) gestantes do estudo são oriundas de três equipes de PSF sendo:

1. Equipe amarela-25 (vinte e cinco) gestantes correspondendo a $64 \%$ do total de gestantes do estudo, moradoras do Cingapura (ex-situação de favela).

2. Equipe vermelha com um total de 9 mulheres, contribuindo com $23 \%$ das gestantes da pesquisa e residentes na região próxima a UBS (Unidade Básica de Saúde).

3. Equipe laranja que perfaz as $13 \%$ restantes, equivalendo a 5 gestantes moradoras da favela.

\subsection{Discussão dos Resultados Obtidos}

A idade das gestantes variou de 14 a 34 anos, sendo que 12 eram adolescentes $(30,9 \%)$. Quase a totalidade das gestantes adolescentes segundo o critério da OMS (Organização Mundial da Saúde-10 a 19 anos) pertencia à equipe amarela. 
Entre as gestantes adolescentes, apenas $8(66,6 \%)$ compareceram às avaliações e eram assíduas às consultas de pré-natal, as demais, adolescentes $(33,4 \%)$, não compareciam ao pré-natal e também não foram submetidas à segunda avaliação. $\mathrm{Na}$ tabela 1 a seguir visualiza-se características das gestantes atendidas na UBS Parque da Lapa. 
Tabela1 Distribuição do número e porcentagem das gestantes, segundo faixa etária, estado conjugal, gestações prévias, número de partos, abortos anteriores, óbitos infantis e resolução da gravidez, UBS Parque da Lapa, 2003.

\begin{tabular}{|c|c|c|}
\hline Variáveis & $\mathbf{N}^{\circ}$. & $\%$ \\
\hline Faixa etária & & \\
\hline $10-15$ & 1 & 2,7 \\
\hline $15 \vdash 20$ & 11 & 28,2 \\
\hline $20 \vdash-25$ & 12 & 30,8 \\
\hline $25 \vdash-30$ & 5 & 12,7 \\
\hline $30-35$ & 10 & 25,6 \\
\hline \multicolumn{3}{|l|}{ Estado conjugal } \\
\hline Casada & 18 & 46,2 \\
\hline Solteira & 21 & 53,8 \\
\hline \multicolumn{3}{|l|}{ Gestações prévias } \\
\hline 0 & 12 & 30,8 \\
\hline 1 & 14 & 35,9 \\
\hline 2 & 6 & 15,4 \\
\hline$>3$ & 7 & 17,9 \\
\hline \multicolumn{3}{|l|}{ Número de partos } \\
\hline 0 & 15 & 35,9 \\
\hline 1 & 12 & 30,8 \\
\hline 2 & 10 & 28,2 \\
\hline$>3$ & 2 & 5,1 \\
\hline \multicolumn{3}{|l|}{ Abortos anteriores } \\
\hline 0 & 31 & 79,5 \\
\hline 1 & 6 & 15,4 \\
\hline$>2$ & 2 & 5,1 \\
\hline \multicolumn{3}{|l|}{ Óbitos infantis } \\
\hline 0 & 36 & 66,7 \\
\hline 1 & 3 & 33,3 \\
\hline \multicolumn{3}{|l|}{ Resolução da gravidez } \\
\hline Normal & 21 & 53,9 \\
\hline Cesárea & 12 & 30,8 \\
\hline Fórcipe & 1 & 2,5 \\
\hline Aborto & 5 & 12,8 \\
\hline
\end{tabular}

Fonte: Unidade Básica de Saúde Parque da Lapa, São Paulo, 2003. 


\section{Faixa etária e gestações prévias:}

Em relação à idade e o número de gestações prévias, as gestantes mais novas de 14 a 19 anos $(28,2 \%)$ eram da equipe amarela, contrastando com $2,7 \%$ da laranja e nenhuma $(0 \%)$ da vermelha, porém as gestantes de maior idade eram da equipe vermelha concentradas nas faixas etárias de 25 a 35 anos e também eram na maioria primigestas, enquanto que as outras gestantes com as mesmas idades das equipes laranja e amarela eram multigestas, principalmente, as gestantes da equipe amarela $(12,8 \%)$ que tinham de 3 a 5 gestações prévias.

\section{Número de partos:}

Das gestantes do estudo,35,9\% não tiveram partos antes da atual gestação,30,8\% tiveram um parto,sendo a atual gravidez, a segunda gestação e $33,3 \%$ das gestantes eram multigestas com mais de 2 a 5 partos anteriores .

As mulheres que tiveram maiores números de partos, também tiveram maior número de parceiros do que as demais gestantes, sendo os filhos de diferentes parceiros e aproximadamente metade delas se encontravam desamparadas pelo cônjuge.

\section{Estado conjugal:}

Com respeito ao estado conjugal, foram consideradas casadas as mulheres que mantinham relação estável e/ou unidas matrimonialmente pela lei vigente do país.

Consideradas solteiras as que residiam com parentes, ou em circunstâncias em que o parceiro não assumiu a gestação.

De acordo com os resultados que constam da tabela 1 , foram consideradas solteiras, ou sem o parceiro $53,8 \%$ das mulheres, sendo que entre as solteiras; 15 (quinze) gestantes $(71,4 \%)$ pertenciam à equipe amarela . 
A condição das mulheres assumirem seus lares sozinhas não é um privilégio apenas das residentes na Vila Leopoldina.Também o número de famílias chefiado por mulheres no Brasil vem aumentando. Em 1991, 18,1\% das mulheres eram as responsáveis pelos seus lares, em 2000 esse indice saltou para 24,9\%(IBGE, 2000) de acordo com a citação da Revista Isto É, dezembro de 2001.

\section{Óbitos infantis:}

A totalidade de óbitos infantis $(33,3 \%)$ ocorreu nas gestantes da equipe amarela onde há a maior dificuldade de acesso aos serviços e mulheres mais pobres. Não foi perguntado às mulheres sobre a causa das mortes por não ser o enfoque do estudo.

De acordo com a FUNDAÇÃO SEADE (2002), o coeficiente de mortalidade infantil total (somando neonatal precoce, tardia e pós-neonatal) da Vila Leopoldina foi de 16,00, sendo o maior índice da Subprefeitura da Lapa.

Diante dos resultados não significativos em relação a essa população, e também por não ter sido investigado, não se pode afirmar com conviç̧ão de que as causas de morte são reflexas da má assistência, como também se as mesmas dependem de fatores sociais e econômicos, e/ou devido ao não acesso aos serviços, ou também por uma distócia pélvica não avaliada.

Segundo estudiosos do Kasongo (citado por OZUMBA e UCHEGBU, 1991) mulheres com histórico de natimorto ou morte neonatal têm um risco de duas vezes maior de ter distócia pélvica.

Apesar de não se poder constatar quais são as verdadeiras razões da mortalidade infantil na Vila Leopoldina, os especialistas e estudiosos da questão explicam que o alto índice é devido à má qualidade no atendimento. 
No dia 12 de junho de 2004, o jornal Folha de São Paulo publicou que a taxa de mortalidade infantil entre os $20 \%$ mais ricos do país era de 15,8 a cada 1000 nascidos vivos, sendo mais que o triplo da média dos países desenvolvidos.

Pediatra entrevistado pelo mesmo jornal, relata que problemas de infraestrutura dos hospitais, querem públicos, querem particulares são os responsáveis pelas mortes que poderiam ser evitadas.

Para o Ministério da Saúde, que também se pronunciou ao referido jornal, as mortes são devidas ao excesso de cesarianas no serviço particular.

Para Tanaka (1999):

“... o desperdicio de vidas é uma realidade que não se altera" (p.3).

E a mortalidade é um sensível indicador de iniqüidade da não acessibilidade aos cuidados adequados de saúde, bem como da incapacidade do sistema de responder às necessidades dessas mulheres.

\section{Resolução da gravidez:}

Os resultados desse estudo foram de $30,8 \%$ de cesarianas, ou seja, $10,8 \%$ acima do recomendado e se aproxima dos resultados encontrados por POTTER e col, em 2001 , de $31 \%$ de cesáreas no serviço público.

Entre os partos normais $(53,9 \%)$ o bebê de uma das gestantes adolescente de 14 anos de idade sofreu uma fratura de clavícula, segundo as informações do agente comunitário de saúde. Dos demais partos normais não foram relatadas intercorrências.

O único parto com extração a fórcipe foi realizado também em gestante adolescente de 15 anos de idade. 
Entre os 5 abortos $(12,8 \%)$, apenas um foi informado a causa (hipertensão arterial sistêmica).

Profissão :

A maioria das mulheres do estudo $(79,4 \%)$ trabalha para auxiliar e/ou sustentar suas famílias, em serviços que exigem esforço fisico (tabela 2): domésticas $(15,4 \%)$, auxiliar de limpeza $(12,8 \%)$, outros $(25,6 \%)$ e $25,6 \%$ dedicam-se aos cuidados do lar. Entre as que não trabalham seis $(15,5 \%)$ são adolescentes e estudantes que interromperam os estudos após a gravidez, as outras duas $(5,1 \%)$ estão desempregadas.

Em outros estão incluídas gestantes que trabalham no comércio de frutas, legumes e flores no CEAGESP.

Tabela 2 Distribuição do número e porcentagem das gestantes segundo profissão, Unidade Básica de Saúde Parque da Lapa, 2003.

\begin{tabular}{lll}
\hline Profissão & $\mathrm{N}^{\circ}$. & $\%$ \\
\hline Doméstica & 6 & 15,4 \\
Auxiliar de limpeza & 5 & 12,8 \\
Outros & 10 & 25,6 \\
Do lar & 10 & 25,6 \\
Não Trabalha & 8 & 20,6 \\
\hline Total & 39 & 100,0 \\
\hline
\end{tabular}

Fonte: Unidade Básica de Saúde Parque da Lapa, São Paulo, 2003. 


\section{Atividade fisica:}

Os esforços fisicos realizados no trabalho doméstico ou profissional não foram considerados como atividade fisica.

As gestantes foram classificadas em dois níveis: ativas ou sedentárias.

Sedentárias: As que relataram não praticar nenhuma atividade fisica por no mínimo dez minutos seguidos e/ou caminhada de meia hora pelo menos; e

Ativas : As que realizavam caminhada de no mínimo trinta minutos, cinco vezes por semana.

A maior parte das gestantes $(41 \%)$ consideradas ativas mora no Cingapura e na Favela. E como descrito anteriormente, realizam no mínimo trinta minutos de caminhada, no entanto, não o fizeram por uma questão consciente, mas por ser a caminhada o seu meio de locomoção para trabalhar e realizar suas atividades relacionadas com os afazeres do cotidiano. Entre as $59 \%$ consideradas sedentárias, três (13\%) delas iniciaram caminhadas durante a gravidez acreditando ser melhor para a saúde, mas o contrário também ocorreu, três que antes caminhavam correspondendo a $18,7 \%$ das ativas, pararam de caminhar convencidas de que era prejudicial ao feto (gráfico 1). 
Grafico 1 Distribuicão da Porcentagen das Gestantes Segundo Atividade Fisica, UBS Parque da l lapa, 2003.

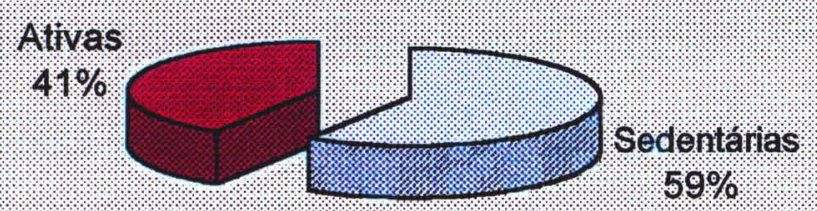

Fonte: Unidade Básica de Saúde Parque da Lapa, São Paulo, 2003. 
Nenhuma das gestantes praticavam qualquer tipo de esporte no período gestacional, e as que anteriormente realizavam algum esporte, um total de 6 gestantes: 4 jogavam futebol, 1 handball e outra andava de bicicleta, todas pararam de o fazer.

Como já citado anteriormente, esta população de baixa renda não tem acesso ao esporte, somente $15,3 \%$ praticavam alguma atividade esportiva, geralmente as mais novas, que freqüentavam a escola.

Soma-se a isso a dificuldade dos profissionais de indicar um programa de exercícios adequados a gestantes e quando os mesmos devam ser iniciados, em contrapartida, existe o mito de que o exercício ou o esforço físico leva ao aborto.

Também o interesse maior das gestantes desse trabalho que faziam exercício era mais quanto à estética e manutenção do peso, pensando menos nos beneficios para o parto.

Ainda quanto à atividade fisica foi perguntado às gestantes sedentárias se as mesmas gostariam de iniciar algum tipo de atividade fisica. Observou-se uma situação diferenciada entre as gestantes residentes nas três áreas.

As gestantes da equipe vermelha que têm acesso ao Clube da Cidade da Prefeitura Municipal de São Paulo conhecido como "Pelezão" responderam que sim. E a maioria das gestantes sedentárias da favela (equipe laranja) e do Cingapura (equipe amarela) responderam que já fazem muito exercício limpando a casa e para vir até o posto.

Nota-se que falta informação do que é atividade física programada e quais são os seus beneficios, ou prejuizos quando realizada incorretamente. 
Mas apesar das respostas acima registradas, as gestantes destas últimas duas equipes são as que mais realizam caminhadas quando comparadas com as da equipe vermelha, por ser o andar o meio de locomoção dessas gestantes.

\section{Hábitos:}

Ainda quanto aos hábitos foi perguntado sobre a quantidade de bebida alcoólica ingerida (etilismo) e quanto ao hábito de fumar.Tocias responderam que não eram etilistas e só bebiam socialmente.

Em relação ao tabagismo, doze $(30,7 \%)$ eram fumantes e interromperam durante a gravidez. Somente uma adolescente de quatorze anos continuou a fumar, e também não aderiu ao pré-natal.

\section{Tratamentos realizados na ocasião da atual gestação:}

Os tratamentos que a maioria das gestantes estavam realizando na época da pesquisa eram para anemia e infecção urinária, nenhuma para lombalgia, ou dores relacionadas às questões musculoesqueléticas.

Além dos tratamentos realizados, os antecedentes pessoais também foram questionados, sem direcionamento, permitindo a livre resposta.

\section{Antecedentes pessoais:}

Devido à variedade de respostas, optou-se por listá-las em ordem decrescente da maior para a menor freqüência de ocorrência, sendo as respostas mais relevantes: lombalgia, quedas, curetagem, depressão, mioma e toxoplasmose.

\section{Cor/raca:}

O pequeno número de gestantes desse estudo não permite expressar com clareza a associação entre cor/raça e tipo de parto, embora trabalhos de décadas passadas relatem uma diminuição da capacidade pélvica maior entre negras. 
STEWART (1979) avaliou radiologicamente 116 primigestas africanas com disfunção no trabalho de parto e constatou que estas pacientes, todas negras, tinham marcantes diminuições das medidas pélvicas requerendo cesárea como solução.

No que se refere aos resultados, já se afirmou que não se trata do objetivo da pesquisa, bem como não são os resultados estatisticamente significativos devido ao número limitado de mulheres estudadas, assim, a característica cor foi avaliada em decorrência dos dados da literatura que afirmam que a morfotipologia pélvica é determinada por características hereditárias relacionadas com a raça,e/ ou a cor da mulher.

Apesar desse número pouco expressivo da população que também não permite uma comparação entre as áreas, encontraram-se diferenças entre os três grupos de gestantes .

Quanto à cor, nota-se nos resultados desse trabalho que mulheres brancas eram todas da equipe vermelha, e que residem na área mais favorável economicamente, enquanto que as negras nas áreas de ex-situação de favela pertenciam ao grupo de gestantes assistidas pela equipe amarela.

Também entre as gestantes da equipe laranja não havia nenhuma negra (gráfico 2). 
Gráfico 2 Distribuição do número de gestantes por equipe, segundo cor, UBS Parque da Lapa, 2003.

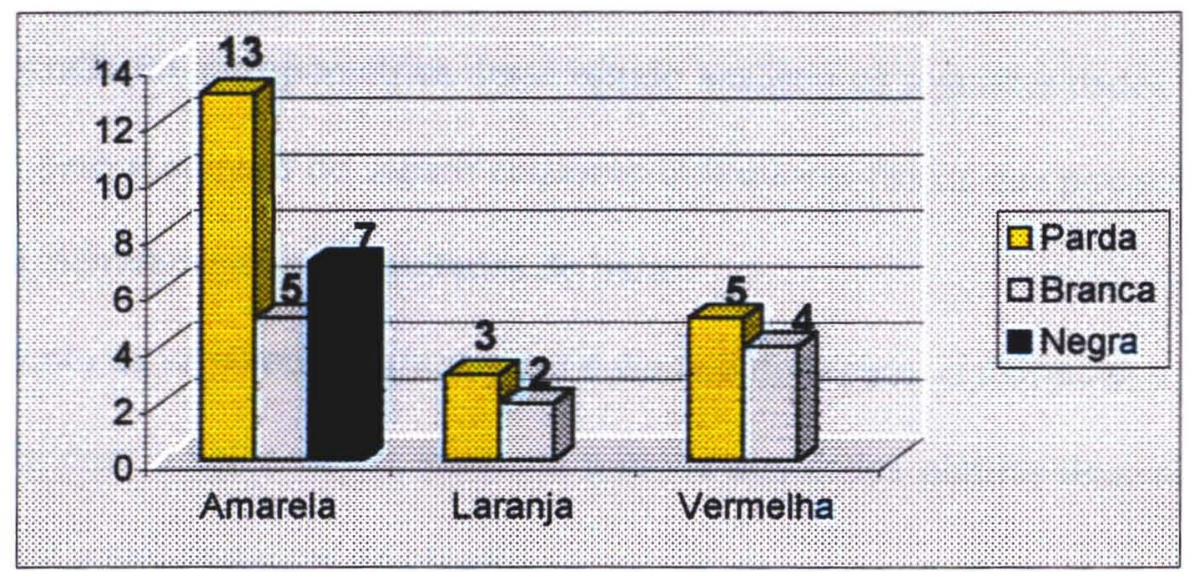

Fonte: Unidade Básica de Saúde Parque da Lapa, São Paulo, 2003. 
O número maior correspondeu às pardas $(53,8 \%)$ mostrando a miscigenação brasileira.

Verificou-se ainda que a população com maiores problemas no parto, com complicações, perdas gestacionais e menor quantidade de partos normais residem ou residiram nas regiões de favela, e principalmente as da equipe amarela composta mais por pardas e negra, não podendo distinguir-se claramente se a cor é um fator importante, ou a condição social, ou a idade e/ou ter apoio do parceiro, ou todos os fatores conjuntamente.

\section{Avaliação antropométrica:}

A avaliação antropométrica desse estudo analisou os seguintes dados maternos: estatura, peso e número do sapato enquanto indicadores fisicos que possam interferir direta ou indiretamente nos resultados do parto.

Quanto as variáveis: estatura, peso e número do sapato, elaborou-se o quadro 2, de acordo com o valor médio, mediano e moda dos dados obtidos da avaliação das 39 (trinta e nove) gestantes do estudo.

Quadro 2 Avaliação antropométrica das mulheres do estudo segundo valores: média, mediana e moda UBS Parque da Lapa, São Paulo, 2003.

\begin{tabular}{|l|c|c|c|}
\hline Dados Maternos & Média & Mediana & Moda \\
\hline Estatura (cm) & 1,58 & 1,57 & 1,58 \\
\hline Peso (kg) & 62,20 & 60,70 & 65,00 \\
\hline Número do sapato & 37 & 37 & 37 \\
\hline
\end{tabular}


$\mathrm{Na}$ África devido à alta prevalência de pelve estreita, aconselha-se adicionar ao exame pré-natal a medida da altura da mulher (LISELELE e col, 2000). Admite-se que as mulheres de baixa estatura tenham, por conseguinte, pés e bacia menores, o que poderá resultar em desproporção fetopélvica, dependendo do tamanho do feto.

FRAME e col (1985) avaliaram a estatura e o número do sapato de 351 mulheres do St Mary's Hospital de Londres, com o objetivo de verificar se ambos são indicadores adequados e úteis para prever a desproporção cefalopélvica. Em seus resultados encontraram que a maior proporção de cesárea ocorreu nas mulheres com estatura entre 1,53 e $1,55 \mathrm{~cm}$ e que $o$ tamanho do sapato sozinho não pode ser considerado um bom indicador.

Na Tanzânia, MÖLLER e LINDMARK, em 1997, analisaram a baixa estatura como um fator de risco obstétrico comparando duas vilas: Ilula e Ikwiriri. Constataram que entre elas haviam diferenças resultantes da situação geográfica e socioeconômica. Uma vila era de característica agrícola, situada na montanha, distante $47 \mathrm{~km}$ do Hospital e com dificuldade de acesso ao serviço. Outra vila era a beira-mar, a economia de subsistência era a pesca e tinha transporte próprio de emergência para chegar ao Hospital de referência. A mortalidade perinatal foi maior em Ilula, vila agrícola, do que em Ikwiriri. As crianças das mulheres de baixa estatura de Ikwiriri não tiveram risco maior do que as mulheres mais altas. A média da altura em Ilula foi de 1,56 e em Ikiriri 1,53 cm. Apesar de na segunda vila as mulheres serem mais baixas, o índice de cesárea também foi menor. MÖLLER e LINDMARK, 1997, concluíram que o risco é relativo e deve ser mais bem elaborado segundo critérios específicos de cada região relacionados com as condições socioeconômicas locais e o acesso aos serviços de qualidade. 
Nos resultados do estudo não se encontrou sinal de que a estatura e o número do sapato fossem indicadores sensiveis e que pudessem auxiliar no prognóstico, pois as mulheres do estudo com altura entre 1,47 e $1,76 \mathrm{~cm}$ e número de sapato entre 34 a 40, apresentaram tanto cesárea como parto normal.

Aliás, a gestante de mais baixa estatura $(1,47 \mathrm{~cm})$ apresentou parto normal nas suas duas gestações. Não se levaram em consideração c peso e tamanho do feto.

A variável peso interferiu em um caso, na qual uma das gestantes da pesquisa que sofreu intervenção cesariana decorrente de obesidade mórbida, pesando $104 \mathrm{Kg}$ antes de completar as quarenta semanas.

Além da avaliação antropométrica, realizou-se a pelvimetria externa, medindose os diâmetros transversos e antero-posterior citados nos procedimentos metodológicos.

Visualiza-se no quadro 3 a seguir a média, a mediana e a moda dos diâmetros considerados: intertrocnateriano, interespinhoso e Antero-posterior ou de Baudelocque.

Quadro 3 Avaliação dos diâmetros pélvicos das 39 gestantes do estudo, segundo os valores: média, mediana e moda, UBS Parque da Lapa, São Paulo, 2003.

\begin{tabular}{|l|c|c|c|}
\hline Diâmetros pélvicos & Média & Mediana & Moda \\
\hline Intertrocanteriano (cm) & 31 & 31 & 32 \\
\hline Interespinhoso (cm) & 22 & 20 & 22 \\
\hline Baudelocque (cm) & 20 & 21 & 22 \\
\hline
\end{tabular}


Confrontando os dados do quadro 3 com a literatura, os valores obtidos estão dentro da média esperada, exceto à distância entre as espinhas ilíacas ânterosuperiores (diâmetro interespinhoso) que se encontra abaixo de 24 a $26 \mathrm{~cm}$ de acordo com o definido nos procedimentos metodológicos. Se as medidas estão dentro da normalidade era de se esperar menor índice de cesáreas, ou então a pelvimetria instrumental é realmente falha para prognosticar os resultados do parto. Deste modo, também se optou por avaliar a forma e as dimensões do Losango de Michaelis.

Com relação à forma do Losango de Michaelis verificaram-se seis variações, as quais convencionou-se classificar em: A, B, C, D, E e F.

Apresenta-se no quadro 4, as figuras esquematizadas dessa classificação, pois a utilização das fotos não foi permitida verbalmente pelo Comitê de Ética em Pesquisa da Faculdade de Saúde Pública da Universidade de São Paulo, devendo constar do Termo de Consentimento Livre e Esclarecido a determinação de que as fotos seriam devolvidas às gestantes no término da pesquisa.

$\mathrm{O}$ registro fotográfico antes e depois, nas últimas semanas gestacionais serviu de um nítido e incontestável parâmetro de evolução nas mudanças ocorridas, e também para verificar as diferentes formas de losango encontradas relacionadas também com o biótipo, além de garantir que as medidas realizadas estavam tecnicamente corretas. Nas fotos em que se verificou algum erro, eliminou-se a medida, sendo a mesma refeita. 
Quadro 4 Formas de Losango encontradas nas gestantes da UBS Parque da Lapa, São Paulo, 2003.

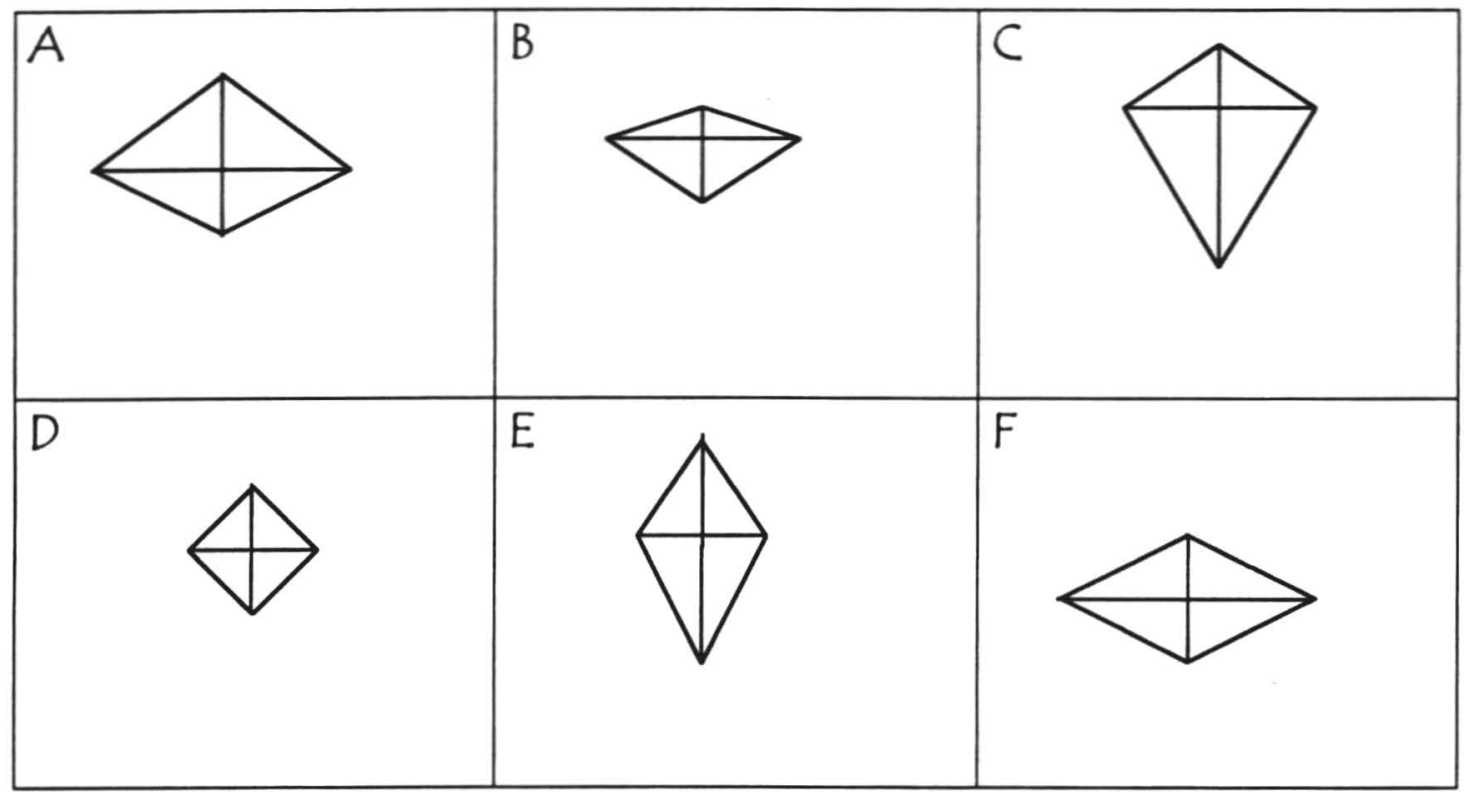

O Losango de Michaelis é uma expressão da forma do osso sacro.

CALDWELL e MOLOY, em 1933, encontraram duas formas de sacro que se reproduziram na figura 17 (A e B).

Figura 17 Formas de sacro encontradas por Caldwell e Moloy.

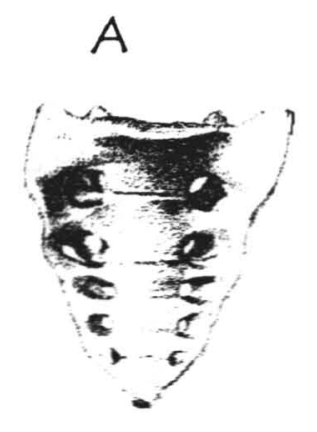

Sacro Estreito

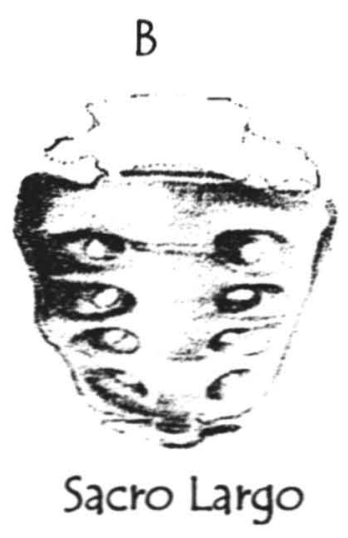

Fonte: Manual de Obstetrícia. GRELLE, 1960. 
Seguindo os princípios da biotipologia de que a forma externa expressa a anatomia interna, e que essa pode ser deduzida por medidas padronizadas, e ter utilidade clínica, associamos as formas de losango encontradas, com as morfologias externas das cinturas das mulheres estudadas. Ilustram-se estes achados na figura 18.

O Losango pode determinar a forma do osso sacro e a sua posição em anteversão, posição neutra, ou em retroversão. Conhecer a curvatura, a forma, e o tamanho é de extrema importância, pois afetam a capacidade pélvica, por conseguinte a acomodação fetal.

$\mathrm{Na}$ figura 19, visualizam-se três diferentes posições do sacro e as suas influências no volume posterior da pelve.

Para classificar o sacro nessas posições, utilizou-se uma metodologia já descrita no Capítulo 5 Procedimentos metodológicos.

Explicita-se no quadro 5 a correlação entre o tipo de losango e a posição do sacro . 
Figura 18 Associação da forma corporal e Losango de Michaelis.

Silueta nádega $A$

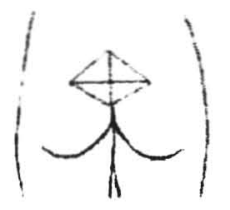

Losango A
Silueta nādega B

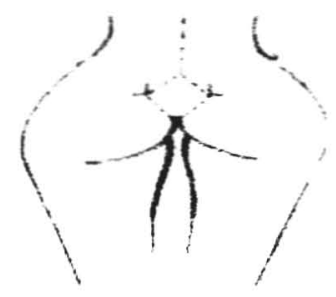

Losango B
Silueta nădega C

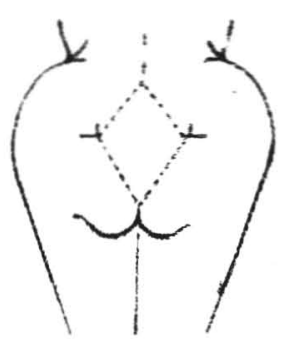

Losango $C$

Silueta nádega D

Silueta nádega $E$

Silueta nádega F

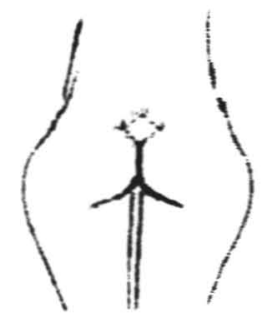

Losango D

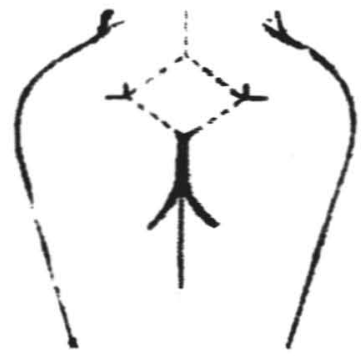

Losango $E$

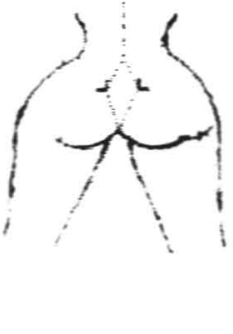

Losango $\mathrm{F}$

Fonte: Siluetas modificadas do encarte do Institut des Chaînes Musculaires et des techiniques, STRUYF, 1996 ; MENS e col 1996. 
Figura 19 Sacro em anteversão (A), em posição neutra (B) e em retroversão $(\mathrm{C})$.

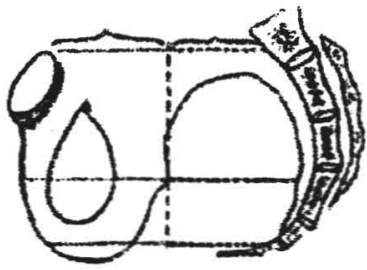

A

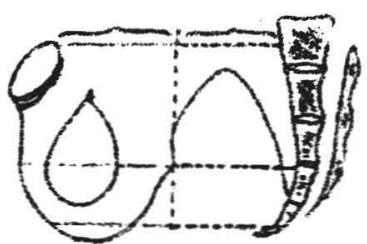

B

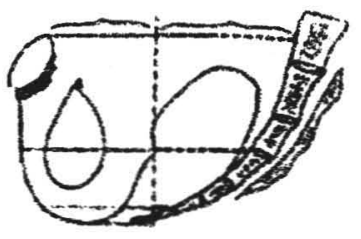

C

Fonte: Manual de Obstetrícia GRELLE, 1960.

Quadro 5 Posição do sacro e a forma de Losango das 39 gestantes do estudo, UBS Parque da Lapa, São Paulo, 2003.

\begin{tabular}{|c|c|c|c|c|c|c|c|}
\hline Sacro & A & B & C & D & E & F & Total \\
\hline $2,5-3,5$ & 1 & 0 & 10 & 0 & 0 & 0 & 11 \\
\hline $3,5-4,5$ & 0 & 0 & 0 & 11 & 2 & 1 & 14 \\
\hline $4,5-5,5$ & 0 & 14 & 0 & 0 & 0 & 0 & 14 \\
\hline Total & 1 & 14 & 10 & 11 & 2 & 1 & 39 \\
\hline
\end{tabular}


Das trinta e nove gestantes do estudo: uma gestante $(2,6 \%)$ tinha a forma de losango A; $35,9 \%$ (14 gestantes) losango $\mathbf{B} ; 25,6 \%$ (10 gestantes) losango $\mathbf{C} ; 28,2 \%$ (11 gestantes) losango D; 5,1\% (2 gestantes) losango E e 2,6\% (1 gestante) losango F.

Observa-se que os losangos C e D têm a forma preconizada pela literatura, por isso optou-se em construir o quadro $6 \mathrm{com}$ as formas principais de losango, $\mathbf{C}$ e $\mathbf{D}$. Apesar da forma $\mathbf{B}$ apresentar maior freqüência que $\mathbf{C}$ e $\mathbf{D}$, nesse estudo.Os demais losangos parecem ser uma derivação dos anteriores.

Conforme os resultados, verificou-se que Losangos de forma mais quadrada configuram sacros em anteversão, enquanto que os losangos com a diagonal longitudinal maior relacionam-se com sacros em retroversão ou na posição neutra.

Pode se estabelecer com esta pesquisa uma relação entre a anatomia interna (tipo de coluna com curvaturas acentuadas ou retificadas), a posição do sacro (anteversão ou retroversão) e a forma de Losango segundo área reduzida ou normal (referência clínica de BRIQUET, 1956).

Assim, prossegue-se nesse processo de "montar um quebra cabeça" como em um sistema de encaixe juntar: o tipo de coluna (retificada com curvas fisiológicas mais brandas, ou acentuada com curvaturas mais aumentadas, o que se convencionou chamar de tipo postural) com a posição do sacro conforme Delmas (citado por KAPANDJI,1985) enuncia em seus trabalhos, o Losango de Michaelis e a morfologia corporal externa.

Para construir o "quebra cabeças" juntamos todas essas peças: posição do sacro, tipo de coluna vertebral, Losango de Michaelis.

No quadro 6 propõe-se a junção dessas quatro peças. 
Quadro 6 Relação entre a forma do Losango de Michaelis, morfologia corporal externa, a posição do sacro e tipo de coluna vertebral, UBS Parque da Lapa, São Paulo, 2003.

\begin{tabular}{|l|c|c|}
\hline Losango de Michaelis & $\begin{array}{c}\text { Biótipo } \\
\text { Morfologia corporal }\end{array}$ \\
\hline variação anatômica
\end{tabular}


Os Losangos foram agrupados em seis grupos: A,B,C,D, E e $\mathbf{F}$ porque apresentam estruturas, formas e complicações que se assemelhavam.

Os mesmos serão comentados no quadro 7 . 
Quadro 7 Semelhanças existentes entre os losangos A,B,C,D, E e F; UBS Parque da Lapa, São Paulo, 2003.

\begin{tabular}{|c|c|c|c|c|c|c|}
\hline Losango & \begin{tabular}{|l|} 
Altura do \\
Normaler $=4 \mathrm{~cm}$ \\
\end{tabular} & $» I T$ & "IE & "AP & $\begin{array}{l}\text { Posição } \\
\text { do } \\
\text { Sacro }\end{array}$ & $\begin{array}{l}\text { Resolução da } \\
\text { gravidez e } \\
\text { Queixas } \\
\text { mioarticulares }\end{array}$ \\
\hline $\bar{A}$ & $\begin{array}{l}\text { Acima do } \\
\text { Normal = } \\
5 \mathrm{~cm}\end{array}$ & $\begin{array}{l}\text { Abaixo } \\
\text { do } \\
\text { normal }\end{array}$ & \begin{tabular}{|l|} 
Muito \\
abaixo do \\
normal
\end{tabular} & $\begin{array}{l}\text { Abaixo } \\
\text { do normal }\end{array}$ & Retroversão & $\begin{array}{l}\text { Parto r cesárea } \\
\text { (1). o parto } \\
\text { anterior } \\
\text { também foi } \\
\text { cesárea.Muitas } \\
\text { queixas. }\end{array}$ \\
\hline B & $\begin{array}{l}\text { Abaixo do } \\
\text { Normal = } \\
2,5 \text { a } 3,0 \mathrm{~cm}\end{array}$ & $\begin{array}{l}\text { Abaixo } \\
\text { do } \\
\text { normal }\end{array}$ & \begin{tabular}{|l} 
Em \\
média \\
abaixo \\
do normal
\end{tabular} & $\begin{array}{l}\text { Em média } \\
\text { abaixo do } \\
\text { normal }\end{array}$ & Anteversão & $\begin{array}{l}\text { A maioria dos } \\
\text { partos foi } \\
\text { cesárea (8), } \\
\text { normais (3), } \\
\text { fórcipe (1), } \\
\text { aborto (2). } \\
\text { Muitas queixas }\end{array}$ \\
\hline C & $\begin{array}{l}\text { Normal }= \\
4 \mathrm{~cm}\end{array}$ & $\begin{array}{l}\text { Normal } \\
\text { ou acima }\end{array}$ & $\begin{array}{l}\text { Em média } \\
\text { normal }\end{array}$ & Normal & Retroversão & $\begin{array}{l}\text { Todos partos } \\
\text { normais (10). } \\
\text { Pouca queixa } \\
\text { em relação às } \\
\text { demais } \\
\text { gestantes. }\end{array}$ \\
\hline $\bar{D}$ & $\begin{array}{l}\text { Normal }= \\
4 \mathrm{~cm}\end{array}$ & $\begin{array}{l}\text { Em média } \\
\text { pouco } \\
\text { acima do } \\
\text { normal }\end{array}$ & $\begin{array}{l}\text { Em média } \\
\text { pouco } \\
\text { acima do } \\
\text { normal }\end{array}$ & Normal & Neutro & $\begin{array}{l}\text { A maioria dos } \\
\text { partos foi } \\
\text { normal (7), } \\
\text { aborto (3) e (1) } \\
\text { cesárea. } \\
\text { Pouca queixa } \\
\text { em relação às } \\
\text { demais. }\end{array}$ \\
\hline $\bar{E}$ & $\begin{array}{l}\text { Abaixo do } \\
\text { normal }\end{array}$ & Normal & Normal & Normal & Neutro & $\begin{array}{l}\text { Um parto } \\
\text { cesárea e (1) } \\
\text { normal.Muitas } \\
\text { queixas. }\end{array}$ \\
\hline $\mathbf{F}$ & $\begin{array}{l}\text { Abaixo do } \\
\text { normal }\end{array}$ & Normal & $\begin{array}{l}\text { Abaixo } \\
\text { do normal }\end{array}$ & \begin{tabular}{|l|} 
Muito \\
acima do \\
normal
\end{tabular} & Neutro & $\begin{array}{l}\text { Cesárea.Muitas } \\
\text { queixas. }\end{array}$ \\
\hline
\end{tabular}

\section{Legenda:}

"IT-Intertrocanteriano

"IE-Interespinhoso

»AP-Antero posterior/Conjugado Externo ou de Baudelocque 
Na tabela 3 a seguir, visualizam-se os dados da resolução das gestações e o tipo de Losango, obtidos da avaliação de trinta e nove gestantes, conforme já explicado anteriormente no Capítulo 5 Procedimentos Metodológicos.

Tabela 3 Distribuição do número e porcentagem de gestantes, segundo tipo de losango e resolução da gravidez, Unidade Básica de Saúde Parque da Lapa, 2003.

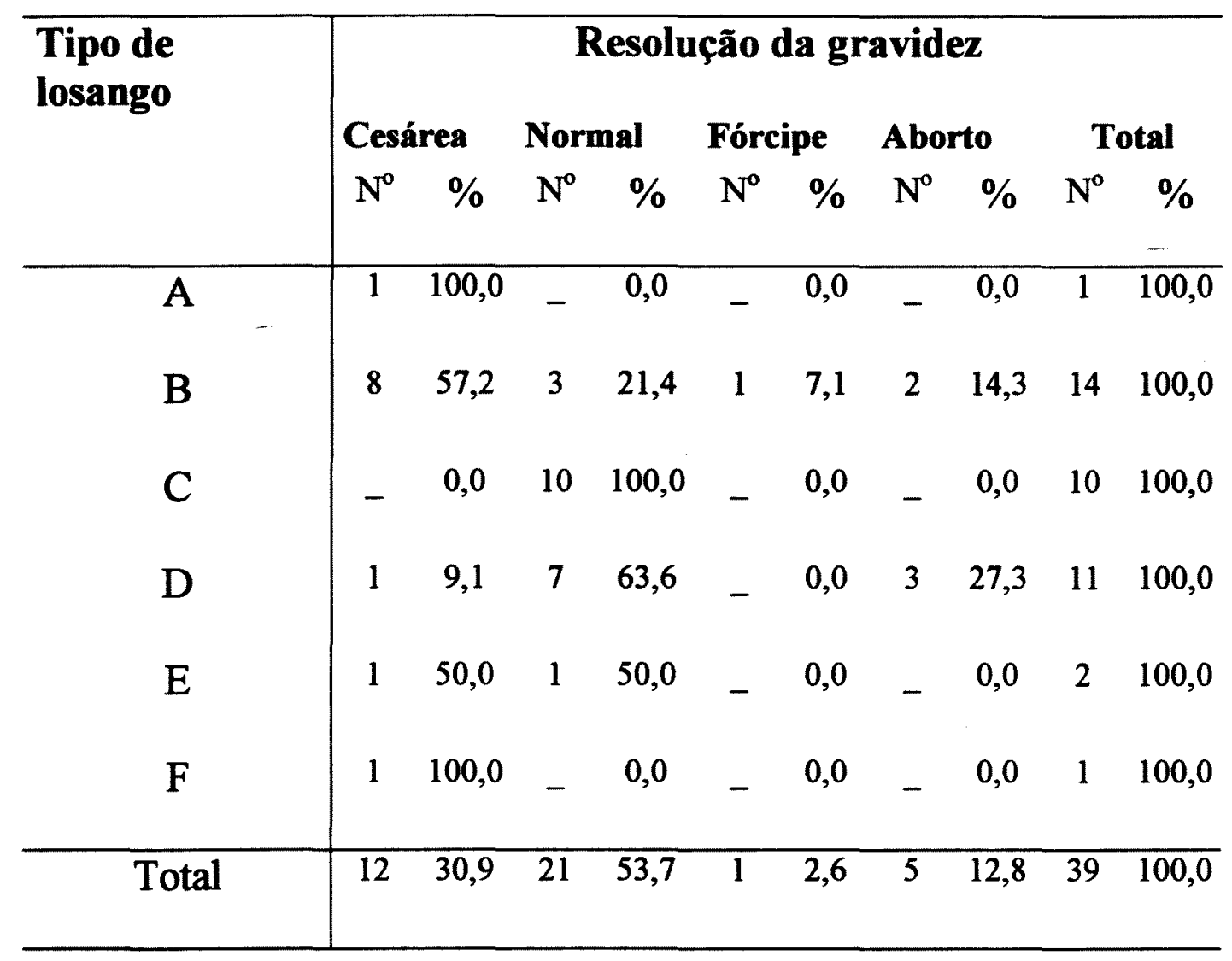

Fonte: Unidade Básica de Saúde Parque da Lapa, São Paulo, 2003. 
$\mathrm{Na}$ tabela 3 observa-se que os losangos do tipo $\mathbf{C}$ e $\mathbf{D}$ foram os que mais apresentaram partos normais, $100 \%$ e $63,6 \%$ respectivamente, sendo que todas as gestantes com o losango tipo $\mathbf{C}$ tiveram partos normais. $\mathbf{O}$ que $\mathbf{C}$ e $\mathbf{D}$ apresentaram em comum foram: a altura normal do Triângulo Supra-Sacro de Tarnier e as medidas pelvimétricas normais, ou em alguns casos um pouco abaixo do normal.

Entre os três abortos encontrados no tipo de losango D, duas gestantes apresentavam todas as medidas reduzidas, denunciando uma pelve estreitada, e tiveram cesárea prévia nas gestações anteriores. A gestante com losango A apresentou todas as medidas muito abaixo dos valores normais, e uma altura anormal do Triângulo Supra-Sacro (um centímetro a mais). Fato registrado apenas nessa gestante.Tanto a sua gestação anterior como a atual foi cesárea.

Das 14 gestantes com losango do tipo B (57,2\%) apresentaram cesárea, 2 (14,3\%) abortaram e tiveram cesáreas prévias, e as 3 gestantes $(21,4 \%)$ que apresentaram parto normal tinham todas as medidas dos diâmetros pélvicos dentro do limite normal, e apenas a altura do supra-sacro diminuído de um centímetro. A que resultou em fórcipe era adolescente e tinha um estreitamento pélvico evidenciado pelas medidas reduzidas.

NWOHA (1995) mostrou que mulheres mais velhas apresentam uma significativa diferença nos valores dos diâmetros pélvicos, sendo maiores do que os das mulheres mais jovens, principalmente o conjugado verdadeiro.

Quanto à idade acredita-se que ela é ótima para engravidar entre os 18 e 20 anos para autores como REZENDE (2000), pois em idades mais jovens o risco de ruptura de partes moles é maior e de lesões pélvicas também, porque a imaturidade e a não completa ossificação geram riscos maiores. Nas idades mais avançadas (acima 
dos 30 anos de idade), as dificuldades são maiores em decorrência das maiores limitações fisicas, como por exemplo, a menor mobilidade da articulação sacrococcígea.

Os losangos $\mathbf{E}$ e $\mathbf{F}$ também resultaram em cesárea apresentando todas as medidas alteradas, sendo que em $\mathbf{E}$ o conjugado verdadeiro foi de $16 \mathrm{~cm}$, a medida mais baixa encontrada entre todas as gestantes. Em $\mathbf{F}$ encontrou-se a altura do suprasacro reduzida, porém a medida do intertrocanteriano muito aumentado $(2 \mathrm{~cm}$ a mais que o normal) o que denota um ângulo subpúbico diminuído. A outra gestante com losango $\mathbf{E}$ apresentou parto normal.

Conforme descrito nos procedimentos metodológicos as medidas das dimensões do Losango de Michaelis foram registradas em duas ocasiões.

Observou-se uma ampliação da área do losango quando comparadas as duas medidas obtidas nos meses iniciais entre as $13^{\mathrm{a}}$ e $17^{\mathrm{a}}$ semanas gestacionais, e as medidas finais entre as $33^{a}$ e $37^{a}$ semanas gestacionais.

Outrossim, algumas gestantes não atingiram a área de $55 \mathrm{~cm}^{2}$ calculada a partir das medidas do losango preconizado por BRIQUET (1956). Na tabela 4, apresenta-se a área final do losango atingida pela pelve das gestantes do estudo.

Tabela 4 Distribuição do número e porcentagem das gestantes segundo área final do Losango de Michaelis, Unidade Básica de Saúde Parque da Lapa, São Paulo, 2003.

\begin{tabular}{lcc}
\hline Área Final & $\mathrm{N}^{0}$. & $\%$ \\
\hline $35-45$ & 10 & 34,5 \\
$45-55$ & 7 & 24,1 \\
$55-65$ & 12 & 41,4 \\
\hline Total & 29 & 100,0 \\
\hline
\end{tabular}


Somente $41,4 \%$ atingiram a área de $55 \mathrm{~cm}^{2}$ ou mais.

Entre as 12 gestantes que atingiram a área, nove delas tinham a forma de losango $\mathbf{C}$ e tiveram parto via vaginal, enquanto que as três outras gestantes a atingir a área apresentaram a forma de losango $\mathbf{D}$.

Comparando os trabalhos realizados por McLane em 1938, citado por GRELLE (1960), DELEE e GREENHILL (1950), em diferentes décadas, concluíram que a capacidade pélvica da mulher vem diminuindo ano após ano. Embora não se possa afirmar que com a mulher brasileira isto também ocorreu, verifica-se nesse estudo que as mulheres têm medidas significativas menores do que as preconizadas em 1953 pelo obstetra paulista Raul Briquet.

Abaixo se expõe o resultado das pesquisas sobre as tipologias pélvicas encontradas nos trabalhos dos dois pesquisadores citados acima.

Quadro 8 Comparação entre a porcentagem de tipologias pélvicas encontradas nos anos de 1938 e 1950.

\begin{tabular}{|l|c|c|}
\hline Tipologia Pélvica & $\begin{array}{c}\text { MCLANE 1938 } \\
\%\end{array}$ & $\begin{array}{c}\text { DELLE e } \\
\text { GREENNHILL 1950 } \\
\%\end{array}$ \\
\hline Ginecóide & 62 & 41,4 \\
\hline Andróide & 18,5 & 32,5 \\
\hline Antropóide & 11,5 & 23,5 \\
\hline Platipelóide & 8 & 2,6 \\
\hline
\end{tabular}

Observa-se que a bacia ginecóide que oferece as melhores condições para o parto normal apresentou uma diminuição para dar lugar ao aumento de bacias andróides que constituem as bacias de menor capacidade, com redução em suas medidas, sendo a de maior risco com indicação de cesárea, pois o estreitamento da pelve materna pode levar ao trauma no nascimento, com a morte do feto. 
ABTIBOL e col (1997) realizaram um estudo para identificar os fatores que no mundo moderno têm contribuído para a diminuição da capacidade pélvica, e verificaram que o hiperandrogenismo estava presente em todos os tipos de pelve, não só na andróide, mas também na ginecóide. Também que as mulheres com bacia andróide foram expostas à atividade física extenuante na adolescência, sendo um risco da modernidade a "corpolatria", ou seja, a idolatria do corpo. Haja vista que as academias estão cada vez mais lotadas, e o público principal é adolescente. E a maior procura é pela musculação submetendo o corpo à sobrecarga de exercícios.

A pelve antropóide foi encontrada mais freqüentemente nas mulheres que na primeira infância adquiriram a postura em pé mais tarde que a idade usual de quatorze meses, enquanto que a pelve platipelóide ocorre com maior freqüência nas mulheres que começaram a andar antes dos quatorze meses de idade.

A forma final da pelve feminina parece ser determinada pela cultura, meio ambiente, exclusão social e não apenas por questões genéticas. Semelhante à dor humana que pode ser de natureza estrutural, por lesão ou disfunção, e ser modificada por questões psicológicas, espirituais e também culturais.Um exemplo que pode muito bem ilustrar essa questão do fator cultural modular à dor é a própria situação do parto, segundo SANVITO (2001):

“... a japonesa, integrada aos costumes dá à luz sem um gemido, a brasileira geme e grita" ( p. 18 ).

No gráfico 3 apresenta-se as queixas de dor de origem osteomioarticular por região anatômica .

A maior freqüência foi de dor sacriliaca $(38,5 \%)$ seguida de lombalgia $(28,2 \%)$; as terceiras causas de dor com $12,8 \%$ foram: a dor na região suprapúbica e anterior 
da coxa; a quarta causa de dor foi de origem sacrococcígea $(5,0 \%)$ e a última causa de dor foi a da região púbica $(2,7 \%)$. Foram excluídas as dores provenientes de aumento de peso, de edema e de infecção urinária (informações obtidas do prontuário da gestante).

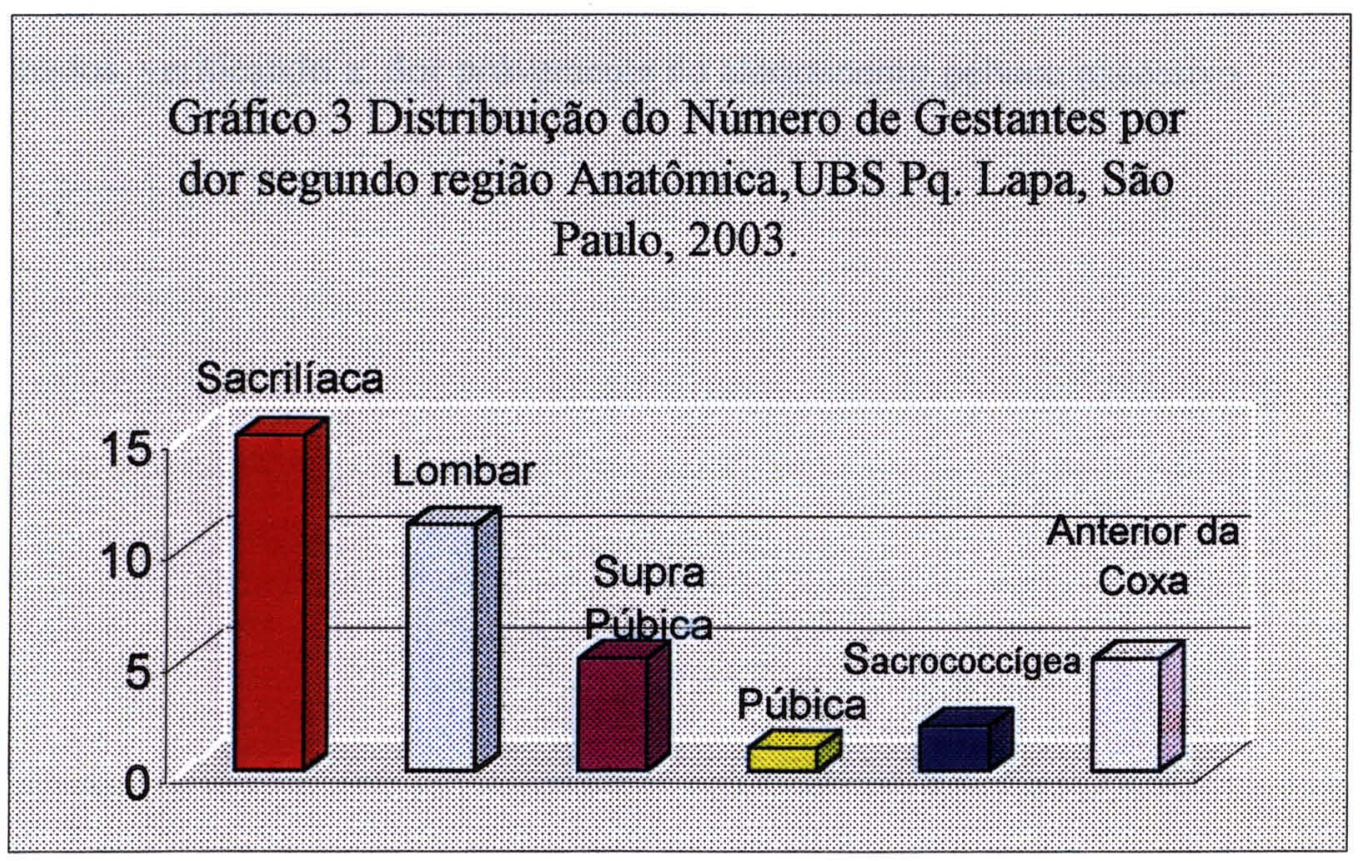


De acordo com os resultados constata-se uma freqüência de dor lombar de $28,2 \%$, mas o estimado na literatura está entre $50 \%$ e $70 \%$. Para FERREIRA e NAKANO (2000), entre todas as mulheres grávidas $48 \%$ a $56 \%$ referem a dor lombar como sendo a mais freqüente. Nos trabalhos de IRELAND e OTT (2000) o fato se repete, sendo a dor pélvica posterior devido à relaxação patológica a segunda causa de queixa.

Neste estudo a situação se inverteu, sendo a dor sacrilíaca a primeira e a lombalgia a segunda causa de dor.

A despeito da maior quantidade de queixas ser da região pélvica posterior, relacionada à articulação sacriliaca e região lombar, e serem as únicas queixas comuns a todas as gestantes, elaborou-se a tabela 5 , relacionando essas duas queixas com a forma do losango.

Sendo a dor sacrilíaca a primeira causa das queixas de dores das gestantes desta pesquisa, também se comparou o afastamento das articulações sacrilíacas por meio das medidas da diagonal transversa do losango, nos períodos gestacionais mencionados, verificando a dor proveniente do alargamento pélvico excessivo. 
Tabela 5 Distribuição do número e porcentagem de gestantes com dor sacrilíaca e lombar, segundo forma do losango, UBS Pq. Da Lapa, São Paulo, 2003.

\begin{tabular}{|c|c|c|c|c|c|c|c|c|c|c|c|c|c|c|}
\hline Dor & & $\overline{\mathbf{A}}$ & & $\mathbf{B}$ & & $\overline{\mathbf{C}}$ & & $\bar{D}$ & & $\mathbf{E}$ & & $\mathbf{F}$ & Tot & \\
\hline & $N^{\circ}$ & $\%$ & $\mathrm{~N}^{\mathrm{o}}$ & $\%$ & $\mathbf{N}^{\mathrm{o}}$ & $\%$ & $N^{\circ}$ & $\%$ & $\mathrm{~N}^{\mathrm{o}}$ & $\%$ & $N^{o}$ & $\%$ & $\mathrm{~N}^{\mathrm{o}}$ & $\%$ \\
\hline Sacrilíaca & 1 & 100,0 & 9 & 64,3 & 1 & 10,0 & 4 & 36,4 & 1 & 50,0 & 1 & 100,0 & 17 & $\overline{43,6}$ \\
\hline Lombar & 0 & 0,0 & 4 & 28,6 & 2 & 20,0 & 3 & 27,2 & 1 & 50,0 & 0 & 0,0 & 10 & 25,6 \\
\hline Sem dor & 0 & 0,0 & 1 & 7,1 & 7 & 70,0 & 4 & 36,4 & 0 & 0,0 & 0 & 0,0 & 12 & 30,8 \\
\hline
\end{tabular}

O losango A apresentou $100 \%$ de incidência de dor sacriliaca, enquanto que as gestantes com a forma de losango B apresentaram $64,3 \%$ de incidência de dor na região sacriliaca, $28,6 \%$ lombalgia e $7,1 \%$ delas não tiveram dor. Das gestantes com losango C, $70 \%$ não apresentaram dor nessas regiões e apenas $1(10 \%)$ teve dor de origem sacrilíaca e $2(20 \%)$ dor na região lombar. As gestantes com losango do tipo D, apresentaram dor em sacriliaca e lombar, $36,4 \%$ e $27,2 \%$ respectivamente e $36,4 \%$ não tiveram dor nas duas regiões anatômicas acima ressaltadas na tabela 5 , mas apresentaram dor em outras articulações, como no joelho, por exemplo. Entre as gestantes com a forma de losango E, metade (50\%) apresentou dor sacriliaca e metade lombalgia (50\%). O losango do tipo F, apresentou $100 \%$ de dor sacrilíaca.

Observa-se que a estrutura anatômica e biomecânica das gestantes com o biótipo que se convencionou nesse trabalho classificar como $\mathrm{C}$, parece estar melhor 
adaptado para as alterações fisiológicas durante o período gravídico; em $\mathbf{D}$, verificase uma situação mais próxima de $\mathbf{C}$, enquanto que os tipos $\mathbf{A}$ e $\mathbf{F}$, apresentam maiores desordens musculoesqueléticas, quando comparados com os outros tipos de losango. Em $\mathbf{B}$ e $\mathbf{E}$ nota-se uma situação intermediária entre $\mathbf{C}$ e $\mathbf{D}$, e entre $\mathbf{A}$ e $\mathbf{F}$. Assim, pode-se classificar em ordem crescente de comprometimento das estruturas osteomioarticulares pélvicas e lombares, utilizando o modelo desenvolvido nesse trabalho. Em ordem de menor para maior risco: $\mathbf{C}<\mathbf{D}<\mathbf{B}<\mathbf{E}<\mathbf{A}<\mathbf{F}$. Visualiza-se na tabela 6, a dor sacrilíaca relacionada com o afastamento maior, ou menor da diagonal transversa do Losango de Michaelis. 
Tabela 6 Distribuição do número e porcentagem das gestantes segundo afastamento da diagonal transversa do Losango de Michaelis e dor sacrilíaca, Unidade Básica de Saúde Parque da Lapa, São Paulo, 2003.

\begin{tabular}{|c|c|c|c|c|c|c|}
\hline \multirow{3}{*}{$\begin{array}{c}\text { Afastamento } \\
\text { da diagonal } \\
\text { Transversa } \\
\text { do } \\
\text { Losango de } \\
\text { Michaelis }\end{array}$} & \multicolumn{4}{|c|}{ Dor Sacrilíaca } & \multicolumn{2}{|c|}{ Total } \\
\hline & \multicolumn{2}{|c|}{ Sim } & \multicolumn{2}{|c|}{ Não } & \multirow[b]{2}{*}{$\mathrm{N}^{\mathrm{o}}$} & \multirow[b]{2}{*}{$\%$} \\
\hline & $\mathbf{N}^{\mathrm{o}}$ & $\%$ & $\mathbf{N}^{\circ}$ & $\%$ & & \\
\hline $1,5 \mid-2,5$ & 3 & 10,3 & 15 & 51,2 & 18 & 61,5 \\
\hline $2,5 \mid-3,5$ & 10 & 34,3 & 1 & 4,2 & 11 & 38,5 \\
\hline Total & 13 & 44,6 & 16 & 55,4 & 29 & 100,0 \\
\hline
\end{tabular}


Obtiveram-se os resultados que são observados na tabela 6 , na qual apresentase a associação entre o afastamento sacriliaco e a presença, ou ausência de dor sacrilíaca.

Verificou-se que das trinta e nove gestantes, 13 delas $(44,6 \%)$ queixaram-se de dor sacrilíaca.

Entre as gestantes com dor sacrilíaca, verificou-se entre as 10 delas, ou seja, $76,9 \%$, que a diagonal transversa do Losango de Michaelis superou o afastamento médio de $2 \mathrm{~cm}$ encontrado nas demais gestantes, atingindo entre 2,5 e $2,8 \mathrm{~cm}$. Podese considerar que a medida da diagonal transversa do losango possa ser utilizada para diagnosticar a relaxação pélvica patológica.

Em 1940 YOUNG, por meio de investigação radiológica, confirmou o afastamento das articulações sacrilíacas de em média $0,8 \mathrm{~mm}$ cada um. Constatou que podem atingir estados patológicos decorrentes de um relaxamento articular excessivo. Verificou que uma mobilidade exagerada causa lesão e incapacidade.

Dados da literatura mais recente de 1999 (LARSEN e col) referem 16\% de relaxação articular patológica na primeira gestação e a sua recorrência em gestações posteriores aumenta para $41 \%$ a $77 \%$, pois estas articulações sofrem um forte bombardeio hormonal a fim de relaxar para permitir a passagem do feto.

Como alguns estudiosos enunciam, na gestante a dor lombar deve ser diferenciada da sacrilíaca e métodos devem ser criados para fazer essa diferenciação. Assim, como citado nos procedimentos metodológicos, fez-se essa diferenciação pelos sintomas e traçados das gestantes. 
Foi citado anteriormente que na primeira avaliação as trinta e nove gestantes do estudo, que tivessem alguma queixa de dor, marcassem o local, no desenho (Anexo 2) da região pélvica descrevendo o que sentiam.

Ilustra-se a seguir os traçados de gestantes com dor sacrilíaca.

A dor sacriliaca é sentida nas nádegas podendo irradiar para as pernas, mas até a altura dos joelhos (figura 20-losangos D e F). Descrita como obtusa e assinalada de maneira localizada (figura 20-losangos A, B, C e E).

Ao exame físico, durante a palpação a paciente refere dor na região sacrilíaca e existe uma limitação nos movimentos relacionados a sacrilíacas. 
83

Figura 20 Traçados característicos de dor sacrilíaca nas gestantes estudadas, UBS Parque da Lapa, São Paulo, 2003.

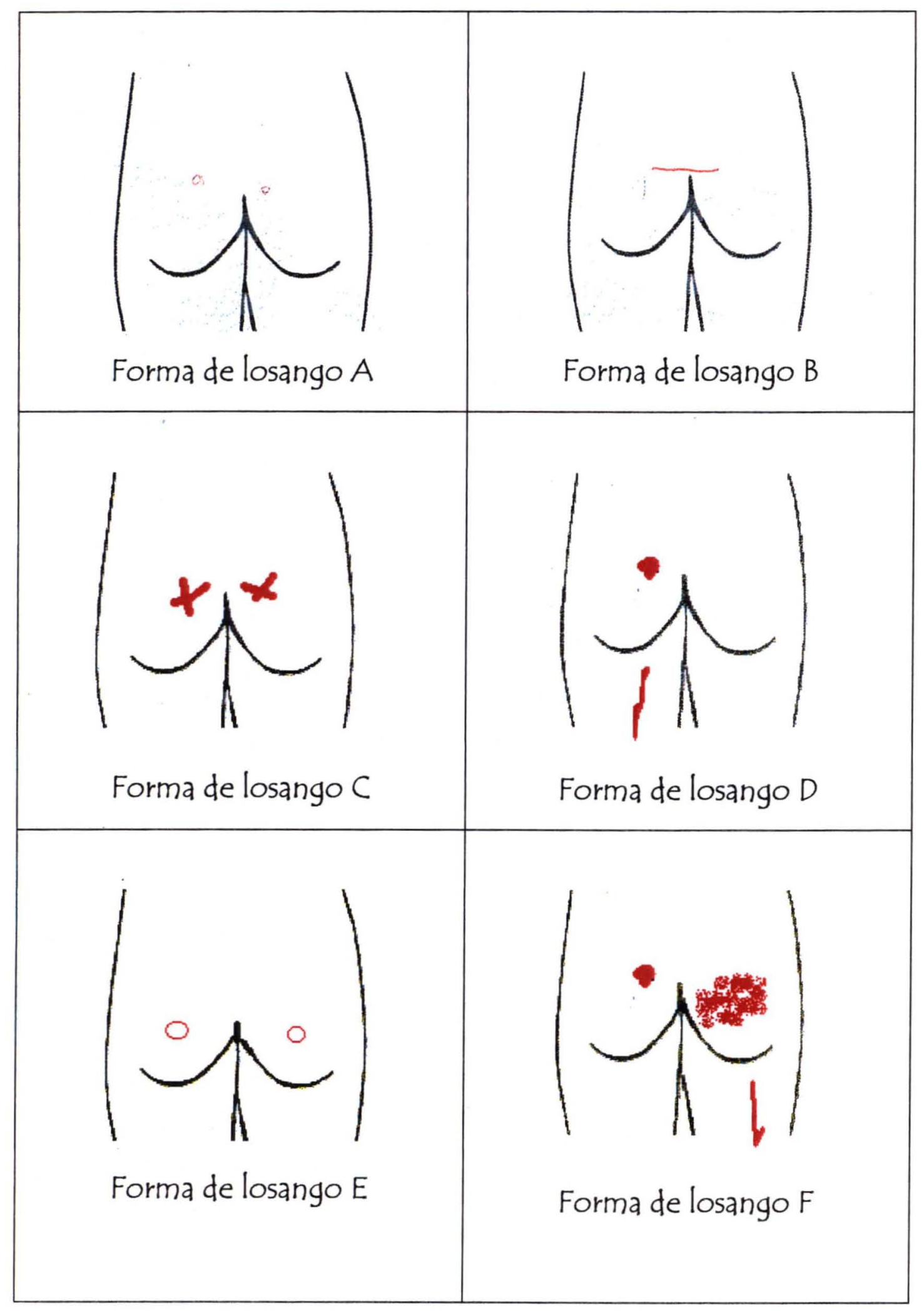


A paciente tem dificuldade de virar-se na cama, subir escadas, e da posição deitada apresenta dificuldade para sentar-se.

A dor sacrilíaca foi registrada de forma pontual com círculos, cruzes, ou traços.Também se demarcou dor irradiada para um dos membros inferiores com traços verticais e pintando a nádega para expressar a dor nessa região.

O que a diferencia do padrão álgico da lombar, tanto quanto ao traçado, como quanto à descrição do padrão de dor anterior.

$\mathrm{Na}$ figura 21(A e B) reproduz-se a forma de registro de duas gestantes.

Figura 21 Traçados de lombalgia das gestantes estudadas, UBS Parque da Lapa, São Paulo, 2003.

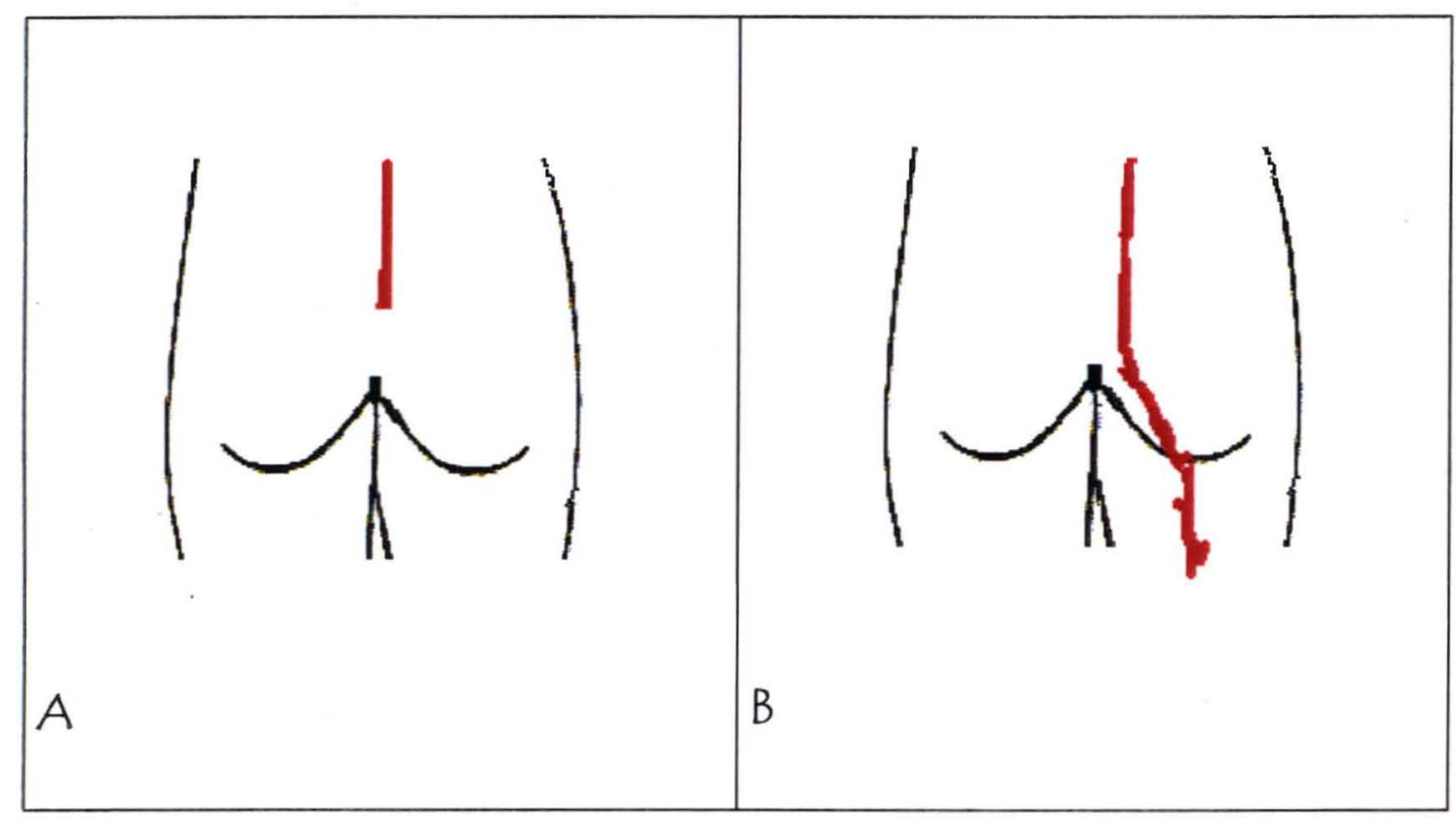

Nos casos da dor lombar, um exame mais consistente deve ser realizado descartando uma discopatia. Normalmente, a dor lombar é descrita como persistente e pode irradiar-se para baixo(B), e freqüentemente é unilateral. É agravada ao andar, alivia com o repouso, e caracteristicamente não dói à noite. É uma dor referida como 
monótona e difusa. A dor produzida por músculos é sempre sentida difusamente e é referida sobre o segmento espinhal como se observa nos desenhos acima.

A hipótese existente é a de que a dor pélvica na gestante é causada: pelo estiramento dos ligamentos, pelos efeitos hormonais gerando lesões ligamentares, pela fraqueza muscular que se torna ineficiente para estabilizar a coluna, e o peso do feto (HODGES e col 1996, MENS e col 1996).

Ilustra-se a seguir na figura22 as demais queixas:

Púbica (A),

$>$ Suprapúbica(B),

Sacrococcígea(C), e

Anterior da coxa(D). 
Figura 22 Ilustração dos traçados de dor púbica (A), suprapúbica (B), sacrococcígea (C) e anterior da coxa(D) das gestantes estudadas, UBS Parque da Lapa, São Paulo, 2003.

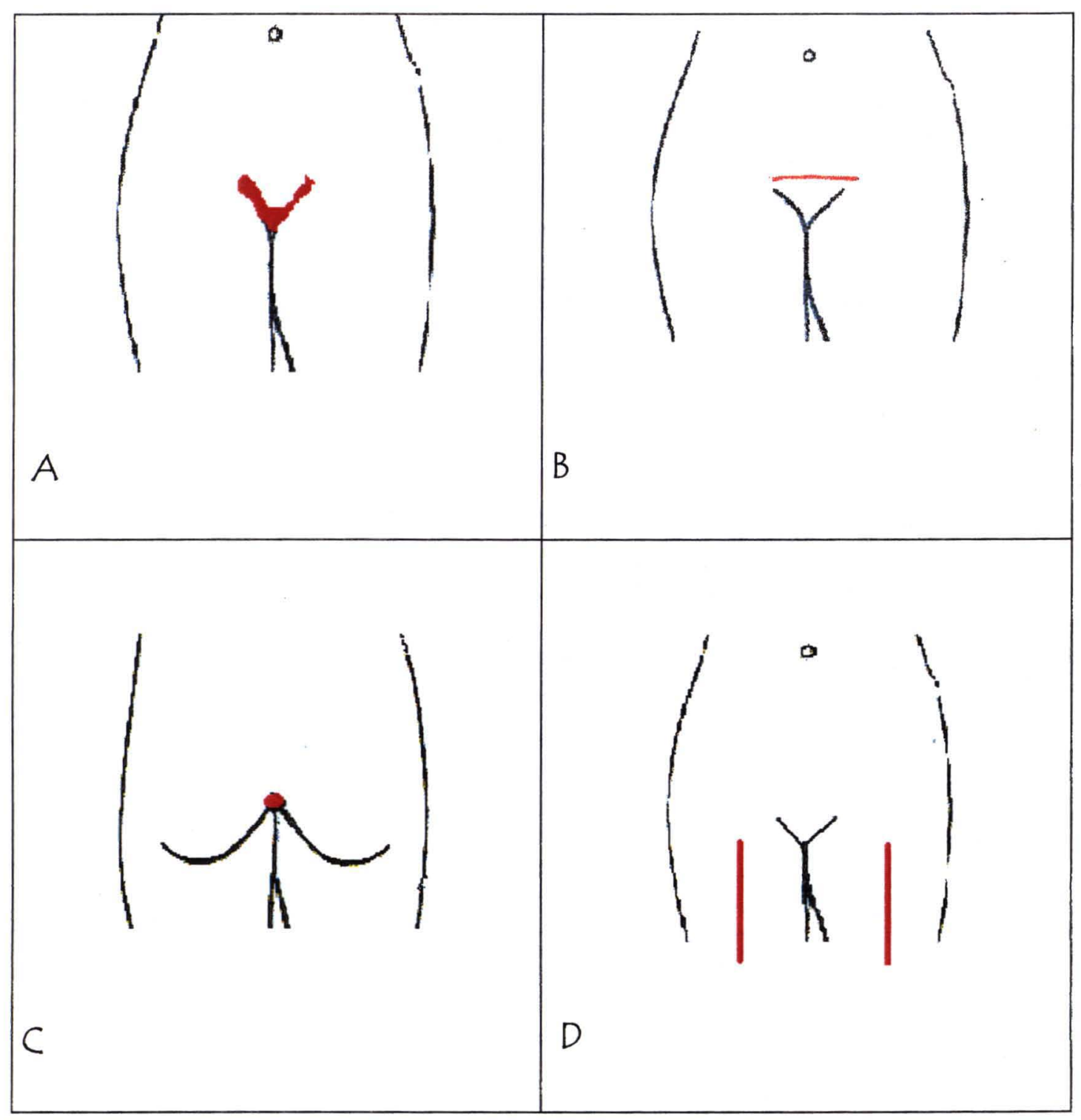


Segundo ARTAL e col (1999), as dores na região do púbis são decorrentes de inflamação da sínfise e estão associadas com lombalgia e dor sacrilíaca (22 A e B). Em $22 \mathrm{C}$ a dor é decorrente de uma fratura sacrococcígea prévia, segundo informações colhidas da gestante. E em $22 \mathrm{D}$ a dor em região anterior da coxa pode ser decorrente da compressão do nervo femoral anterior. E a mulher queixa-se de dormência.

A dor tem um grande componente subjetivo, no entanto é possível avaliar essa subjetividade e fazer um diagnóstico diferencial, por meio do traçado e do desenho do corpo, ou região em que se deseja investigar.

Para finalizar, construiu-se no quadro 9 a possibilidade de pelos Losangos de Michaelis encontrados (B, C, D e E) e a morfologia corporal externa, determinar a anatomia interna utilizando os desenhos de CALDWELL e MOLOY de 1933.

Como se observou pela literatura, a bacia andróide tem aparecido em maior número, tal como nos resultados desta pesquisa ( $36 \%$ das Gestantes). Em segundo lugar surge neste trabalho a bacia platipelóide $(28,3 \%)$, a bacia ginecóide em terceiro lugar com $25,7 \%$ e a antropóide em último com $5 \%$ (quadro 9). 
Quadro 9 Relação Bacia Ossea, Arco Subpúbico, Posição do Sacro, Silueta Externa, Porcentagem de Gestantes do estudo e

Losango de Michaelis; UBS Parque da Lapa, São Paulo,2003.

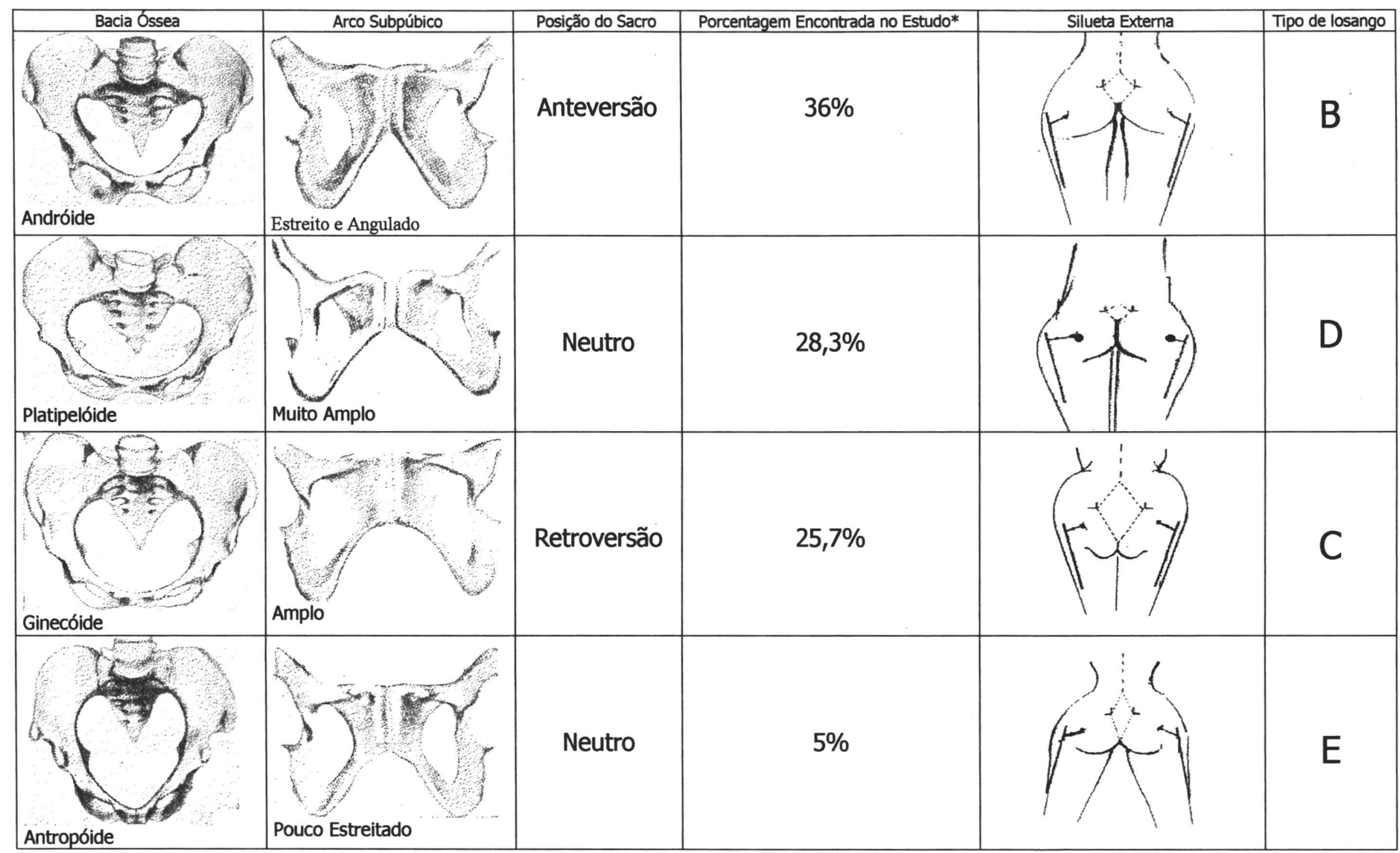

$* 5 \%$ correspondem às duas gestantes com losangulo do tipo $\mathrm{A} \mathrm{e} \mathrm{F}$. 
Levanta-se a hipótese de que esses resultados decorrem de múltiplos fatores advindos do atual estilo de vida ditado pela modernidade e desigualdades sociais.

Os bebês hoje em dia andam antes do amadurecimento biológico pelos constantes estímulos, assim, a bacia platipelóide toma o segundo lugar, de acordo com a explicação, já citada antes, dada por ABTIBOL em 1997, a respeito das influências modernas sobre a formação da pelve feminina.

As gestantes, deste estudo foram expostas, na grande maioria, a cargas físicas desde a infância. Assumiram irmãos menores precocemente, e os afazeres domésticos. Suas profissões são geralmente relacionadas à baixa remuneração e ao esforço físico. Também a maioria das gestantes que apresentaram o tipo de bacia andróide eram pardas e negras, as quais têm geneticamente determinada uma pelve diminuída em suas dimensões.

Provavelmente, esses fatos justifiquem maior número de bacias andróides com anteversão, características da raça negra e seus descendentes.

A bacia ginecóide apareceu mais em brancas, com o Losango preconizado pela literatura como o mais apropriado no prognóstico do parto, e todas apresentaram parto normal com menor número de queixas álgicas.

Pode-se também supor que a exclusão social imposta historicamente para os negros contribua com as pelves reduzidas. Sabe-se que o aporte calórico dessa população não é suficiente para suprir as necessidades da formação óssea em fase de crescimento.

Em 2000, LISELELE e cols utilizaram a pelvimetria externa e o Losango de Michaelis para avaliar a associação entre as medidas pélvicas e complicações no parto. 
$\mathrm{Na}$ análise foram incluídas 2413 mulheres avaliadas em um periodo de três anos no Hospital e Maternidade da República do Zaire. Pequenas distâncias pélvicas mostraram boa probabilidade de previsão no mínimo uma das quatro seguintes complicações: cesárea por falência no progresso, cesárea eletiva de repetição, extração a vácuo ou a fórceps, ou natimorto.

Entre todas as variáveis pélvicas, a diagonal transversa do Losango de Michaelis foi a única estatisticamente associada com essas quatro complicações e o diâmetro intertrocanteriano com as três primeiras.

Embora a maioria das cesáreas apontadas neste estudo seja de cesárea prévia, constatou-se uma associação de cesárea com a redução de medidas da área do Losango de Michaelis, do conjugado externo, e dos diâmetros intertrocanteriano e interespinhoso.

A diminuição das dimensões pélvicas encontradas em pacientes negras mencionadas em outros estudos também se reflete neste trabalho, pois a anatomia dos ossos pélvicos têm uma íntima relação com a origem da mulher, e conserva por disposições hereditárias características comuns, encontradas não só em africanas, mas também em mulheres brasileiras.

Assim, obteve-se no estudo formas de losango tendendo a forma de um quadrado que representa a diminuição da capacidade pélvica.

Nas gestantes negras desse trabalho foram encontrados losangos de forma $\mathbf{B}$ e D com dimensões reduzidas, relacionados com o osso sacro em anteversão (losango B) e aumento de curvaturas da coluna, principalmente da lordose lombar, enquanto que entre as gestantes com o losango $\mathbf{D}$, verificou-se o osso sacro em posição neutra e também o aumento das curvaturas da coluna vertebral. 
Em gestantes negras com o biótipo e losango $\mathbf{B}$, a maioria dos partos foram cesáreas, como se verifica em dados da literatura, no entanto, as gestantes negras com biótipo e losango D, apresentaram um grande número de partos normais. Levanta-se a hipótese de que biomecanicamente existe uma vantagem de um tipo sobre o outro quanto à mobilidade das articulações pélvicas, segundo teoria de Delmas, citado por KAPANDJ, 1987.

Entre as gestantes brancas foram encontrados losangos de forma $\mathbf{A}$ e $\mathbf{C}$, com sacro em retroversão. Nas gestantes de biótipo C com curvas mais retas, todos os partos foram normais, somente em $\mathbf{A}$, o parto resultou em cesárea.

Também quanto à localização territorial, e condições socioeconômicas, as gestantes negras desse estudo estão entre as piores situações, comparadas com as brancas que residem em área de melhor acesso.

As gestantes pardas apresentaram maior diversidade de formas: C, D, E e F e de circunstâncias, ora semelhantes às brancas, ora às negras.

Assim, não se desconsideraram os múltiplos fatores que interferem nos resultados do parto, mas o corpo é reflexo concreto de fatores sociais e econômicos, muitas vezes passíveis de mudança. 
7 Considerações Finais

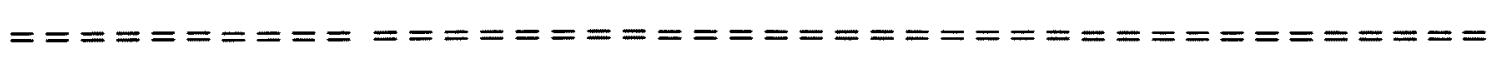

Embora o universo deste trabalho não seja suficiente e não represente a situação real da população da Vila Leopoldina, alguns indícios se pronunciam nele.

A localização territorial dentro de uma mesma região padroniza alguns hábitos e condições determinadas multifatorialmente, pois as mulheres localizadas nas áreas mais carentes do território e com maior dificuldade de acesso à unidade têm um número maior de abortos prévios, óbitos neonatais e comprometimentos musculoesqueléticos mais acentuados quando comparadas com as demais. Nota-se que as desigualdades sociais e a precariedade da assistência são fatores primordiais nos agravos da saúde materno-infantil.

Soma-se a esses fatos, a dificuldade de realizar atividades físicas, essas gestantes não se exercitam porque não têm acesso ao esporte e a caminhada é um meio de locomoção para algumas delas. O estilo de vida sedentário e o despreparo físico, bem como o contrário, o excesso de exercícios físicos na adolescência, incentivado pela mídia ("qual o modelo do corpo perfeito") pode interferir na arquitetura óssea da pelve.

As influências da modernidade como a alimentação inadequada, a rapidez com que tudo deve ser feito, a grande estimulação precoce das crianças, também são elementos que contribuem para gerar alterações nas dimensões ósseas. Desse modo, torna-se interessante repensar as políticas públicas, a forma de implantação de programas de saúde, a questão da multidisciplinariedade da equipe, e a formação acadêmica do médico generalista . 
Também o investimento financeiro no ensino e na mudança curricular de todos os profissionais da saúde, incluindo especialmente outros métodos de avaliação pélvica; no caso do atendimento à gestante, pois o distanciamento da avaliação da pelve é um risco eminente para a saúde da mulher, contribui para o aumento de cesáreas desnecessárias e para o risco de vida da mulher e do seu bebê.

Preconiza-se nessa pesquisa que as medidas de avaliação fisica possibilitam a intervenção precoce que podem minimizar os prejuízos causados pelo desconhecimento da disfunção sacriliaca.

Apreciando essas circunstâncias, o estudo permite identificar complicações por meio das medidas das distâncias pélvicas externas, principalmente pela a diagonal transversa do Losango de Michaelis associadas a pelvimetria, avaliação da forma do losango e da morfologia corporal externa.

Não só no que diz respeito ao periodo gestacional, mas também ao parto, as desordens musculoesqueléticas podem levar à incapacidade decorrente de lesões e dor, assim deve-se estabelecer um programa terapêutico mais adequado a cada tipo de pelve feminina.

A avaliação realizada pelo fisioterapeuta norteia o programa terapêutico,e o tratamento das disfunções que requer intervenções, as quais não fazem parte da formação de todas as categorias profissionais, pois não são o seu modelo de assistência e função. $O$ fisioterapeuta também atua sobre as algias decorrentes da gravidez, sendo a dor, fenômeno complexo, dificil de ser expresso, ou entendido devido a sua subjetividade, mas pode-se criar modelos para reproduzi-la por meio do desenho e da descrição verbal das sensações, a fim de realizar um diagnóstico diferencial. 
Também como citado anteriormente, as medidas da diagonal transversa do Losango de Michaelis podem verificar afastamentos patológicos da relaxação pélvica excessiva, que comprometem a função das articulações sacriliacas, propulsoras do parto, e não somente para a análise da dor, pois o formato do Losango também denuncia as gestantes com maiores riscos de terem maior risco de estreitamento pélvico, e de ter uma maior chance de apresentar complicações no parto ou no pósparto. Verifica-se que o sistema atual não está apto para suprir as necessidades das gestantes. Certas marcas dos sistemas anteriores de saúde permanecem e condições importantes para a saúde materno-infantil não são até agora consideradas relevantes.

Assim, entrou-se no século XXI e o Brasil ainda não conseguiu resolver problemas básicos de saúde que seriam solucionados no nível chamado de atenção primária.

O Programa de Saúde da Família (PSF), lançado em 1994, surge como uma estratégia para amparar o sistema esgotado, em perigo e com poucas condições de resolver seus problemas. No entanto, analisando as mudanças que vêm ocorrendo no país, no campo político e social, verifica-se uma série de implicações, as quais levam a questionar a eficácia do atual modelo empregado para esse fim.

Este novo modelo de atenção constitui um programa paralelo com orçamento aquém das necessidades, considerado suficiente pela área econômica do Governo Federal, que atinge claramente a qualidade da prestação de serviços. Por isso também o Programa tem uma atenção rudimentar destinada às áreas mais carentes e de populações pobres e não atende todo o território, gerando exclusões.

Além dos fatos mencionados, que contribuem para um pequeno êxito da "nova estratégia", as desigualdades sociais permitem aos mais ricos o acesso à tecnologia 
de alto custo para o diagnóstico de doenças, enquanto que as gestantes atendidas pelo Programa de Saúde da Familia (PSF), não conseguem por vezes realizar mais que um ultra-som obstétrico.

Assim, a saúde igualitária para todos é um conceito a ser questionado, pois os pobres são atendidos pelo médico generalista no PSF, a classe média nos serviços especializados do SUS (Sistema Único de Saúde), quando o convênio não cobre, e os ricos são assistidos com alta tecnologia, acesso rápido e garantido nos melhores serviços, especializados, ou não.

Segundo CARVALHO (2003) o PSF é antigo e foi lançado no Brasil em 1500 pelos jesuítas, preparados pelos conventos, para cuidar da saúde das populações excluídas. Para esse mesmo autor, atualmente, exclui-se parte da população onde o Programa não foi implantado e geram-se maiores desigualdades. Ele conclui que o PSF é uma "cesta básica" para as camadas mais pobres, sem integração com a média e alta complexidade de atendimento.

Não só o princípio da universalidade sofre distorções, mas também a acessibilidade aos serviços de qualidade.

Outra questão levantada por CARVALHO (2003) é a falta de cuidado na contratação de pessoal e a criação de terceirização ilegal gerando inúmeros problemas, o que não o torna muito diferente do antigo PAS (Plano de Assistência à Saúde).

No PSF não se vê a inserção do fisioterapeuta e o mesmo acontece com a nutricionista, bem como com outros profissionais de saúde. Há muita discussão sobre a inclusão desses profissionais dentro da proposta do PSF. O que irá fazer o fisioterapeuta? Atendimento domiciliar? Grupos educativos para a terceira idade? 
Para garantir a qualidade da assistência primária deve ser oferecido o atendimento multidisciplinar. Este modelo não superou o modelo herdado dos antepassados centrados na figura médica. Duvida-se também da integralidade da assistência.

Além da universalidade, eqüidade, integralidade e acessibilidade há a questão da qualidade. Na revista Ser Médico publicada pelo Conselho Regional de Medicina do Estado de São Paulo (2003), coloca-se em debate as novas implementações curriculares dentro de um projeto político fundamentado no SUS, que o país exige com esse "novo" modelo de assistência.

No debate foram registradas frases como estas:

“A proposta é acabar com essa medicina que se fundamenta em lesão e no sintoma. Estamos preparando pessoas para fazer o atendimento primário, promoção de saúde e não praticar a medicina em todos os domínios... Até concordo com a proposta de formar o médico com o mínimo de conhecimento possível para o atendimento primário... $O$ Programa não é feito com o embasamento que deveria ter. Eu sofro pela mudança e concordo com a proposta de colocar o estudante junto à comunidade para provocar uma mudança afetiva desse aluno, que vem de classes superiores" (P. 24).

Torna-se dificil acreditar em uma estratégia que investe pouco na estrutura e na capacitação profissional. Embora o Ministério e as Subprefeituras queiram instituir o programa como uma experiência válida, notam-se transgressões que continuam a se repetir com denominações diferentes. 
As Subprefeituras assumem a função de intervir em sua área de abrangência, verificando as suas diversidades.

Além de tudo isso, outra questão primordial que caracteriza o Programa (PSF) é o retorno de um profissional médico, hesitante em atender toda a família e sem formação para tal.

Reflete-se sobre a criatividade dos governantes em criar taxas, impostos e programas de saúde, mas infelizmente não se vê a mesma criatividade para assumir o mínimo compromisso de realmente resolver os problemas básicos de saúde da população, uma vez que falta infra-estrutura mínima para a eficiência dos programas de saúde. 


\section{Conclusões}

Apreciando todas essas circunstâncias, salienta-se nesse estudo que as distâncias pélvicas externas podem ajudar a identificar complicações e principalmente a diagonal transversa do Losango de Michaelis.

O Losango pode também ser utilizado com outros fins e não somente para prognóstico do parto:

1. Para acompanhar o afastamento das articulações sacriliacas, identificar estados patológicos de relaxação pélvica, e possíveis disfunções da articulação sacrilíaca. No entanto, sugere-se outros estudos a fim de esclarecer o real distanciamento articular de segurança que não constitui risco de lesões das articulações pélvicas.

2. O afastamento acima de $2,5 \mathrm{~cm}$ da diagonal transversa do Losango de Michaelis resulta em comprometimentos fisicos e intervenções terapêuticas manuais pelo fisioterapeuta sobre a pelve devem ser consideradas e melhor estudadas levando-se em conta as diferenças anatômicas.

3. Deve-se repensar a forma de implantação do Programa de Saúde da Família e a questão da multidisciplinaridade da equipe, bem como a capacitação do médico generalista e no investimento financeiro do ensino, na mudança curricular dos profissionais de saúde, e não regredir aos modelos anteriores que eram centrados na figura do médico. Outros profissionais devem ser inseridos na equipe nuclear do PSF na assistência à gestante como o fisioterapeuta, a fim de avaliar, 
estabelecer o programa terapêutico mais adequado, bem como orientar a prática de exercícios corretos a cada condição e idade gestacional.

4. Um novo modelo associando os princípios da biotipologia, da pelvimetria manual, das dimensões e formas do Losango de Michaelis e de baixo custo, poderia ser implementado para melhor administrar o periodo gestacional e o parto.

5. A dor é um fenômeno complexo, sendo dificil expressá-la ou entendêla devido a sua subjetividade, mas pode-se criar um modelo para reproduzi-la por meio do desenho e da descrição verbal das sensações, a fim de realizar um diagnóstico diferencial da dor lombar e da articulação sacriliaca para obter-se sucesso no tratamento.

6. Nesse estudo não se concluiu que a disfunção sacrilíaca seja a causa de lombalgia, mas que são duas queixas distintas e com padrões diferenciados, sendo uma o fenômeno decorrente do afastamento excessivo das articulações sacrilíacas, e o outro, a lombalgia decorrente do comprometimento muscular, ou articular e/ou ligamentar das estruturas da região lombar.

7. Verifica-se que entre os diferentes tipos posturais há um maior ou menor risco de complicações osteomioarticulares na gravidez, decorrente de adaptações anômalas determinadas também pela variação anatômica.

8. Pode-se utilizar o método desenvolvido no estudo para identificar riscos de lesões e desordens musculoesquelética da pelve na gravidez, bem como para prever maior incidência de dor na região lombar e pélvica. 
9. Raramente são providenciadas medidas preventivas, ou oferecido tratamento às gestantes com lombalgia, ou dor sacriliaca. Muito menos são avaliadas ou consideradas essas queixas. A dor sacrilíaca e a lombalgia por disfunções osteomioarticulares afeta um grande número de gestantes e resulta em riscos para a saúde materno-infantil com impactos sobre a sociedade.

9.Fazem-se necessários programas de saúde que contemplem diagnóstico clínico diferencial, ações preventivas e o tratamento fisioterápico deve ser incluído no pré-natal.

10. Os tipos posturais e suas variaçōes anatômicas têm efeitos sobre a gravidez. 
10 Referências

Abitbol MM, Taylor-Randall UB, Barton PT, Thompson E. Effect of modern obstetrics on mothers from Third-world countries. J Matern Fetal Med 1997; 6(5): 276-80.

Albert H, Godskese M, Westgaard J. Evaluation of clinical tests used in classification procedures in pregnancy related pelvic joint pain. Eur Spine J 2000; 9 (2): 161-6.

Al - Mufti R, McCarthy A. Fisk NM. Obstetricians ' personal choice and mode of delivery. Lancet 2000; 347(9000): 544.

Artal R, Wiswell RA, Drinkwater BL. O exercício na gravidez. $2^{a}$. Ed. São Paulo: Editora Manole LTDA; 1999.

Bellinghini RH. Mulheres pobres vêem cesariana como opção de bom atendimento. O Estado de São Paulo, São Paulo, 2002, abr 20;geral 1: 1.

Berardinelli W. Noções de Biotypologia: constituição, temperamento, carater. Rio de Janeiro: Schimidt Editor; 1932.

Bottcher B, Radley SC. Pelvimetry:changing trends and attitudes.J Obstet Gynaecol $2001 ; 21(5): 459-462$.

Borell U, Fernstrom I. The movements at the sacro-iliac joints and their importance to changes in the pelvic dimensions during parturition. Acta Obstetr et Gynecol Scandinav 1957; 36: 42-57.

Briquet R. Obstetrícia normal. São Paulo: Edições Raul Briquet;1956 . 
Caldwell WE, Moloy HC. Anatomical variations in female pelvis and their effect in labor with a suggested classification. Am J Obstetr Gynecol 1933; 26: 479-505.

Carvalho G. O real e o virtual na Saúde Pública. In: Couto EE. O COFFITO: número 6. São Paulo: Insert consultores em comunicação; 2003.

CEAGESP [online] 2003; (1). Disponivel em < URL:http://www.ceagesp.com.br [2003 set 4].

Costacurta L. Anatomia Médico-cirúrgica da pelve feminina. São Paulo: Atheneu Editora; 1975. Aspectos Anátomo-funcionais da pelve feminina ; p. 3-22.

Cunha AA, Portela MC, Amed AM, Camano L. Modelo preditivo para cesariana com uso de fatores de risco. RBGO 2002;1 (24): 21-28.

Davis DC. The discomforts of pregnancy. JOGNN 1996; 25(1): 73-81.

Delee J, Greenhill JP. Tratado de Obstetrícia. Rio de Janeiro: Guanabara Koogan; 1950. Tomo II.

Deurell M, Worm M. Is CV measurement relevant for the verdict "vaginal delivery prohibited"? Ugeskr Laeger 2001; 163(42): 5832-5.

Dujardin B, Van CR, Lambrechts T. The value of maternal height as a risk factor of dystocia: a meta-analysis. TM \& IH 1996; 1(4): 510-521.

Dunn P. James Matthews Duncan (1826-90) and the dynamics of labour. Arch Dis Childhood Fetal Neonatal Ed 1997; 76 (2): 140- 142.

Ferguson JE, Sistrom CL. Can fetal-pelvic disproportion be predicted? Clin Obstetr Gynecol $2000 ; 43(2) ; 247-264$. 
Ferreira CHJ, Nakano AMS. Lombalgia na gestação: etiologia, fatores, de risco, e prevenção. Femina 2000; 28(8): 435-8.

Frame S, Moore J, Peters A, Hall D. Maternal height and shoe size as predictors of pelvic disproportion: an assessment. Brit J Obstetr Gynaecol 1985; 92: 1239-1245.

Franklin ME, Conner KT. Analysis of posture and back pain in the first and third trimesters of pregnancy. J Orthopaedic Sports Physical Therapy 1998 ; 28(3): 133-138.

Fundação SEADE. Mortalidade infantil por posto avançado da Cidade de São Paulo: 2002, São Paulo; 2003.

Gois A . Mortalidade Infantil é elevada até na elite. Folha de São Paulo 2004 jun 12; cad 1: 1 .

Grelle FC. Manual de Obstetrícia. 2". Ed. Rio de Janeiro:Livraria Atheneu S.A; 1960. 1v.

Hansen A, Jensen DV, Wormslev M, Minck H, Johansen S, Larsen EC, Wilken JC, et al. Symptom giving pelvic girdle relaxation in pregnancy. Symptoms and clinical signs. Acta Obstetr Gynecol Scand 1999;78(2 pt II):111- 115.

Hodges WP, Hons BP, Richardson CA. Inefficient muscular stabilization of the lumbar spine associated with low back. Spine1996; 22(21): 2640-50.

Ireland ML, Ott SM. The effects of pregnancy on the musculoskeletal system. Clin Orthopaedics Related Res 2002; 372: 169-179.

Kapandji IA . Fisiologia Articular. 5'. Ed. São Paulo: Editora Manole LTDA; 1987. 2v. e 3v. 
Keifer WS. Preparing for obstetrics in the twenty-first century: quo vadis? Am J Obstetr Gynecol 1993; 168(6): 1787-1790.

Kwast BE. Obstructed labour : its contribution to maternal mortality. Midwifery 1992; 8(1): 1-2.

Larsen EC, Wilken JC, Hansen A, Jensen Dv, Johansen S, Minck H et al. Symptom giving pelvic girdle relaxation in pregnancy. Prevalence and risk factors. Obstetr Gynecol Survey 1999; 54 (9 pt I): 547-548.

Lau TK, Leung CMY, Li CY. A study of the use of radiological pelvimetry in a Chinese population. Acta Obstetr Gynecol Scand 1998; 77(1): 41-44.

Lee D. A cintura pélvica. São Paulo: Manole; 2001.

Lilford RJ, Glanville JN, Gupta JK, Shrestha R, Johnson N. The action of squatting in the early postnatal period marginally increases pelvic dimensions. Brit J Obstetr Gynaecol 1989; 96: 964-966.

Liselele HB, Tshibangu CK, Meuris S. Association between external pelvimetry and vertex delivery complications in African Women. Acta Obstetr Gynecol Scand 2000; 79(8): 673-678.

Maclennan AH, Maclennan SC. Symptom giving pelvic girdle relaxation of pregnancy, postnatal pelvic joint syndrome and developmental dysplasia of the hip. Acta Obstetr Gynecol Scand 1997; 76(8): 760-764.

Mariscal JDO. Direitos sexuais e reprodutivos da mulher. In: Regina Ribeiro Parizi Carvalho. Ser Médico Ano IV Número 15 (São Paulo): Cia Litinográfica Ypiranga, 2001. 
Martensen RL. For deliberate election: cesarean sections in the 1890s. JAMA 1994; 271(20): 1557.

Mello JMHP, Gotlieb SLD, Laurenti R. A Saúde no Brasil: análise do período 1996 a 1999. São Paulo: Centro de Documentação da Organização Pan-Americana da Saúde/OPAS; 2001.

Mens JMA, Vleeming A, Stoeckart R, Stam HJ, Stam HJ, Henk J, Snijders CJ . Understanding peripartum pelvic pain: implications of a patient survey. Spine 1996; 21(11):1363-369.

Möller B, Lindmark G. Short stature: an obstretic risk factor? A comparison of two villages in Tanzania. Acta Obstet Gynecol Scand 1997; 76:394-7.

Moir CJ . Use of radiology in predicting difficult labor. J Obst Gyn Brit Emp $1947 ; 54: 20$.

Nwoha PU. The anterior dimensions of the pélvis in male and female Nigerians. Afr J Med Sci 1995; 24(4): 329-35.

O Brasil é Delas. Revista Isto É, São Paulo, 2001 dez 26; p. 26.

Vila Leopoldina. Distrito Vila Leopoldina. [ Sistema Viário ]. São Paulo: Mapograf Editora; 2002.

Ostgaard HC, Zetherson G, Roos HE. Back pain in relation to pregnancy: a 6-year follow-up. Spine 1997; 22 (24): 2945-2950.

Ozumba BC, Uchegbu H. Incidence and management of obstructed labour in eastern Nigeria. Aust NZJ Obstet Gynaecol 1991; 31(3): 213- 6. 
Pschyrembel W. Obstetrícia Práctica. 2a . Barcelona: Editorial Labor S.A.,1967. p. 21-27.

Pschyrembel W. Obstetrícia Práctica. 33. Ed. Barcelona: Editorial Labor S.A., 1976.

Potter JE, Berquó E, Perpétuo IHO, Leal OF, Hopkins K, Souza MR, Formiga MCC. Unwanted caesarean sections among public and private patients in Brazil: prospective study. BMJ 2001; 323: 1155-8.

Rezende J, Araujo JO. Obstetrícia. 8. Ed. Rio de Janeiro: Guanabara Koogan ; 2000 .

Riggs T F. A comparative study of white and negro pelves. Johns Hopkins Hosp Rec $1904 ; 12: 421-454$.

Russell RD, Dundas R, Reynolds F. Long term backache after childbirth: prospective search for causative factors. BMJ 1991; 312 (7043): 1384-388.

Sanvito WL. O mau gênio da Dor. Ser Médico 2001; 4(17): 16-19.

Schuitemaker N, Van RJ, Dekker G, Pieter VD, Herman VG, Jack BG. Maternal mortality after cesarean section in the Netherlands. Acta Obstetr Gynecol Scand 1997; 76 (4): 332-334.

Schwarzer AC, Aprill CN, Bogduk N. The sacroiliac joint in chronic low back pain. Spine 1995; 20(1): 31-37.

Silbar EL. Factors related to the increasing cesarean section rates for cephalopelvic disproportion. Am J Obstet gynecol 1986; 154(5): 1095-8. 
Snow RE, Neubert AG. Peripartum pubic symphysis separation: a case series and review of the literature. Obstetr Gynecol Survey 1997; 52(7): 438-443.

Sporri S, Gyr t, Schollerer A, Werlen S, Schneider H. Methods, techniques and assessment criteria in obstetric pelvimetry. Z Geburt Perinatol 1994 ; 198(2):37-46.

Steer, P; Flint C.ABC of labour care:Physiology and management of normal labour. BMJ 1999; 318(7186): 793-796.

Stewart DB. The pelvis as a passageway. II the modern human pelvis. BR J Obstet Gynaecol 1979; 91 (7): 618-23.

Struyf GD .Institut dês Chaînes Musculaires et des Techniques [encarte]. France; 1996.

Sze EHM, Kohli N, Miklos JR, Roat T, Karram MM. Computed tomography comparison of bony pelvis dimensions between woman with and without genital prolapse. Obstetr Gynecol 1999; 93(2): 229-232.

Tanaka ACd'A. Desperdício de vidas numa realidade que não se altera. Jornal da Rede Saúde, São Paulo, 1999 mai 17; inf: 3-4.

Thiery M. Obstetrical study of pelvis: a historical overview. Verh $\mathbf{K}$ Acad Geneeskd Belg 1995 ; 57(3) : 199-228.

Thomas SM, Bees NR, Adam EJ. Trends in the use of pelvimetry techniques . Clin Radiol 1998; 53(4): 293-295.

Vaughan $\mathrm{K}$. The shape of the pelvic brim as the determining factor in childbirth. $\mathbf{B r}$ Med J 1931; 2: 939-941. 
Vleeming A, Volkers ACW, Snijders CJ, Stoeckart R. Relation between form and function in the sacroiliac joint. Clinical anatomical aspects. Spine 1990; 15(pt a): 130-132.

Vleeming A, Volkers ACW, Snijders CJ, Stoeckart R. Relation between form and function in the sacroiliac joint. Biomechanical aspects. Spine 1990; 15 (pt b): 133136.

Young J. Relaxation of the pelvic joints in pregnancy: pelvic arthropathy of pregnancy. J Obst. Gyn of Brit Emp 1940; 47(5): 493-524. 
Anexo 1 - Ficha de avaliação inicial

Anexo 2 - Ficha de avaliação da dor pélvica

Anexo 3 - Ficha de avaliação final

Anexo 4 - Modelo do termo consentimento livre e esclarecido

Anexo 5 - Documento de aprovação do projeto pelo comitê de Ética em Pesquisa da FSP

Anexo 6 - Relatório do Exame do Projeto 
Gestante número:

\section{Ficha de Avaliação Inicial}

1. Identificação

Nome:

Data de Nascimento:

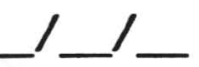

Idade : anos

Data:

RG

Endereço:

Telefone:

Profissão:

Cor:

Estado conjugal:

Semana Gestacional:

$13^{\mathrm{a}}\left(\right.$ ) $14^{\mathrm{a}}\left(\right.$ ) $15^{\mathrm{a}}() 16^{\mathrm{a}}\left(\right.$ ) $17^{\mathrm{a}}($ )

2. Exame fisico geral:

Estatura:

Peso:

No. do sapato:

3. História de partos prévios e/ou gestação atual

$N^{\circ}$. de gestações prévias

$N^{\circ}$. de partos

$N^{\circ}$. de abortos

$N^{\circ}$. de óbitos infantis 
Gestação Atual:

1. Data da Última Menstruação

2. Data Prevista do Parto

- Antecedentes

Pessoais:

- Cirurgias

Preguessas:

- Acidentes / quedas:

- Hábitos:

Tabagismo ( ) Etilismo ( ) Sedentarismo ( ) Caminhada ( ) Exercícios ( )

4. Tratamentos Realizados:

5. Apresenta dor : (Sim-S) (Não-S) (S): assinalar no desenho

\section{Losango de Michaelis}

\section{Medidas triângulos:}
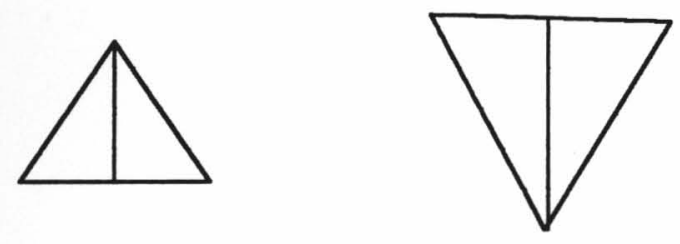

Supra-sacro de Tarnier 
7.Forma do Losango

8.Pelvimetria externa:

Diâmetros Transversos: Interespinhoso:

Intertrocanteriano:

Antero-posterior (Baudelocque):

9.Avaliação Lordose: foto distância tipo de coluna vertebral: $(A)(R)(N)$

A:curvas aumentadas

$R:$ curvas retificadas

$N:$ Neutra 
Data da Avaliação:

Nome:

Data de Nascimento:

No.

- Semana Gestacional

- Peso Atual

Avaliação da dor pélvica

Assinale o local da dor: Idade: 
Gestante número:

1.Identificação

\section{Ficha de Avaliação Final}

Data:

Nome: RG

2. Semana Gestacional:

$33^{\mathrm{a}}\left(\right.$ ) $34^{\mathrm{a}}(\mathrm{C}) 35^{\mathrm{a}}() 36^{\mathrm{a}}() 37^{\mathrm{a}}()$

3.Losango de Michaelis

Medidas triângulos:
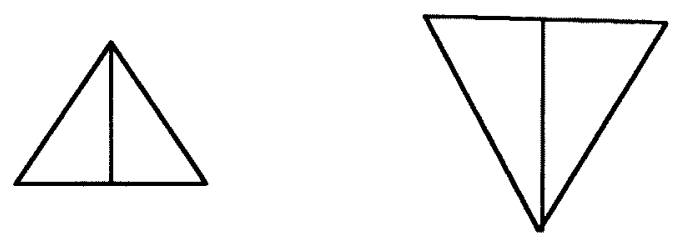

Supra-Sacro de Tarnier

4. Classificação do Losango:

$A($ )

$B($ )

$C()$

$D()$

$E($ )

F( )

5. Resolução da gravidez:

6.Intercorrêcias: 


\section{TERMO DE CONSENTIMENTO LIVRE E ESCLARECIDO}

Aceito participar da pesquisa "Tipos Posturais: Variações Anatômicas e Efeitos sobre o Parto", da pesquisadora Lea de Oliveira Françoso do Curso de Saúde Materno-infantil da Faculdade de Saúde Püblica da Universidade de São Paulo.

Fui esclarecida que a pesquisa pretende avaliar a capacidade da minha bacia de moldar-se mês a mês durante o desenvolvimento da gravidez. Os benefícios que terei serão tratamento adequado caso seja identificado algum problema.

Como participante da pesquisa serei entrevistada e convidada a responder questões sobre meus dados pessoais (nome, idade, profissão...), questões de saúde e gestaçōes anteriores. Serei avaliada no início e no fim da minha gravidez. Serão realizadas medidas da minha bacia com uma fita métrica e um instrumento para medir as distâncias ósseas. As mudanças serão avaliadas com o uso de uma régua e etiquetas adesivas, registradas com māquina fotogräfica.

Fui esclarecida que meu nome não será divulgado nos resultados da pesquisa e que as informações que darei serei utilizadas somente para os propósitos da pesquisa. As fotos serão utilizadas apenas para avaliar as mudanças da minha bacia. As mesmas me serão entregues ao final da pesquisa.

Sei que tenho liberdade de me recusar a participar da pesquisa e de deixá-la a qualquer momento sem nenhum prejuizo aos meus cuidados prestados pela instituição.

\section{Assinatura}

Nome

$\overline{\text { Assinatura da pesquisadora }}$

Telefone para contato: 3066-7703

Data: 


\section{Universidade de São Paulo}

Faculdade de Saúde Pública

COMITÊ DE ÉTICA - COEP

Av. Dr. Arnaldo, 715 - CEP 01246-904 - São Paulo - Brasil

Telefones: (55-11) 3066- 7734 - fone/fax (55-11) 3064 -7314 - e-mail: mdgracas@usp.br

\section{Of.COEP/255/02}

08 de outubro de 2002

Pelo presente, informo que o Comitê de Ética em Pesquisa da Faculdade de Saúde Pública da Universidade de São Paulo-COEP, analisou e aprovou, em sua 8. a $/ 02$ Sessão Ordinária realizada em 08.10.02, de acordo com os requisitos da Resolução CNS/196/96, o Protocolo de Pesquisa n. ${ }^{\circ}$ 851, intitulado: "TIPOS POSTURAIS: VARIAÇÕES ANATÔMICAS E EFEITOS SOBRE O PARTO", apresentado pela pesquisadora Lea de Oliveira Françoso.

Atenciosamente,

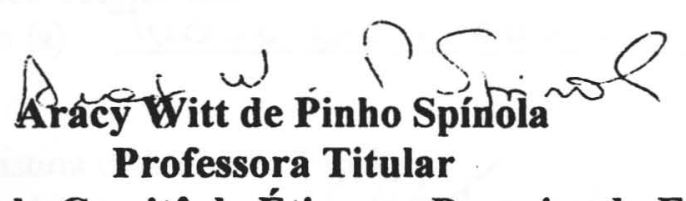

Vice-Coordenadora do Comitê de Ética em Pesquisa da FSP-COEP 


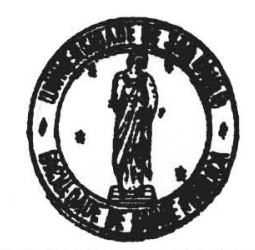

\section{UNIVERSIDADE DE SÃO PAULO \\ FACULDADE DE SAÚDE PÚBLICA}

ÁREA DE CONCENTRAÇÃO SAÚDE MATERNO-INFANTIL Av. Dr. Amaldo, 715 sala 218 - CEP 01246-904 - São Paulo - Brasil

Telefones: (55-11) 30667703 - Fax (55-11) 3085 -0240

RELATÓRIO DO EXAME DE PROJETO DA CANDIDATA AO TÍTULO DE "MESTRE EM SAÚDE PÚBLICA", ÁREA DE CONCENTRAC̣ÃO SAÚDE MATERNOINFANTIL LÉA DE OLIVEIRA FRANÇOSO

Aos dez dias do mês de dezembro de 2002, às 14 horas, na sala José Martins de Barros da FSP/USP, reuniu-se a Comissão Julgadora composta pelos membros Professora Doutora Amélia Pascoal - Departamento de Fisioterapia, Fonoaudiologia e Terapia Ocupacional FMUSP, Professora Doutora Maria Alice Tsunechiro - Departamento de Enfermagem Materno-Infantil e Psiquiátrica EEUSP e Professora Associada Ana Cristina d'Andretta Tanaka - Departamento de Saúde Matemo-Infantil FSP/USP (Orientadora e Presidente da Comissão), para a realização do exame de proejto da candidata ao titulo de "Mestre em Saúde Pública" - área de concentração Saúde Materno-Infantil - aluna Lea de Oliveira Françoso, de acordo com as Normas e Instruções dos Cursos de Pós-Graduação da Faculdade de Saúde Pública da Universidade de São Paulo. A candidata apresentou o projeto de dissertação intitulado: "TIPOS POSTURAIS: VARIAÇÕES ANATÔMICAS E EFEITOS SOBRE O PARTO". A Comissão Julgadora passou à arguição pública da candidata. Encerradōs os trabalhos de argüiçĩo, os examinadores deram o parecer final:

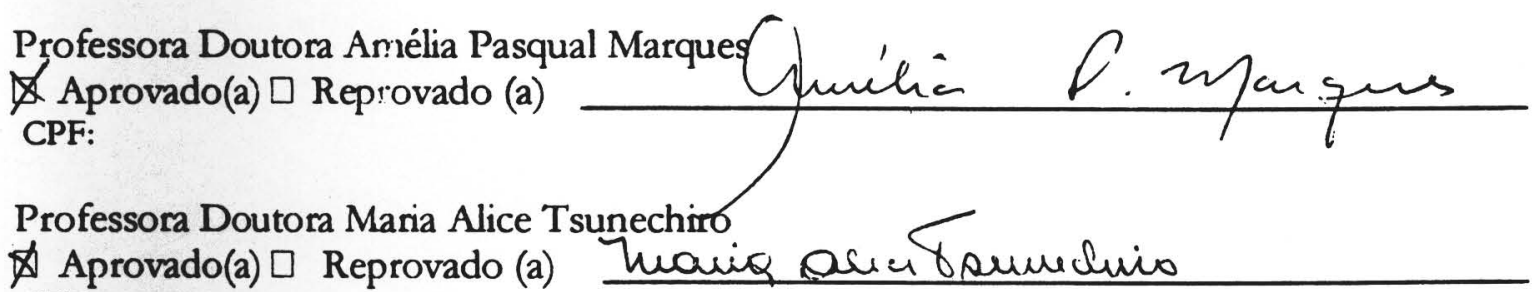
Aprovado(a) $\square$ Reprovado (a) CPF:

Professora Associada Ana Cristina d'Andretta Tanaka A Aprovado(a) $\square$ Reprovado (a) CPF:

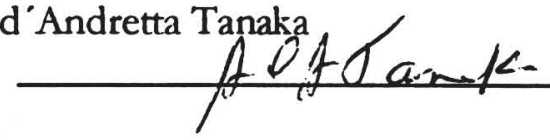

Presidente da Comissão Examinadora

- Orientadora - 